Portland State University

PDXScholar

2-11-1993

\title{
The Liberal-Communitarian Debate and the Development of a Political Conception of the Person
}

Kenneth Howard Biggs

Portland State University

Follow this and additional works at: https://pdxscholar.library.pdx.edu/open_access_etds

Part of the Political Science Commons

Let us know how access to this document benefits you.

Recommended Citation

Biggs, Kenneth Howard, "The Liberal-Communitarian Debate and the Development of a Political Conception of the Person" (1993). Dissertations and Theses. Paper 4570.

https://doi.org/10.15760/etd.6454

This Thesis is brought to you for free and open access. It has been accepted for inclusion in Dissertations and Theses by an authorized administrator of PDXScholar. Please contact us if we can make this document more accessible: pdxscholar@pdx.edu. 
AN ABSTRACT OF THE THESIS OF Kenneth Howard Biggs for the Master of Science in Political Science presented February 11, 1993.

Title: The Liberal-Communitarian Debate and the Development of a Political Conception of the Person.

APPROVED BY THE MEMBERS OF THE THESIS COMMITTEE:

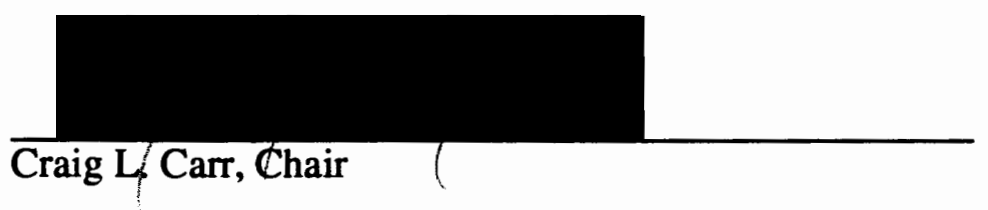

David A. Smeltzer

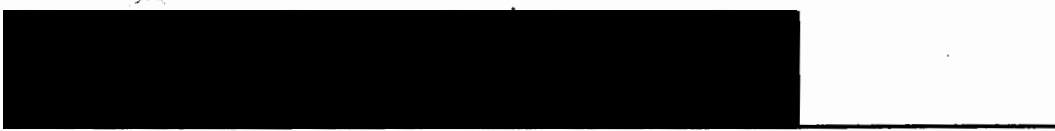

Donald R. Moor

Without doubt, John Rawls's $A$ Theory of Justice is one of the most important statements of Anglo-American political philosophy in the twentieth century. Through a revival of the social contract device, Rawls formulates a set of principles of correct political association ("the right") that he argues must be considered as prior to any conception of the good. These principles apply to all persons as free and equal beings in 
society, but more importantly they assume some things about the nature of persons in that society.

On the institutional aspect of his theory, Rawls conceives of the state as a neutral arbiter of the good. This, coupled with a conception of persons as individuals that affirm the values of autonomy and equality, has drawn extensive critical fire from philosophers within and without liberalism. One such group of critics, the communitarians, claim that Rawls's idea of the person is too abstract or "groundless" to account for shared values, and thus fails to appreciate the extent to which we understand ourselves as embedded within our culture. Michael Sandel has thus argued that Rawls's person so conceived is too abstract to be of any theoretical let alone practical use, while Alasdair MacIntyre has argued that such a conception of persons is incoherent: liberal "persons" do not know themselves, and so they cannot know what is right or what is good. This thesis analyzes the liberal-communitarian debate by comparing and contrasting some terms used by both sides in the debate. By analyzing the terms, I will present a liberal conception of the person as properly understood in Rawls's theory.

- Rawls has not been idle since the publication of $A$ Theory of Justice. He has defended his theory in a series of articles and lectures that have developed his position in response to these and other criticisms. Specifically, by positing his theory within liberaldemocratic culture, by acknowledging individual formative conceptions of the good, and by emphasizing and relying upon a modus vivendi view as the basis for political liberalism and a liberal culture, Rawls has answered the communitarian objections by incorporating and responding to those pertinent criticisms.

I will argue that Rawls's recent emphasis on a theory of political liberalism successfully accounts for his idea of persons because it accords with our considered moral principles, it treats persons as free and equal beings worthy of respect, and it incorporates the only coherent construction of the social embeddedness thesis to a greater 
3

degree than communitarians acknowledge or appreciate. Rawls's political liberalism thus surpasses this aspect of the communitarian critique. 
THE LIBERAL-COMMUNITARIAN DEBATE AND

THE DEVELOPMENT OF

A POLITICAL CONCEPTION OF

THE PERSON

by

KENNETH HOWARD BIGGS

A thesis submitted in partial fulfillment of the requirements for the degree of

MASTER OF SCIENCE

in

POLITICAL SCIENCE

Portland State University

1993 
TO THE OFFICE OF GRADUATE STUDIES:

The members of the Committee approve the thesis of Kenneth Howard Biggs presented February 11, 1993.
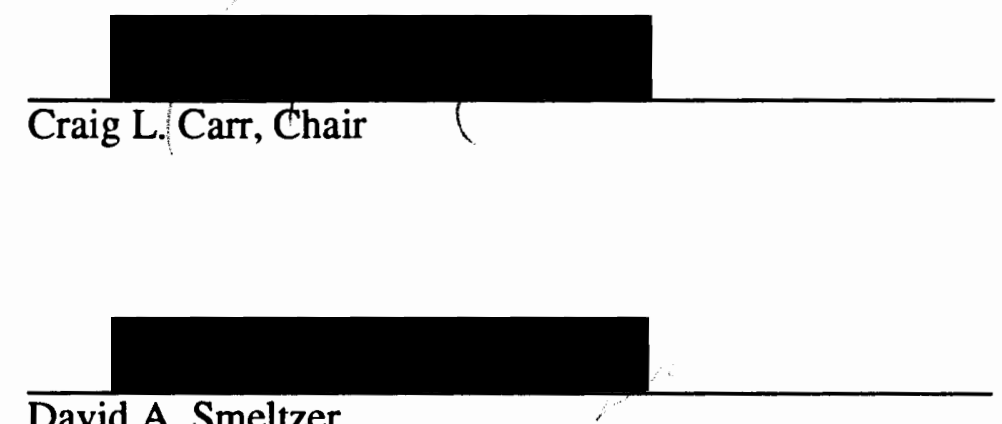

David A. Smeltzer

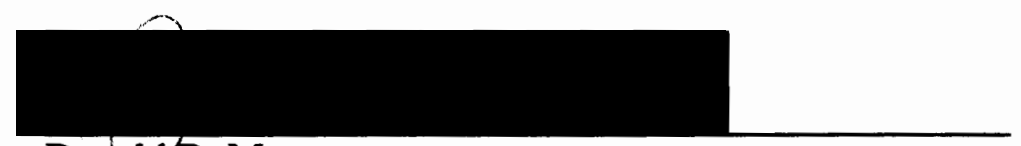

Donald R. Moor

APPROVED:

Gary L. Sčott, Chair, Department of Political Science

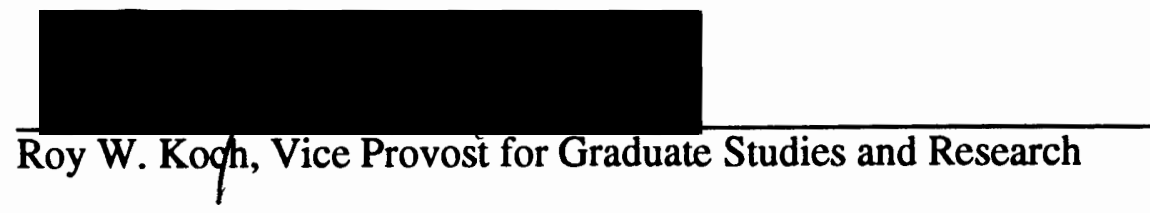




\section{DEDICATION}

To my wife. 


\section{ACKNOWLEDGEMENTS}

I would like to thank the following people (an incomplete list and in no particular order) without whose help this project could not have been accomplished:

Professor David Smeltzer, for the many conversations in which we have talked about teaching in general, but also many topics relating to fairness;

Professor and Mrs. Dennis Anderson, from whom I have received much moral support and encouragement, amongst other things;

Tory Mitchell, for the many conversations about liberalism that we have engaged in that have pushed me to ask some more questions about liberalism than I was willing to address;

My advisor, Professor Craig Carr, from whom I have learned not only about political philosophy, but who has also instilled in me an appreciation of the importance of theory in our very lives;

and of course, Elaine, without whose patience, support, and (especially) love this project would not have been possible. 


\section{TABLE OF CONTENTS}

ACKNOWLEDGEMENTS $\ldots \ldots \ldots \ldots \ldots \ldots \ldots \ldots$ iii

\section{CHAPTER}

I INTRODUCTION $\ldots \ldots \ldots \ldots \ldots \ldots \ldots \ldots \ldots \ldots \ldots$

Limits of Inquiry $\ldots \ldots \ldots \ldots \ldots \ldots \ldots \ldots \ldots \ldots \ldots \ldots \ldots$

JAF and Political Liberalism in the Debate . . . . . . . . 5

Structure of the Thesis $\ldots \ldots \ldots \ldots \ldots \ldots \ldots$

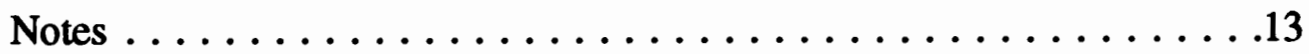

II RAWLS AND THE DEVELOPMENT OF "JUSTICE AS FAIRNESS" 15

Exposition and Clarification of JAF: $1957-1979 \ldots \ldots \ldots \ldots \ldots$

Basic Considerations

The Justifications of and Arguments for JAF

The Model-Conceptions

Three Advantages of JAF

Reflective Equilibrium

The Right and the Good

Shifts in Emphasis: 1980-1982 . . . . . . . . . . . . . . 27

"Kantian Constructivism"

The Aims of Political Philosophy

The Model-Conceptions: Expanded Roles

The Objects of and Some Objections To a Situated Moral Theory

"The Basic Liberties and Their Priority"

Difficulties and Unanswered Questions

JAF Responds: The Advent of Political Liberalism, 1985-1989 . . . . 38

"Political, Not Metaphysical"

Additional Model-Conceptions

Political Liberalism

Particular-Political vs. Comprehensive-Moral Conceptions

Five Facts of Political Sociology 
Conclusion ........................47

Notes ............................49

III THE ONTOLOGICAL CRITIQUE OF MICHAEL SANDEL . . . . . 55

Communitarianism and Liberalism: A Study in Contrasts? . . . . . . 57

The Communitarian Challenge

A Response: Clarifying the Project of Liberalism

Ontology and Persons in JAF . . . . . . . . . . . . . 61

Sandel's Two-Pronged Critique

The OP and the Derivation of the Self: Objections

The Claims Regarding Persons, Justice, and the Community

The Social Embeddedness Thesis . . . . . . . . . . . 72

Metaphysical or Political Beings?

Wholly or Partially Determined Social Beings?

Oscillation Between Conceptions

Liberal Responses . . . . . . . . . . . . . . . . 77

Objection One: "Interesting Misreadings"

Objection Two: Context and Constitution

Objection Three: Of Distinctions and Difference

Objection Four: Against a Political Conception

Conclusion $\ldots \ldots \ldots \ldots \ldots \ldots \ldots \ldots \ldots \ldots \ldots \ldots \ldots \ldots \ldots \ldots$

Notes ............................. 90

IV ALASDAIR MACINTYRE AND THE VIRTUE OF THEORY $\ldots \ldots \quad 95$

The Call: A Return to Virtue . . . . . . . . . . . . . . . . .97

Three Theses

"A Disquieting Suggestion"

Practices, A Unified Life, and Traditions

Some Preliminary Objections

The Social Embeddedness Thesis . . . . . . . . . . . . . 106

Two Distinctions

Between Conceptions 
Accounting for Rationality $\ldots \ldots \ldots \ldots \ldots \ldots \ldots \ldots$

The Role of the Virtues In Modernity

Aspects of Rationality in Liberalism

Analogy and Dichotomy

A Question of Justification

The Christian Dilemma

The Critique of Liberalism and Rationality

Of Heterogeneity and Plurality: Strength or Weakness?

Liberalism As A Tradition

Disparate Views, Disparate Rationalities? . . . . . . . . . 125

Notes ..............................127

V POLITICAL LIBERALISM $\ldots \ldots \ldots \ldots \ldots \ldots \ldots \ldots \ldots \ldots$

Introduction $\ldots \ldots \ldots \ldots \ldots \ldots \ldots \ldots \ldots \ldots \ldots \ldots \ldots \ldots \ldots \ldots \ldots$

Ethics or Epistemology?

Structure of the Chapter

A Review of the Argument, and Some Conclusions . . . . . . . 136

Rawls Reconsidered

Sandel Reconsidered

MacIntyre Reconsidered

Foundations and Limitations of Political Liberalism . . . . . . . . 142

Conceptions and Persons

Dignity and Equality

Liberty

Aims and Justifications of Political Liberalism $\ldots \ldots \ldots \ldots \ldots \ldots$

Skepticism

Neutrality

Rationality

Aims and Norms of Political Liberalism . . . . . . . . . . 157

The Norms of Political Liberalism

Moral and Personal Ideals: Kantian Ideals?

Conclusion ............................ 164 


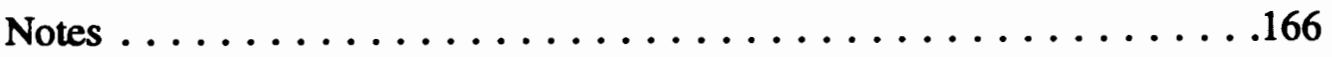

VI CONCLUSION $\ldots \ldots \ldots \ldots \ldots \ldots \ldots \ldots \ldots \ldots \ldots \ldots \ldots \ldots \ldots \ldots$

Rawls or Larmore? Liberty or Neutrality? . . . . . . . . . . . . . . . . . 172

Beyond the Debate Over Persons . . . . . . . . . . . . . . . . . . 175

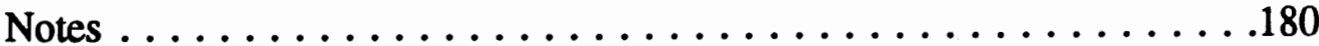

SELECTED BIBLIOGRAPHY $\ldots \ldots \ldots \ldots \ldots \ldots \ldots \ldots \ldots$ 


\section{CHAPTER I}

\section{INTRODUCTION}

At present we are combating a trend. But this trend will die out, superseded by others, and then the way we are arguing against it will no longer be understood; people will not see why all this needed saying.

\section{Ludwig Wittgenstein 1}

Since the publication of John Rawls's A Theory of Justice in 1971,2 political theory and philosophy have changed significantly. Contemporary political theorists are, to a great extent, involved in defending or criticizing the liberal theory of justice advanced and defended by Rawls. This development has had important consequences for theories of justice and for liberalism in particular. Liberalism has responded to changes not only in the concepts of justice, neutrality, equality and liberty, but more importantly in the manner in which these concepts are viewed and justified, e.g., by hypothetical social contract, by utilitarian methods, or an altogether different basis such as convergence or commonality theories.

As Rawls and similar-minded theorists have developed their respective theories since the publication of Theory, a question has arisen surrounding the current debate between liberals and a group - the communitarians - that appears to be opposed to many basic liberal tenets. In what ways has liberalism of the kind that Rawls wishes to promote and defend changed in response to those communitarian criticisms, and what consequences have these changes had for a liberal theory of justice? I suggest that an answer lies in part in the exchange between these two groups of theorists, an exchange that has been labeled by some as "the liberal-communitarian debate."3 
In this presentation of the liberal-communitarian debate (sometimes called an "argumentative dialogue" in order to distinguish it from that form of public speaking and parliamentary procedure), I want to point out some distinctions between different kinds of reasoning and argument. There are four kinds of argumentative dialogue that we can distinguish here. First, there is a critical discussion where, while the goal is to convince other positions of the superiority of one's own view, the benefit derived is mutual understanding. Secondly, there is an inquiry which seeks to demonstrate the validity of claims or conjectures, and has the benefit of accumulating knowledge and gaining conceptual coherence. A third kind of argument is the negotiation, which seeks settlement and/or consensus on an issue, and seeks to maximize goals of a particular side in an argumentative dialogue. Finally there is a debate which, although usually presented as an adversarial contest, nevertheless seeks to clarify an issue. ${ }^{4}$ Some of the contributors to this debate seem to not have paid close attention to these significant if fine distinctions; that is, some responses both by liberals and communitarians have taken on the less desirable characteristics of a debate (primarily that of exacerbating conflict) while contributing only slightly towards understanding or reconciliation. While not excluding debates per se, the first three kinds of argument are preferable for academic inquiry; each of these kinds of argumentation have occurred in the liberal-communitarian debate to various degrees. It is my purpose here to engage in both a critical discussion and an inquiry into how well the debate has proceeded and why that might be so.

\section{LIMITS OF INQUIRY}

Following Rawls and Patrick Neal, ${ }^{5}$ will hereafter refer to the theory of justice proposed and developed by Rawls as "justice as fairness" or "JAF," and later as "political liberalism." (I will occasionally refer to "Rawls's theory"; the distinction will, I hope, be clear from context.) This distinction is necessary, as Neal points out, for at least two rea- 
sons. First, Rawls himself distinguishes between his own theoretical constructions and the underlying ideas of JAF. Secondly, this will allow me to concentrate not solely on Rawls's theory of justice insofar as it is concerned with the two principles of justice, but additionally the larger question of JAF and political liberalism in general, i.e., as a liberal theory of justice, not only as a particular philosopher's theory.

Granted, the explications and developments of the many concepts - "model conceptions" - that Rawls has added to JAF over the years seem to be more embellishments or shifts of emphasis than anything. But some developments can be seen as clarifications or embellishments; some are shifts in emphasis or role of particular model-conceptions; still other developments can be seen as additions or departures - radical change - from the initial theory. Thus, many subtle shifts can result in significant change. ${ }^{6}$ We should also be careful to note that some perceived ambiguities in Rawls's thought might not be the result of changes in his theory, but rather with his disinclination to disagree sharply with his critics or defend his position via explanation and reply. ${ }^{7}$

Many liberal thinkers have written either in defense of or to constructively criticize JAF; other liberal writers have responded by formulating their own theories of justice along slightly different (but often liberal) lines. However, supporters and defenders have taken a different tack since the advent of Rawls's "new" theory of political liberalism. Many have moved to support Rawls's latest development, and in so doing have transformed "what liberalism is all about," so to speak. This thesis is then devoted to the idea that political liberalism is a satisfactory and successful response to the communitarian critique.

Since the publication of Theory, a veritable closet industry has developed with supporters and detractors of Rawls and liberalism adding fuel to the fire and rhetoric to the debate. As noted, one of the strongest group of detractors are the group loosely-labeled as communitarians, and just as there are numerous liberalisms or liberal theories (perhaps 
corresponding to the number of theorists advancing particular conceptions of a political theory), there are also numerous communitarian positions. (While a truism, this is not an unimportant point.) I will discuss only two of these positions: Michael Sandel's epistemological-ontological critique of the Kantian justification of JAF, ${ }^{8}$ and Alasdair MacIntyre's historical-traditional critique that argues against liberalism's perceived foundational absence and lack of conceptual coherence. ${ }^{9}$

I will not be able to address those criticisms or theories that are predominantly: (a) legal- and epistemologically oriented such as Roberto Unger's of the CLS movement; (b) liberal legal and rights-oriented such as Ronald Dworkin's (which relies rather heavily on Rawlsian liberalism); (c) libertarian-oriented such as Robert Nozick's; (d) theories that (in some ways) seek to "bridge the gap" between weaker forms of community and liberalism such as Michael Walzer's; or (e) theories such as Charles Taylor's dialectic- and republican oriented theory that serves to reconstruct Hegel and interpret people and institutions in politics from a logical-historical approach. ${ }^{10}$ Neither will my limited inquiry allow me to address some of the most thorough inquiries into the conception of the self in modern society in general: Derek Parfit's Reasons and Persons, and Charles Taylor's Sources of the Self. ${ }^{11}$ These are (unfortunately) beyond my purview. Finally, I will not be able to discuss debates within liberalism, in particular different theories that produce different results as the theorist "tinkers" with the conditions of choice under the social contract. 12

So while I will not discuss some things that liberals are wont to discuss - e.g., rights and liberties - this thesis could perhaps be viewed as a defense of a basis for liberal rights. My concern is both more narrow and more deep or fundamental: how does liberalism view the concept of the person? Why did Rawls's conception of persons in JAF come under such attack from the communitarian critics? Has deontological liberalism in its current form survived the communitarian critique? If so, what does it "look like" 
now? In addressing Sandel's and MacIntyre's claims against Rawls's liberal theory, I will evaluate their respective aptness - and therefore their success - as well as Rawls's and his defenders' success in responding to those criticisms.

\section{JAF AND POLITICAL LIBERALISM IN THE DEBATE}

Rawls draws upon many great historical philosophers in his theory, primarily Kant

and Locke, but also Aristotle, Sidgwick, Hume, Montesquieu, Madison and even Hegel. ${ }^{13}$ While I cannot address this line of criticism, we should note that some critics base their objections in part upon their interpretation of Rawls's fidelity to the philosophy of a particular historical thinker, Kant in particular. ${ }^{14}$ This, I think, misunderstands the direction and purpose of Rawls's theory, as well as his unique position. Rawls's theory is not intended as an historical reconstruction of a particular philosophy or theory. Rather, Rawls has looked for ways to return to ground-level considerations ("first-order theory") in political and moral theory, as opposed to focusing on "second-order analysis" of ethical ideas and principles. Rawls's project has been a desire to return to studies of proposing and describing the principles of association that are desirable and feasible for our society, not just a second-order analysis of those principles we think we see in our own society and culture.

Political liberalism is a current trend in liberal political theory. It is primarily an outgrowth and defense of the developments in JAF that have been undertaken both by Rawls and his defenders since the publication of Theory. Rawls's project of providing a socio-political basis for a universal ethic of association has remained essentially intact. It has in some ways been constrained and altered by placing the theory within a specific context: a liberal society with free-market capitalism within the political regime of a representative constitutional democracy, and the movement towards a situated theory belies a concern for social order and structure that has become increasingly important to fueling 
JAF. But it also underlies much of Rawls's concern (and liberalism's concerns in general) to justify liberal principles of association that are politically oriented yet have a basis and reason established in history, and that account for our moral notions and attitudes towards communal association.

JAF has always been concerned with the construction and operation of the basic structure of society. But, as I will demonstrate, Rawls's initial presentation of JAF was concerned more with people than is his current theory. This opens JAF and political liberalism to a two-pronged criticism. If JAF is neither an adequate nor accurate representation of the place of the person in political society, then political liberalism's emphasis on theoretical and institutional matters to the (almost) exclusion of personal considerations is even worse; political liberalism then fails to account for social and political theories of the person. The political liberal's quick rejoinder to this objection is: Is the person an adequate basis for the conception of politics? That is, while any theory of justice must account for and justify a conception of the person, how "deep" or formative must that conception be? Moral considerations and moral theory certainly must be used and accounted for; but to what extent and what areas of moral inquiry are truly appropriate in a political theory?

There are two important distinctions here. First, this way of putting the issue is not simply a confusion or conflation of the distinctions between ethics, or the treatment of individuals towards each other, usually formulated in the question: "How ought I to act?" or "What ought I to do?", and questions of justice which Rawls formulates as questions about the basic structure of society or "rules of the game," and their answers as formulated in our institutions. It is, rather, a question of how ethics is put into practice in our political institutions. Second, and following from the first distinction, it is a way of considering if there is a just manner of conceptually constructing people (citizens) so as to account for "the moral assessment and justification of institutions," 15 but additionally to 
consider how individuals must act in accordance with those institutions. (Throughout this thesis I will be concerned primarily with the first distinction.)

As it has developed, political liberalism does in some ways describe a more appropriate aim or target for political theory. It eschews fundamental or "comprehensive" moral questions and belief-systems, relying instead upon reasoned and considered moral notions, judgments, and justifications that can be used to lay a groundwork for political agreement. That is, political liberalism uses moral theory as a guide to chart a course through the thicket of comprehensive moral systems and modus vivendi-type theories, cutting a path towards a political overlapping consensus. ${ }^{16}$

Of course, liberalism is, was, and remains a theory of political legitimacy, not one of moral legitimacy or philosophical psychology; liberalism is not a theory of the person or of humankind. When liberalism is characterized or presented as a moral, sociological, or psychological theory, it quickly runs up against charges of individualism and estrangement. That is not to say that political liberalism does not in some aspects rely upon a theory of man or of human nature. The project of political liberalism has been to move away from epistemological and psychological questions that have dominated much discussion in current social and political theory, and concentrate instead on moral and political ones. This recasting of liberal political theory in less expansive terms recalls the theories of some of the earliest liberals such as Locke, whose concerns for order fueled his ideas of toleration, an issue that is currently under close scrutiny and re-examination. ${ }^{17}$

I will suggest, as has been argued in some recent periodic literature, that a primary objective of political philosophy - an objective that some have overlooked in the liberalcommunitarian debate - is to conceptually construct the person-politics relation to enable moral considerations to play a part in our political association, and thereby accommodate different and various communities and groups (disparate conceptions of the right and the good) without exacerbating intolerance between them. A great deal then hangs on what 
precisely is meant by the political liberals' "political conception of persons" and its implicit concepts.

Unlike some liberal writers, I do not think that the communitarian critique is fundamentally a "misconceived debate."18 Despite some questionable theoretical assumptions and misrepresentations of liberal theory, I think that the current communitarian critique of liberalism is valuable even if its only contribution has been, through secondorder analysis of the terms of debate, a clarification of the terms, assumptions and justifications of the respective philosophical positions.

One common liberal criticism of communitarianism is that the writings, as critiques of liberalism and modernity, are almost wholly destructive and thus serve little constructive purpose; communitarians do a lot of diagnosis, but provide little in the way of a "cure." A second, related criticism is that in the few places where communitarians do advance genuinely distinct theories of social and political association, these theories are marked either by unsubstantiated claims or rest on dubious assumptions about the ways we associate and the ways we conceive of that association. My purpose here is not to analyze the liberal communitarian debate as a whole, but instead to examine and evaluate one significant aspect of that debate - the placement of the person in society or what has been called the social thesis or social embeddedness thesis - and some of the consequences of that placement for the aims of political philosophy, and neutrality.

I will argue that some communitarian criticisms properly address shortcomings of liberal theory, but on this particular aspect of the debate the communitarian criticism has failed because liberals, and particularly Rawls in his theory of political liberalism, have incorporated the only coherent construction of the social embeddedness thesis into liberal theory. I will argue that political liberalism has a superior conception of the person for several reasons: it successfully answers major communitarian objections, and proceeds to articulate a theory of persons in politics that is at once capable of sustaining that is more 
coherent, complete, and sufficient, if not defensible and workable. ${ }^{19}$ In short, I will not be concerned so much with the theories as I will with the way these theories are advanced, justified, and critiqued with respect to some shared concepts about persons.

\section{STRUCTURE OF THE THESIS}

I will argue three main points. First, political liberalism as currently put forth by Rawls and his primary supporters is a viable liberal and political theory as well as a theory of justice because (a) it has successfully responded to appropriate communitarian criticisms, even though (b) it has not altogether sufficiently distinguished and justified the components of the theory. I will also suggest, along with some liberal critics, that (c) while political liberalism as justified has not altogether successfully charted a course between comprehensive moral conceptions and modus vivendi or Hobbesian-style arguments, this does not pose a significant obstacle to the theory. Most liberals who endorse this development in JAF explicitly or implicitly suggest (and sometimes demonstrate how this can be done) that political liberalism can develop into an overlapping consensus that can be more than a modus vivendi, and yet not be so constrictive - rely upon or contain such a full or thick conception of the good - that the theory becomes instead a comprehensive moral conception.

Second, while the communitarian critique is an important contributor to the larger ontological debate about philosophical psychology, epistemology, and social composition, it does not appear to have adequately addressed the focus of liberal theories. However interesting communitarian writers and their theories may be, some of them seem to have "missed the point" of liberalism. This is not to say that all the communitarian criticisms of liberalism are inappropriate; indeed some of what they have to say about liberalism is indeed apt and brings up important questions that liberals have yet to answer. (Michael Walzer is especially important in this regard, an argument that 
unfortunately I cannot address.) I will try to demonstrate where some of these communitarian critics appropriately address JAF, and also where they fail to do so.

Third, as suggested by the above quotation from Wittgenstein, the liberal-communitarian debate is still in progress; it has not yet developed to the point where any definitive statements about the future of liberalism or communitarianism or some sort of mutual relation (perhaps even an Hegelian synthetic theory) can be made. Many contributors to the debate have rightly focused on relatively narrow issues: a defense of JAF, a destructive critique of liberalism, what is meant by neutrality in liberalism, etc. So, while very few writers have noted areas of consensus or agreement between the two camps, this is to be expected due to the currency of the debate. But this is not to suggest that such a synthesis or consensus is impossible; only that it may be undesirable for both sides as the time may not be ripe, or there might simply be too much at stake. As some contributors have noted, significant concessions would have to made by both sides, concessions that would eventually undermine the respective theories.

I will analyze the debate by looking at how political liberalism and communitarianism each view and justify four ideas central to the conception of persons: the social embeddedness thesis, rationality, and the companion concepts of liberty and equality. Much of my discussion will then be devoted to how these theories respectively view these concepts, and how these concepts make sense within the theoretical structure.

I will proceed by chapters as follows. In Chapter II, which is primarily expository, I will present and analyze the pertinent aspects of JAF as it has developed since the publication of Rawls's Theory of Justice, especially the later years where JAF has yielded to political liberalism.

In Chapters III and IV, I will discuss two of the more prominent communitarian theorists, Alasdair MacIntyre and Michael Sandel. I will do several things here: review MacIntyre's and Sandel's theories-cum-critiques against liberalism, evaluate the commu- 
nitarian criticisms against JAF and political liberalism (particularly their criticisms against the conception of persons), and evaluate the aptness and success of those critiques in general by analyzing these theorists's respective uses of the social embeddedness thesis.

Chapter Vis an examination and analysis of political liberalism not only as it has been defended and developed by Rawls, but also from some other articulate defenders of political liberalism such as Will Kymlicka and Charles Larmore, and other theorists who share some liberal concerns such as Susan Mendus and Steven Lukes. After a brief review of the argument up to that point, I will examine some of the conceptual bases and limits of political liberalism and see how it has been defended against the communitarian criticisms through self-critique and examination. I will argue there that political liberalism's conception of persons is a coherent and sufficient response to the communitarian objections.

I will conclude in Chapter VI by noting that because of the eternal nature of these questions, this debate can never be fully resolved. However, the last decade or so - "our current way of arguing" - must be seen as an important and significant development in the history of political philosophy. Perhaps Michael Walzer is correct: "The communitarian critique is like the pleating of trousers: transient but certain to return."20 (I cannot hope at this point to be so complacent as to the status - or ascendancy - of liberalism.) So while I endorse political liberalism, I also think that some points of concession and consensus must be reached between the two parties if the debate is to move forward; hopefully my analysis will point to one area of this debate that can be settled. This then does not commit me to the idea that political liberalism is indeed the "best available" theory of justice, only the currently best available liberal theory that adequately responds to the communitarian critique. That is, when shorn of some of the “conceptual baggage" of Rawls's earlier formulations in Theory, political liberalism 
seems to offer the most coherent theoretical conception of modern democratic political culture by offering the least restrictive account of principles of political association, yet maintaining an acceptable adherence to moral principles. 


\section{NOTES}

1 Ludwig Wittgenstein, Culture and Value, trans. Peter Winch (Chicago: The University of Chicago Press, 1980): $30 \mathrm{e}$.

2 John Rawls, A Theory of Justice (Cambridge, MA: Belknap, 1971). N.b.: I will refer to this work hereafter as Theory.

${ }^{3}$ Charles Taylor, "Cross-Purposes: The Liberal-Communitarian Debate," in Liberalism and the Moral Life, ed. Nancy L. Rosenblum (Cambridge, MA: Harvard University Press, 1989): 159.

${ }^{4}$ Douglas N. Walton, "What is Reasoning? What is an Argument?" The Journal of Philosophy 87 (1990): 412-15.

5 Patrick Neal, “Justice as Fairness: Political or Metaphysical?” Political Theory 18 (1990): 26.

${ }^{6}$ Chandran Kukathas and Philip Pettit, Rawls: ATheory of Justice and Its Critics (Stanford: Stanford University Press, 1990): 119.

7 Thomas Pogge, Realizing Rawls (Ithaca, NY: Cornell University Press, 1989): 4. 1982).

${ }^{8}$ Michael Sandel, Liberalism and the Limits of Justice (Cambridge: Cambridge University Press,

${ }^{9}$ Alasdair MacIntyre, After Virtue: A Study in Moral Theory, $2 \mathrm{~d}$ ed. (Notre Dame, IN: Notre Dame University Press, 1984); Whose Justice? Which Rationality? (Notre Dame, IN: Notre Dame University Press, 1989).

10 (a) Roberto Mangabeira Unger, Knowledge and Politics (New York: The Free Press, 1975); (b) Ronald Dworkin, Taking Rights Seriously (Cambridge, MA: Harvard University Press, 1978) and A Matter of Principle (Cambridge, MA: Harvard University Press, 1985); (c) Robert Nozick, Anarchy, State, and Utopia (New York: Basic Books, 1974); (d) Michael Walzer, Spheres of Justice (New York, Basic Books, Inc.: 1983); (e) Charles Taylor, Hegel (Cambridge: Cambridge University Press, 1975), and in general Philosophy and the Human Sciences: Philosophical Papers 2 (Cambridge: Cambridge University Press, 1985).

11 Derek Parfit, Reasons and Persons (Oxford: Oxford University Press, 1984); Charles Taylor, Sources of the Self (Cambridge, MA: Harvard University Press, 1989).

12 I have in mind the alternative liberal theories of Bruce Ackerman, Social Justice in the Liberal State, (New Haven, CT: Yale University Press, 1980), James Fishkin, Tyranny and Legitimacy: A Critique of Political Theories (Baltimore, MD: Johns Hopkins Press, 1979) and Dialogues of Justice ( and Robert Nozick, op cit., amongst others.

13 Recent analyses and criticisms of Rawls have drawn some not altogether flattering comparisons of Rawls with Hegel. See e.g., Kukathas and Pettit, 144-48; Neal, "Political or Metaphysical?" 46-47, 49-50. 
${ }^{14}$ Examples here are William Galston, "Moral Personality and Liberal Theory: John Rawls' Dewey Lectures." Political Theory 10 (1982): 514-15; but cf. Michael Sandel's now famous (infamous?) comparison of Rawls with Hume, Liberalism and the Limits, Introduction and Chapter 1.

15 Thomas Pogge, Realizing Rawls (Ithaca, NY: Cornell University Press, 1989), §§ 1.4.2-1.6, 21-28.

16 I should note that not all theorists who have either subscribed to or propounded a theory of political liberalism feel that a liberal theory of justice must make its way between these two extremes. Charles Larmore, for example, embraces political liberalism as a modus vivendi (Charles Larmore, Patterns of Moral Complexity (Cambridge: Cambridge University Press, 1987)), although this position has been altered somewhat in his "Political Liberalism," Political Theory 18 (1990): 339-360. This altered claim I will address in my conclusion.

${ }^{17}$ Susan Mendus's work here is especially important in this regard. See, e.g., her Justifying Toleration: Conceptual and Historical Perspectives (Cambridge: Cambridge University Press: 1985), and Toleration and the Limits of Liberalism (Atlantic Highlands, NJ: 1989). Also see Susan Mendus and David Edwards, eds., On Toleration (Oxford: Clarendon Press, 1989), and Mendus and J. Horton, eds., Aspects of Toleration (London: Methuen, 1985), both of which are collections of essays on the conceptual and historical limits of toleration and its place in political theory.

18 The literature here is voluminous, but some useful articles are, in no particular order: Stephen Holmes, "The Permanent Structure of Antiliberal Thought," in Liberalism and the Moral Life, Nancy L. Rosenblum, ed. (Cambridge, MA: Harvard University Press, 1989); Simon Caney, "Liberalism and Communitarianism: A Misconceived Debate," Political Studies 60 (1991): 273-89; Amy Gutmann, "Communitarian Critics of Liberalism," Philosophy and Public Affairs 14 (1985): 308-22; and Emily R. Gill, "MacIntyre on Traditions," Polity 24 (1992): 433-57. The phrase is from Caney, "A Misconceived Debate," 273.

19 The terms (in)complete, (in)coherent, and (in)sufficient are from Alfonso Damico, "Introduction," to Liberals on Liberalism (Totowa, NJ: Rowman and Littlefield, 1986): 1-2.

${ }^{20}$ Michael Walzer, "The Communitarian Critique of Liberalism," Political Theory 18 (1990): 6. 


\title{
CHAPTER II
}

\section{RAWLS AND THE DEVELOPMENT OF "JUSTICE AS FAIRNESS"}

\begin{abstract}
Naturally, my aim must be to say what the statements one would like to make here, but cannot make significantly.
\end{abstract}

\section{Ludwig Wittgenstein ${ }^{1}$}

John Rawls's liberal theory of justice as fairness has changed in some substantial and significant ways since the publication, some twenty-two years ago, of $A$ Theory of Justice. ${ }^{2}$ That Rawls's theory continues to fuel debate about basic principles of political association and the role of political theory in contemporary political philosophy is undeniable; certainly, this is a tribute to Rawls the man and philosopher. But how have these changes affected liberal political theory, and what affect have these changes had for the theory of JAF? My purpose in this chapter is to present and analyze the principal aspects of JAF as found in Theory that have gained prominence in JAF since its publication.

Rawls's work can be roughly divided into four different periods. The first period consists of articles and writings up to the writing of his magnum opus, $A$ Theory of Justice, including the drafts for that work. ${ }^{3}$ Although these works are important in gaining an understanding of Rawls's work and its development as a whole, I shall not consider the works from this period in my analysis as it is the developments following the publication of Theory with which I am concerned. The second period consists of (along with Theory) articles from 1972 through 1979.4 This period is the exposition and development of JAF. While I will be primarily concerned with Theory in this section, 
some subsequent writings will be addressed to clarify points in Theory. The third period, from 1980 through 1982,5 is a transitional stage. Here Rawls adds some concepts to JAF, and further clarifies the roles these concepts play in their inter-relations; these are the shifts in emphasis in JAF. But as we shall see, this is also where Rawls departs from some of the basic ideas of JAF: the role of the person, and the aims of political philosophy. This has had important and not altogether desirable consequences for JAF. The fourth period, found in Rawls's four most recent articles 1985 through $1989,{ }^{6}$ is where Rawls has, in some fundamental and radical ways, departed from the initial project in Theory, and developed instead a different although closely related theory of political association: political liberalism. I will address these periods in chronological order.

These broad areas of change in JAF can be usefully viewed by following the development of the model-conceptions that have become increasingly important to the theory: the well-ordered society, the moral person, and the original position (hereafter OP) amongst others. How these ideas are developed and related also has a great deal to do with Rawls's most controversial step, the formation of political liberalism.

As it has developed, JAF has been primarily concerned with two subjects: the basic structure and how it is arrived at or derived, and the construction and placement of the individual in political society. The first contains Rawls's response to critiques and accusations that JAF was too abstract, too Kantian, to be of any practical application or to understand and explain contemporary political culture. The second contains Rawls's response to critics, primarily communitarians, who have questioned the conceptual basis of the individual, and how the individual "fits" into society in the scheme of JAF. A great deal of space, then, will necessarily be devoted to the development of those modelconceptions. 


\section{EXPOSITION AND CLARIFICATION OF JAF: $1957-1979$}

\section{Basic Considerations}

As initially developed in Theory, JAF is a complex and complicated theory of social and distributive justice. Due to the subject and style, it can be either deceptively attractive or mind-bogglingly expansive: "Some students [have become] so enamored of the elegant, central treatment of the social contract that they [are] unable to look objectively at the book.... Other students [have] the opposite reaction. They [are] unable to grasp the general outlines of Rawls's theory because they [become] so bogged down in the many details of Rawls's exposition."7 But for all it's length and breadth, JAF relies on some fundamental assumptions and basic concepts in political theory. 8

The Basic Structure, As a liberal, Rawls has always and will remain concerned with the basic structure of society; it is the primary subject of justice. "By the basic structure of society, Rawls means the entire set of major social, political, legal, and economic institutions."9 The Constitution, private ownership of the means of production, competitive markets, and the monogamous family are all examples of components of the basic structure. The primary problem of justice, given the inequalities inherent in any system of social organization, is "to formulate and justify a set of principles which a just basic structure must satisfy." 10

The Two Principles of Justice. As a theory of distributive justice, JAF is concerned with the way primary social goods, e.g., rights, opportunities, power, authority, and even specific goods such as wealth and access to social services, are to be meted out to the members of society. The intuitive idea (as Rawls would note) is to structure a conception of justice that answers questions about political association and distribution of social goods by addressing how we get what we do in politics (as opposed to how we give). 
The main ideas of JAF are found in a set of two inter-related principles (the second of which has two parts) that are formulated and designed to accord with both our intuitive notions of justice and our more considered judgments and decisions about justice. The principles are often referred to by their common names, as given.

1. [The Equality Principle] Each person is to have an equal right to the most extensive total system of equal basic liberties compatible with a similar system of liberty for all. both:

2. Social and economic inequalities are to be arranged so that they are

(a) [The Difference Principle] to the greatest benefit of the least advantaged; and

(b) [The Principle of Fair Equality of Opportunity] attached to offices and positions open to all under conditions of fair equality of opportunity. ${ }^{11}$

The subtle contrast between the two principles with regard to primary social goods should be noted. Where the equality principle is concerned with the distribution of a subset of the total set of primary goods (that is, the basic liberties), ${ }^{12}$ the difference principle by contrast is concerned with social goods such as wealth, income, power, and the like; hence the phrase "social and economic inequalities." The equality principle is relatively straightforward: all persons are accorded the same rights and liberties that are present in a social structure so long as those rights and liberties are compatible with all persons sharing or claiming those rights as individuals.

The difference principle, on the other hand, is more complex. The phrase "least advantaged" means either the representative worst-off person or the representative worstoff class of peoples. (This definition has been variously interpreted.) There are two definitions here, "either of which, or some combination of them, will serve well enough."13 The representative worst-off person or class can be defined as either a particular social position, e.g., an unskilled worker, or by making no reference to social class, relying "solely [upon] terms of relative income and wealth with no reference to social position." The representative worst-off is not some "ideal individual" who might 
happen to fit the characteristics of either definition; it is not a hard-and-fast rule for determining who such a person is or might be, but rather "it is the practical criterion itself that is to be evaluated from the perspective of the original position."14 So the worst-off are simply a way of describing the OP in a manner consistent with the desire to provide justice upon equal grounds. For the same reasons that we exclude race and sex from some decisions about justice, wealth and social status are excluded.

The third principle, that of fair equality of opportunity, is intended to ensure that all people, regardless of social standing, are afforded equal access to social goods, and are placed on a level or fair playing field relative to other competitors. Presumably fairness in equality of opportunity (or fair equality of opportunity, or equal opportunity for short) might require that in some cases that the disadvantaged are to be awarded some form of financial aid in order to compete fairly with others who, all other aspects aside (including financial), have similar capabilities and desires. ${ }^{15}$ However, this last point is not entirely clear, as we will see in chapter 4 when I discuss neutrality.

Priority Rules. Conflict amongst these principles is anticipated. Rawls forestalls this by noting a lexical priority rule that governs the reference and application of these principles. The principle of equal liberty (principle 1) is to be considered before the second principle, and within the second principle, the principle of fair equality of opportunity (principle 2 (b)) is to come before the difference principle (principle 2 (a)). ${ }^{16}$ The principles and their lexical priority are summarized in Rawls's general conception:

All social primary goods - liberty and opportunity, income and wealth, and the bases of self-respect - are to be distributed equally unless an unequal distribution of any or all of these goods is to the advantage of the least favored. ${ }^{17}$

\section{The Justifications of and Arguments for JAF}

Two Intuitive Arguments. There are three related justifications for these principles; this comprises the bulk of Rawls's initial theory and its subsequent developments. The 
first two justifications appeal to our considered moral judgments and notions; the third, a philosophically- and theoretically-oriented approach, has generated the most debate. The first justification "rests on the thesis that if a principle accounts for our considered moral judgments about what is just or unjust, then this is a good reason for accepting that principle."18 This justification suggests - and stands or falls on the idea - that the principles adequately and accurately account for what is just and unjust. The second justification notes that "if a principle would be chosen under conditions which, according to our considered moral judgments, are appropriate conditions for choosing principles of justice, then this is a good reason for accepting the principle."19 If we are not willing to look any further, then we can accept these principles if we feel that they accord with our considered ideas about principles of justice, or if we feel that they were decided in an appropriate venue and manner (if the principles were derived under conditions appropriate to render mutually agreeable principles of justice: the OP).

The Kantian Interpretation. But if we are more concerned with questions about justice and what it entails, then we must look to Rawls's third justification. The OP and rationality play an important role in this third or "Kantian" interpretation and justification of a theory of justice. This Kantian interpretation uses the concepts of the OP and a specific conception of rationality in a particular way.

Rawls suggests that persons in the OP be thought of as rational agents (Kantian "noumenal selves") that by virtue of their situation (a form of limited ignorance) are truly autonomous and independent. They have no ties to bias them, and they must then accept what rationality demands: the proposal and acceptance of principles that can serve for all peoples, not only people with contingent desires. Buchanan summarizes the central point of this argument:

[W]hen persons such as you and I accept those principles which we recognize would be chosen from the original position, we are expressing our nature as noumenal selves, i.e., we are acting autonomously. There 
are two main grounds for this thesis, corresponding to two features of the original position. First, since the veil of ignorance...excludes information about particular desires, acceptance of the principles does not depend upon the particular desires which an agent may or may not have. Second, since the formal constraints on the choice of principles include the requirement that the principles must be universalizable, the principles will be rational principles in Kant's sense. ${ }^{20}$

This may seem incredulous at first. Such a description of the social considerations from which we decide our lives and roles - or have them decided for us - goes against such basic assumptions of the way in which we decide from a particular social position. That is, we are products of our culture, and because that is so there are only so many conceivable roles or lives that we could pursue, given our social status, education, etc. (This is a crude formulation of the social embeddedness thesis, which will be crucial in my subsequent analysis.) This is a common objection to JAF, one that Rawls does not answer satisfactorily until his fourth period. It is there that Rawls reconsiders such objections in light of communitarian critiques - particularly Michael Sandel's now famous accusation that JAF is "deontology with a Humean face" - and responds persuasively to them. But it should suffice for the moment to note that such social considerations - relative scarcity of resources, and the derivation and importance of moral education in our action and political association - are answered more satisfactorily by Rawls in his later period.

Rational Actors. The principles of justice and association chosen in the OP would be chosen according to the principle called maximin. In rational choice theory, it is a way of choosing the safest alternative: a person using the maximin criteria (or choice method) will maximize the chance that the chosen alternative will have the best worst outcome (in this case, principles of political association and social/distributive justice). That is, even if what is chosen ends up being a "bad" choice, the way we choose and the ensuing situation will end up being the best, given the circumstances available from which to decide, and in which to live once that decision has been made. ${ }^{21}$ 
Although an account of rationality and the rational person is important in JAF, it has become clear as JAF has developed that the OP and other model-conceptions are focused on the moral and rational situation of agents from which they choose an agreeable set of principles. So while rational choice still plays a part in the theory, particularly in the OP, as JAF has progressed, Rawls's reliance upon rational choice theory has diminished. (We shall see a little later that in political society, persons are restrained by concepts of the reasonable and the rational.)

\section{The Model-Conceptions}

The OP. Much has been said of Rawls's OP. The OP allows the connection of the theory of justice with rational choice. ${ }^{22}$ It considers the chosen principles as the result of a collective decision within a context that makes some basic assumptions regarding rationality and action. The OP emphasizes that there are some base-level commitments and responsibilities that go along with that decision and that the decision is reached by voluntary means: no one is coerced to join per se, but it is strongly suggested that it would be irrational (if not anti-social) not to join. There are, according to Rawls, four primary features of the OP that make it a rational and even advantageous choice for per-

sons in the OP: (a) the rational motivation of the parties, (b) the veil of ignorance, (c) the formal constraints of the concept of right, and (d) the list of competing principles of justice. This last point will not be addressed here as it is peripheral to my analysis. ${ }^{23}$

The rational motivation of the parties assumes that people are, to an extent, motivated by desires to form a "life plan" that is designed to accumulate an individual portion of primary social goods. Mutual disinterestedness is assumed here to ensure the independence of the agents in the OP. By relying on rational choice, members of a to-bearranged society hypothetically gather together under a mutual veil of ignorance - feature (b) - in order to discuss what kinds and which specific moral and political principles to 
live by. This veil is relatively "thick." (Another way to say this is that the normative conception of the person in the OP is relatively "thin.") It excludes knowledge of one's socio-economic place in society; particular ideas of the good or how to lead and live a good life; particular social circumstances such as technological sophistication or socioeconomic situation; it excludes generational reference; and the parties must not know their own personal contingencies (physical attributes, and what might be desirable under a particular set of social circumstances). ${ }^{24}$ Persons, as potential members of such a society, thus gather together in mutual ignorance in order to decide the rules to live by. Rawls suggests that the original position (another name for the social contract that has characterized many different of theories of political association) is ideal because it removes from consideration any and all information that might be useful in order to make decision that might be biased in any way, particularly in one's favor. It is important to note that because he wishes to exclude these concepts about ourselves that we often take as granted that Rawls assumes that persons have and act from the observed inherent traits of selfishness and egoism. Despite claims to the contrary, Rawls implicitly relies upon some fundamental assumptions about human nature. (Critics have referred to these assumptions about human nature by various names, e.g., philosophical anthropology, a theory of the person, a conception of the self, or a theory of the moral subject.) ${ }^{25} \mathrm{By}$ removing these psychological states from consideration, Rawls hopes to derive principles of justice that would be fair to all under fair considerations: "The aim is to use the notion of pure procedural justice as a basis of theory." 26 That is, if the principles are derived under completely fair conditions, with all players being equal, then we cannot help but choose those principles fairly.

The Veil of Ignorance. The veil of ignorance and the OP are the embodiment of Rawls's desire in JAF to envision and build the basic structure upon the idea of pure procedural justice. ${ }^{27}$ The veil of ignorance in the OP is thus a central and fundamental 
aspect of JAF: the importance of this, even in the later developments of JAF, cannot be overstated.

Now, we must be clear about the role of the OP and the veil of ignorance. The OP should not be considered a starting point for rational or moral inquiry. Rather, it is a way of "arguing through" the moral thicket of differing and disparate conceptions of good that can influence the concept of right; ${ }^{28}$ it is more procedure than substance. The purpose of the $\mathrm{OP}$ is to remove doubt about the applicability of rational choice and moral notions in a theory of justice, and to be able to account for a feasible and desirable account of the person in the outcome of that procedure.

Formal Constraints On the Concept of Right. Feature (c) reflects some of the considered moral notions and judgments about political association that can be found in a liberal-democratic culture, or what Rawls calls the formal constraints of the concept of rights. The principles of justice, in order to provide a just basic structure that at least qualifies for the first two types of justification, must have some specific characteristics. They must be: (i) general, (ii) universal in application, (iii) universalizable (as distinct from generalizable; i.e., they must be "for all persons as moral persons"), (iv) available and known to the public, (v) adjudicative and transitive (they must be able to provide an ordering of conflicting claims about distributive justice), and (vi) they must be final. ${ }^{29}$

\section{Three Advantages of JAF}

Due to the circumstances found in the OP and the above-mentioned formal constraints upon the concept of right, Rawls feels that there are three advantageous consequences of JAF as a political theory. (These are additionally reasons that could be used to persuade others disinclined to accept the OP, or for OP participants to accept justice as fairness over other conceptions.) First is the "strains of commitment" argument. The idea here is that "the principles of justice as fairness are principles that...the parties in the 
OP can rely on one another to adhere to once adopted. There will be no consequences they cannot accept." 30 That is, the principles will be more than merely a contract: they become a basis for society that is mutually acceptable to all because it is fair to all. All persons are accorded an equal opportunity to take part in (or simply take) their share of social primary goods.

Secondly, Rawls proposes an argument from stability. Because justice as fairness generates its own support and allegiance, and because everyone's good is affirmed within the limits of reason and rationality, JAF will be more stable than other conceptions that might require certain sacrifices of, say, individual rights and liberties. ${ }^{31}$ "[E]ach person's liberties are secured, and yet the difference principle ensures that everyone is benefited by social cooperation.... Since everyone's good is affirmed, all acquire inclinations to uphold the scheme."32

Rawls's third reason is the most important, and it becomes more so as JAF develops. This is the argument for self-respect; both the concept and the argument are tied to Rawls's concept of primary social goods. In fact, self-respect is "perhaps the most important primary good" because

Without it nothing may seem worth doing or if some things have value for us, we lack the will to strive for them. All desire and activity becomes empty and vain, and we sink into apathy and cynicism. Therefore the parties in the original position would wish to avoid at almost any cost the social conditions that undermine self-respect. ${ }^{33}$

Self-respect ensures that people will respect others as well. It is a way of saying, by a Kantian reckoning, "that the principles of justice manifest in the basic structure of society men's desire to treat one another not as means only but as ends in themselves." 34

\section{Reflective Equilibrium}

Reflective equilibrium is a conceptual necessity for JAF. It is a way of balancing between our intuitive notions and our considered judgments about justice. In this respect, 
reflective equilibrium is Socratic because it allows us the opportunity to "change our present considered judgments once their regulative principles are brought to light."

But the notion varies depending upon whether one is to be [1.] presented with only those descriptions which more or less match one's existing judgments except for minor discrepancies, or [2.] whether one is to be presented with all possible descriptions to which one might plausibly conform one's judgments together with all relevant philosophical arguments for them.... Clearly it is the second kind of reflective equilibrium that one is concerned with in moral philosophy. ${ }^{35}$

Persons then, in the OP and as citizens, use reflective equilibrium as a tool or method to compare and contrast conceptions of what is good and right, and to arrive at a decision as to which principles to adopt depending upon how those conceptions are supported (justified). Reflective equilibrium is Rawls's allowance in JAF for the person to "step outside one's self" so to speak and evaluate principles of justice as they develop. Rawls does not say that this is a neutral procedure any more than he says that JAF is a completely neutral conception of justice; it is instead Rawls's way of proceeding towards an objective method to derive a conception of justice in society.

An Objection. An important objection to this use of reflective equilibrium as a balancing tool is that we then have no standard from which to judge such a balance: we can reason from our intuitions or we can reason from our considered judgment, but then when do we know we have "arrived at" a balance that is acceptable, i.e. that satisfies both of those approaches? Rawls does not answer this objection in this period of his work. But, as we shall see, an answer is provided that develops out of the concepts of equal respect and rational dialogue, the primary and controlling concepts of what Rawls later calls political liberalism.

\section{The Right and the Good}

Having developed and justified JAF, Rawls wishes further to convince us that JAF meets an additional considered notion about morality as found in the relationship of the 
right and the good: that what is right is compatible with what is good, and further that justice and goodness are congruent. ${ }^{36}$ Briefly, Rawls maintains a distinction between deontological theories like JAF that assert that what is right does not depend upon or is independent of a conception of the good (variously good, social goods, the good life, etc.), and teleological theories that assert that what is right depends upon what is good. ${ }^{37}$ For JAF, the right embodied in the two principles and the model-conceptions is prior to the good: the "rules" for a just culture must be considered before the content of the culture. "Something is good only if it fits into ways of life consistent with the principles of right already on hand."38 So the arguments from commitment, stability, and self-respect are additionally arguments for a concept of right, or our desire "to maintain and express our nature as free and equal rational beings."

[This] can be fulfilled only by acting on the principles of right and justice as having first priority. This is a consequence of the condition of finality: since these principles are regulative, the desire to act upon them is satisfied only to the extent that it is likewise regulative with respect to other desires. It is acting from this precedence that expresses our freedom from contingency and happenstance. 39

With the basic ideas of JAF reviewed in this second period of the development of JAF, I will proceed to an examination and evaluation of Rawls's third stage.

\section{SHIFTS IN EMPHASIS: $1980-1982$}

\section{"Kantian Constructivism"}

The more important of the two articles in this second period is Rawls's Dewey Lectures, "Kantian Constructivism in Moral Theory," which he later notes should have been named "Kantian Constructivism in Political Philosophy."40 Rawls begins by limiting the scope and breadth of JAF. "Kantian constructivism" does not propose a system of political ethics or moral obligations that descend from Kant's construction of the moral universe and serve to subsume a moral and political culture; rather, the purpose is "to establish a suitable connection between a particular conception of the person and first 
principles of justice, by means of a procedure of construction."41 The approach is Kantian in that it provides a justification for moral actions that refer directly to deontological principles and duties that can or may be acknowledged as "good," or derived from analyzable à priori knowledge; it does not rely upon the more emotive characteristics of humanity, e.g., desires, passions, instincts and the like. The approach is constructivist in that it uses a procedural method to derive a fair outcome according to mutual agreement, that is, by a reliance upon pure procedural justice.

\section{The Aims of Political Philosophy}

The primary objective is to establish a theory of justice that will aid in achieving social cooperation through the principles of JAF. This suggests that Rawls has become more concerned with sociability and social stability. JAF (and therefore justice within a democracy) is then limited to an inquiry of the meaning of justice "in order to settle a fundamental disagreement over the just form of basic institutions within a democratic society under modern conditions."

This attenuated aim of JAF additionally has consequences for the aims of political philosophy.

The aim of political philosophy, when it presents itself in the public culture of a democratic society, is to articulate and to make explicit those shared notions and principles thought to be already latent in common sense; or, as is often the case, if common sense is hesitant and uncertain, and doesn't know what to think, to propose to it certain conceptions; and principles congenial to its most essential convictions and historical traditions....

The real task is to discover and formulate the deeper bases of agreement which one hopes are embedded in common sense, or even to originate and fashion starting points for common understanding. ${ }^{42}$

This suggests several changes. First, that Rawls is reconsidering the aims of political philosophy in general and in JAF in particular. Second, and more importantly, JAF has shifted from being concerned with discovering the principles of justice and political association, to actively formulating and applying principles that meet with our 
desired moral ends of political association. So the "search for reasonable grounds to achieve agreement on basic principles" uses reflective equilibrium in a slightly different way than initially proposed: "On the one hand imagining what we would agree to (in idealized conditions) will reveal to us the right principles of justice; on the other hand, we need to construct such principles as will secure agreement."43

\section{The Model-Conceptions: Expanded Roles}

The Well-Ordered Society Rawls moves to an expanded view of the role of the model conceptions in JAF. A well-ordered society is first one where "such a society is effectively regulated by a public conception of justice" that the basic structure satisfies derived and agreed principles; secondly, it is one where those principles are the result of "generally accepted methods of inquiry." 44 Thirdly, the members of a well-ordered society, as moral persons, have three characteristics: they are free in that they are entitled to pursue some ideas of the good and "make claims upon the design of their common institutions"; they are equal in that they regard each other as equal in the determination of the first principles of justice; and they are moral beings in a rather special way, given the constraints of rational as opposed to full autonomy (discussed below). 45

The Original Position. In moving from the constraints of the veil of ignorance in the OP to the well-ordered society, Rawls envisions four successive stages where reasonability and rationality gain prominence. At the initial stages of decision, ignorance (hence the definition of persons) and the flexibility of the principles (hence the exercise of the reasonable and the rational) is relatively great. But as the tasks, decisions and therefore the normative moral content of the society become progressively more specific, ignorance lessens and the constraints of reasonability and rationality increase: the further one progresses in JAF towards a fully-defined society, the less flexibility there is in the constraints of reasonability and rationality, and therefore justice. That is, as we move 
from theory to practice, our account of persons becomes progressively more "full."

"While the constraints of the Reasonable are weakest and the veil of ignorance thickest in the original position, at the [final] stage these constraints are strongest and the veil of ignorance thinnest." 46 The OP has now been recharacterized as that place in society that "incorporates pure procedural justice at the highest level." 47

The Moral Person. The role and constraints placed upon the parties in the OP (moral persons) are fairly clear in this passage:

The essential thing is that when we formulate the model-conception of the original position, we must view the parties as selecting principles of justice which are to serve as effective public principles of justice in a wellordered society, and hence for social cooperation among persons who conceive of themselves as free and equal moral persons....

The original position would represent the parties not solely as free and equal moral persons, but instead as persons also affected by social fortune and natural accident. Thus, these and other limitations on information are necessary to establish fairness between the parties as free and equal moral persons and, therefore, to guarantee that it is as such persons that they agree to society's basic principles of justice. ${ }^{48}$

The model-conception of moral persons constrained by rational autonomy thus becomes central to the understanding of the choices available to the parties in the OP. Their choices and actions are limited by particular conceptions of rationality and justice, which also considers their collective and individual interests and desires. So moral persons are

...characterized by two moral powers and two highest-order interests in realizing and exercising these powers. The first power is the capacity for an effective sense of justice, that is, the capacity to understand, to apply and to act from (and not merely in accordance with) the principles of justice. The second moral power is the capacity to form, to revise, and rationally pursue a conception of the good. Corresponding to the moral powers, moral persons are said to be moved by two highest-order interests[:] to realize and exercise these powers... . These interests are supremely regulative as well as effective....

In addition, I assume that the parties represent developed moral persons, that is, persons who have, at any given time, a determinate scheme of final ends, a particular conception of the good. Thus the modelconception defines moral persons as also determinate persons.... 49 
On the one hand then, individuals in the OP are rationally autonomous because they are subject to pure procedural justice, and they are guided by highest-order interests because they are in rational pursuit of specific conceptions of primary goods.

Reasonability, Rationality and Full Autonomy. On the other hand, full autonomy is characterized by a distinction between the reasonable and the rational, and tempered by the presumption of background justice. The reasonable is "a conception of the fair terms of cooperation, that is, terms each participant may reasonably be expected to accept, provided that everyone else likewise accepts them. [These terms] articulate an idea of reciprocity and mutuality...."50 The reasonable is then Rawls's basic concept of justice as fairness embodied within the individual: each of us is capable of reason, and this capacity for reason is instructive in our intuitive and our considered notions of what is and is not fair. Implied here is that the reasonable contains what would commonly be called responsibility: responsibility to act in an appropriately moral fashion according to the precepts and notions dominant in society, and responsibility to accept the consequences of one's actions whether they were morally informed and correct or not.

The rational, by contrast, "expresses a conception of each participant's rational advantage, what, as individuals, they are trying to advance."51 It is Rawls's conceptual and theoretical mechanism for imbuing individuals with the drive to choose and pursue a sense of the good that would actually be of benefit to them. The constraints of background justice subsume this distinction: "[I]t is only if the basic structure satisfies the requirements of background justice that a society treats its members as equal moral persons." 52 So full autonomy is "a moral ideal and part of the more comprehensive ideal of a well-ordered society," whereas "rational autonomy is not...an ideal at all, but a device of representation used to connect the conception of the person with definite principles of justice."53 So persons as moral agents in Rawls's scheme are allowed to be neither lib- 
ertines nor altruists; either choice might accord with full autonomy (though this is doubtful), but neither would accord with rational autonomy.

A point of clarification. Later when I discuss rationality and practical rationality, this does not refer only to Rawls's conception of "the rational." As a more generic term, “rationality" entails Rawls's use of the moral person as discussed above.

The Conception of the Person: Foundational or Derivative? This suggests a significant change in the concept of the person since Theory. In Theory, the person as an OP participant chose the principles of justice and allowable conceptions of the self as a rational or prudential agent similar to subjects found in rational/social choice theory or classical economics. There Rawls avoided ethical or moral motivations for persons in the OP so that the concept of person "enjoyed at most a derivative status.... The ideal of the person was not the foundation, but rather the outcome, of the theory of justice." 54 But now, with the idea of the person as a moral agent being a central concept of JAF, the person "plays a direct rather than a derivative role." So people in JAF are now seen as moral agents when they enter the OP in that "their choices are seen as pursuing, or expressing, basic features of moral personality," and that the constraints of rationality are no longer constraints upon individual choice (personal composition of the choosing subject, so to speak); they become instead "representations of the moral personality of the individuals themselves."55 The importance of this move for Rawls's general conception of persons cannot be over-emphasized; it is one of the most important and significant changes in his theory.

To summarize: the moral person in JAF is a hierarchically- or lexically-ordered being who, depending upon the circumstances perceived and the interests in consideration, will operate on one level of rationality or another. That is, according to the concepts of full and rational autonomy, the moral person is allowed only that palette of appropriate choices in a given situation, whether it is a situation in which to choose primary princi- 
ples of association (the OP), a situation in which to choose personal attributes (the construction of the self), or any run-of-the-mill situation in which a person might find themselves choosing between different moral positions in a well-ordered society. But now, instead of choosing "the self" along with the principles of justice, the formal constraints upon the moral self are established prior to the choice of principles of justice.

\section{The Objects of and Some Objections To a Situated Moral Theory}

"Three Points of View" The model-conceptions situate JAF and limit it to modern democratic society. The theory now does not answer the larger question "What is justice?," but rather "What is justice for us?," the "us" meaning variously (a) the parties in the OP, (b) the citizens in a well-ordered society, or (c) observers/philosophers, i.e., people interested in questions about justice and society. ${ }^{56}$ Rawls is concerned here with what justice means when analyzed from these "three points of view" because "we" implies the members of a liberal, democratic, constitutional, capitalistic society within a particular historical period.

What is not clear about this conceptual tool is whether those different views are constitutive of a particular view, or if they are merely contingent views. Rawls gives us little indication one way or the other, although most critics have decided that Rawls relies upon a contingency-based view. But still, this does not decide the question as to whether membership in one of those views is a necessary or sufficient determinant of the opinions, beliefs, etc., that might be held by individual members. This ambiguity affects the manner in which citizens perceive, justify, and accept JAF.

Preliminary Objections. The revised model-conceptions, while still subject to some of the objections raised against rational-choice theory, ${ }^{57}$ share some procedural problems: which is prior, background justice, or the concept of the moral person? Given the restrictions of rational autonomy, how is full autonomy to be achieved? Certainly, "the reason- 
able presupposes the rational," 58 but how then are we to conceive the relation between full and rational autonomy?

Preliminary Answers. Rawls proposes two answers to these objections that center on the distinctions he is wont to make about rational versus full autonomy and the reasonable versus the rational. One is found in his discussion of the three points of view in "Kantian Constructivism in Moral Theory." 59 Rawls here carefully distinguishes between the roles of the conception of the person and of a theory of human nature: because the distinction between the reasonable and the rational is important to set Rawls's theory into motion and to situate it in a contemporary liberal democratic context, it presupposes an idea of a particular kind of rationality with which the participants in the OP enter prior to any discussion of principles. Certainly, such pre-conceived notions of rationality would carry with it more than that which is allowable under the veil of ignorance, even as revised.

In that case, the conditions within the veil of ignorance are to be revised, a move that is allowable under reflective equilibrium. But this distinction between a conception of persons and a theory of human nature still logically holds. Rational autonomy is a conception derivable (in a sense) from the concept of full autonomy, and as such is a "higher level" test for the role of persons in society. It implies that the move from the OP to JAF in society has been made, and we now dealing with person in society, not within the OP.

So Rawls's previous view of people in JAF - as "products of the OP and moral-rational considerations - has been altered so that persons as citizen-participants in the OP come to that initial social contract situation with more fully informed ideas of the concept of rationality in society, and what place a moral-rational actor would choose. The veil of ignorance is less thick than before with regard to knowledge of the basic structure and of 
the concept of a self, but more thick with regard to personal contingencies (i.e., knowledge about one's own self).

\section{"The Basic Liberties and Their Priority"}

A second response to the objections centering on the conception of persons is found in the Tanner Lectures, "The Basic Liberties and Their Priority." This lecture is a response to criticisms leveled at JAF (primarily Rawls's conceptions of liberty and autonomy, and their relation) from other liberal theorists, especially H. L. A. Hart in his article "Rawls on Liberty and Its Priority."60 Hart is concerned mainly with Rawls's "account of the relationship between justice and liberty, and in particular with [the] conception that justice requires that liberty may only be limited for the sake of liberty and not for the sake of other social and economic advantages." 61 Hart's contention, and what Rawls later develops in the Tanner Lectures, is an account of why participants in the OP would adopt the basic liberties and accept them in a lexical priority, and how those basic liberties are to be specified and substantively defined given a particular social order. ${ }^{62}$

The Revised Principles. Rawls's initial response was to revise the first principle. This revision, along with the conceptual additions of "Kantian Constructivism" allows Rawls to subtly alter his position: there is now "no priority to liberty as such," but only to certain basic liberties. ${ }^{63}$

1. Each person has an equal right to a fully adequate scheme of equal basic liberties which is compatible with a similar scheme of liberties for all.

2. Social and economic inequalities are to satisfy two conditions. First, they must be attached to offices and positions open to all under conditions of fair equality of opportunity; and second, they must be to the greatest benefit of the least advantaged members of society. ${ }^{64}$

(I have emphasized the differences between this reformulated presentation of the principles and the former statement, infra, p. 4. Also, it should be noted that the principles are now grammatically presented in their lexical priority.) 
This accords with Rawls's interpretation of the history of democratic thought, ${ }^{65}$ and also accords with his description of a four-stage institutional process of arriving at or agreeing upon principles of justice as outlined in Theory, $\S 31$. The relevance of this move for our purposes is that this further constrains the reasonableness of the actors in the OP. "At each successive stage [in the four-stage process of the OP] the agents have less leeway as they are more and more constrained by the conclusions of previous stages. They have to act rationally, but as the task becomes less general and more specific, the demands of the Reasonable become stronger (and the veil of ignorance becomes thinner)." 66 This is part of Rawls's primary goal in the defense of his theory: to show that the Kantian enterprise is not merely an abstraction, but a conceptual way of incorporating Western - and especially American - concepts of freedom and equality as found in democratically-conceived and -operated institutions into JAF.

Recalling the three points of view, we can see that Rawls emphasizes the view that “...justice as fairness is addressed not so much to constitutional jurists as to citizens in a constitutional regime." 67 In accord with the distinctions between the reasonable and the rational and between rational and full autonomy, Rawls emphasizes the "practical nature" of JAF. It applies, like positive law, to our very lives as regulative and regulating principles, discovered and formulated according to operations of reflective equilibrium and rationality.

Additionally though, these conceptual re-definitions have altered the importance of Rawls's two principles of justice, particularly the second or priority principle. An essential part of the earlier theory was the priority of liberty, and the claim that liberty could only be attenuated for the sake of liberty. Revising the principles in light of criticism has indeed allowed greater room for the preservation of liberties, e.g., civil liberties and human rights. The revised priority principle now holds that liberty (of choice and the capacity for rationality) must be preserved for the sake of liberties (guarantees of freedom 
to act in certain socially-sanctioned ways) or their potential, as opposed to the preservation of liberty merely for the sake of liberty (full autonomy unbound by rationality). Thus, the revised priority principle has become more essential and fundamental to the concepts of liberty and equality, particularly when compared to the difference principle. It now allows the individual a limited ability to choose his or her attributes according to the principles of rationality prior to the OP.

\section{Difficulties and Unanswered Ouestions}

Goods and Neutrality, Rawls's revised scheme for the OP in this second period affects the way social goods are ordered, too. For example, because people come to the OP with moral knowledge, it is unclear how impartiality or neutrality in conceptions of the good would be maintained throughout the decision process. Rawls's answer to this difficulty reveals his pre-occupation with the practical application of his theory. As William Galston notes, rather than arguing "that rational judgment about the worth of different conceptions of the good is impossible,... he emphasizes the practical difficulties of institutionalizing a specific conception." 68 But, again, the kind of ignorance that is now allowed in JAF calls into question the neutrality of conceptions of the good. Additionally, Rawls offers no better reasons to accept limited ignorance over full information to ensure neutrality or impartiality.

The Modified Aims of Political Philosophy. This period of development also displays Rawls's increasing concern for practical matters. But this is, as Galston notes, at odds with the professed Kantian nature of his enterprise: "For Kant, it is reason - not the need or agreement, not the circumstances of agreement - that determines the content of our appropriate social undertakings." 69 However Kant may be interpreted in the history of ideas, this movement restricts the demesne of both liberal theory and political philosophy. More immediately, for Rawls this move has not yet resolved the tension that he had 
hoped to resolve in Theory: the tension between liberty and equality. Because of the limited Kantian nature of JAF, Rawls's desire to place equality (in the guise of participants under the veil of ignorance) above freedom (in the guise of the tensions between the reasonable and the rational, and rational and full autonomy) biases from the beginning the allowable conceptions of the good and the right: "Rawls's practical conception of political philosophy is, I suspect, governed by his overall practical intention - to uphold the principle of equality that stands at the heart of democratic culture."70

\section{JAF RESPONDS: THE ADVENT OF POLITICAL LIBERALISM, 1985-1989}

\section{"Political, Not Metaphysical"}

The current conception of JAF is captured in Rawls's four most recently published articles: "Justice as Fairness: Political not Metaphysical," "The Idea of an Overlapping Consensus," "The Priority of Right and Ideas of the Good," and "The Domain of the Political and Overlapping Consensus." 71 In these four articles, where JAF is radically altered and ultimately transformed into political liberalism, Rawls again concerns himself with charges that despite the shifts in emphasis, his theory remains abstract and depends upon metaphysical and ontological claims about persons and the social structure that are normative, universal, and essential to JAF.

A Kantian Enterprise? Rawls begins by explaining once again the Kantian nature of his enterprise. However, in distinguishing his theory from Kant's, Rawls notes that "justice as fairness is not intended as the application of a general moral conception to the basic structure of society, as if this structure were simply another case to which that general moral conception is applied."

The essential point is this: as a practical political matter no general moral conception can provide a publicly recognized basis for a conception of justice in a modern democratic state.... ${ }^{72}$ 
The objective has now become "not a conception of justice that is true, but one that can serve as a basis of informed and willing political agreement between citizens viewed as free and equal persons."

[W]e must recognize that...public agreement on the basic questions of philosophy cannot be obtained without the state's infringement of basic liberties. Philosophy as the search for truth about an independent metaphysical and moral order cannot, I believe, provide a workable and shared basis for a political conception of justice in a democratic society. ${ }^{73}$

This idea about the goal of political philosophy and how it conceives the role of the state - to provide a feasible basis for the promotion of a well-ordered society - gains prominence in Rawls's later work, as can be seen particularly in the idea of an overlapping consensus. Implied in this new conception of the aims of political philosophy is a denial of constitutive claims regarding the essential nature and formative identity of persons in political society. But this does not mean that a firm conception of the roles and characteristics of the person is unnecessary or unimportant for JAF. In a concise summary of his earlier position in "Kantian Constructivism in Ethics," Rawls explains the role of the moral person, both as a citizen and as a participant in the OP:

1. [Persons are] free and equal in virtue of their possessing to the requisite degree the two powers of moral personality..., namely, the capacity for a sense of justice and the capacity for a conception of the good. These powers [are] associated with two main elements of the idea of cooperation and the idea of each participant's rational advantage, or good. ${ }^{74}$

2. Persons are free in that they have moral powers to conceive and pursue a conception of a conceived good; are self-originating sources of valid claims; and have responsibility for their desired ends and claims as a limitation upon individual pursuits. 75

Rawls wishes here to show that justice as fairness is a particular and not a comprehensive moral doctrine, one that is valid for us because it is situated within and derived from a democratic culture. Furthermore, it accords with our basic intuitive and our considered and reflective judgments as to what justice is and how it operates; because we are able to agree on some basic political ideas and concepts that are subsumed by our democratic culture, we can appeal to these ideas in the effort to promote specific 
decisions and policies, simultaneously promoting social unity and stability. So the concept of the person has become of secondary but still crucial importance to JAF. The person remains derivative of the social structure and situation of justice, and is not "preformed" as William Galston has noted. ${ }^{76}$ So while it is true that the importance of the basic structure to JAF has increased while the conception of the person has diminished, the person remains important.

\section{Additional Model-Conceptions}

It is at this point that Rawls adds some model-conceptions to help explain the way persons are conceived in a liberal political society. These are a "reasonable moral psychology," and the "historical and social conditions of modern democratic societies."77 The reasonable moral psychology is a summary of the two moral powers and higherorder interests introduced in "Kantian Constructivism" and reiterated in "Justice as Fairness: Political Not Metaphysical." To this, Rawls adds the idea that as people act as moral agents with these controlling concepts in mind, they will grow to trust each other more and more, thus helping to establish and engender an overlapping consensus. Legitimacy and confidence, both in our political theory and its application to our institutions, are thus contingent upon sustained cooperation.

Secondly, democratic societies are characterized by the permanent presence of pluralism in a culture that resembles a Humean state of moderate scarcity, a condition that can be overcome either through state tyranny or mutual cooperation. Obviously, mutual cooperation is preferable to tyranny. This emphasis on the basic structure and the conditions that would promote cooperation for economic and material gain as well as tolerance and neutrality towards visions of the good is Rawls's idea of an overlapping consensus: "[It] is not a happy coincidence, even if aided as it no doubt must be by 
historical good fortune, but is rather in part the work of society's public tradition of political thought."78

\section{Political Liberalism}

These additional model-conceptions lay the groundwork for the more complete presentation of political liberalism. The ideas behind political liberalism flow from Rawls's concern to return to a classical conception of political philosophy that is more or less strictly political and does not address epistemological or psychological questions per se. Political liberalism hopes to overcome two objections - skepticism and indifference, and the lack of social or political support to assure compliance with the principles of justice in part by answering two objections. ${ }^{79}$ First, Rawls appeals to the principle of a reasonable moral psychology and its concomitant notions of trust and cooperation. Second, political liberalism requires citizens to affirm throughout the political society a uniform conception of themselves as free and equal citizens, and to accept that there are only some permissible conceptions of the good, or conversely that some conceptions of the good are not permissible. ${ }^{80}$ I think it is important to see that political liberalism is, on this view, neutral in a particular way. To operate, it must have some agreement at the most basic level of political society, and the state must then employ something like "coercive neutrality," a neutrality of aim to ensure continuity and consistency in a liberal political culture. ${ }^{81}$ Rawls refers to this as the "priority of the right over ideas of the good." (I shall have more to say about how this justificatory neutrality - the priority of the right over ideas of the good - operates in political liberalism in chapter 4.)

Unity and Pluralism. But how can a particular political and moral conception achieve political stability and unity in the face of a pluralistic culture? Rawls provides an answer by eschewing some of the more traditional conceptions of justice. First, justice in a democratic society cannot be "a mere modus vivendi, dependent on a fortuitous con- 
junction of contingencies." 82 Those who seek to promote stability through the construction or imposition of a constitutional regime or modus vivendi merely manage the conflict inherent in a pluralistic society; they do nothing to help promote social stability and development because they do not refer to agreement on the most fundamental political concepts. What Rawls seeks here is a conception of justice that articulates the values and ideals of a democratic constitutional regime, not a system of constitutional design formed to guide the construction of political institutions as means of controlling group or individual interests. ${ }^{83}$ An important objection to Rawls's position is that a modus vivendi need not be based upon "a fortuitous conjunction of contingencies." Rawls's own examples of the English Revolution of 1649 and the Glorious Revolution of 1688 could certainly be interpreted that way, as "mere historical fate," as it were. But there are other historical reasons and arguments that should persuade us otherwise. ${ }^{84}$ So it is not clear that a modus vivendi is not a viable basis for a political culture.

Rawls answers this by saying that a modus vivendi can be the historical beginnings of a political culture that is governed by the principles of JAF, but that a modus vivendi could never amount to anything but that. However, my point is that a modus vivendi is able to incorporate the ideas of JAF, but not necessarily to the extent that an overlapping consensus strives for.

Secondly, JAF in the liberal-democratic conception is a particular moral conception, one that Rawls is at pains to distinguish from other more traditional and comprehensive doctrines such as utilitarianism and perfectionism. "[A] political conception of justice involves...no prior commitment to any wider doctrine. It looks initially to the basic structure and tries to elaborate a reasonable conception for that structure alone."85

This is congruent with some of Rawls's earliest concepts of a political and moral theory of association, namely that political and moral philosophy should be similar yet distinct in some fundamental ways. ${ }^{86}$ That is, Rawls still appears to be "looking for a 
way of adjudicating between the competing claims of different interests."87 Justice on any account requires "the establishment, within the structure of a practice, of a proper balance between competing claims."88 This thread of Rawls's thought has remained relatively constant. But Rawls now emphasizes, like the above distinction between political and moral philosophy, that his theory is "best understood [and was only intended as] a political rather than a moral doctrine - and as such is committed to no metaphysical theses." 89

\section{Particular-Political vs. Comprehensive-Moral Conceptions}

This distinction does not by itself resolve the problem. While JAF "is intended as a political conception of justice," 90 it contains and is to a large degree fueled by metaphysical and ontological conceptions regarding ethical theory and moral insight. In particular it implies, as Michael Sandel has amply demonstrated, that these metaphysical and ontological premises in Rawls's theory commit him to a particular conception of the self and its relation to political society. Be that as it may, Rawls insists upon a distinction between "a political conception of justice and a comprehensive religious, philosophical, or moral doctrine"91 as a basis for a political theory of justice.

The distinction is largely "...a matter of scope," i.e., a matter of how encompassing and fundamental a conception of the good is to a conception of justice. It is in this manner that Rawls understands the Kantian maxim of the right prior to the good. The political idea of the good is focused on or by a rationality of the kind defined in "Kantian Constructivism": the rational advantage of pursuing a particular conception of the good tempered by social cooperation (or the reasonable which presupposes the rational). 92 But the pursuable social goods, as categorized, are still those things contributing to individual autonomy and conceptions thereof, and are further constrained by their permissible contribution to a well-ordered society. So there are necessarily some pursuits of the good 
that in a neutral liberal society cannot be allowed due to the particular construction of neutrality of aim or outcome. That is, the basic structure must be designed (1) to exemplify and promote neutrality, which means that (2) (a) the basic structure cannot promote one vision of the good over another or any others, nor (b) can the basic structure inhibit, prohibit, or otherwise denigrate one vision of the good over others.

There is another distinction here, between a vision of the good - which this certainly is - and an account of neutrality that allows a particular vision of the good - which this is also. This kind of neutrality is not itself a morally neutral conception of neutrality or the good. It is instead a morally biased yet acceptable justification of a neutral procedure that allows pluralism, yet de-emphasizes intolerance.

Rawls does not imply that JAF is intended to be an "all inclusive" liberalism, one that accepts pluralism without question. Loss of "certain forms of life" is indeed lamentable, but "any society will prove uncongenial to some ways of life. But these social necessities are not to be mistaken for arbitrary bias or injustice."93 Nor, apparently, are they to be mistaken for non-neutrality.

\section{Five Facts of Political Sociology}

This conception of neutrality is refined when Rawls again emphasizes that political liberalism is determined or situated within an existing liberal culture. ${ }^{94}$ The existing liberal culture is characterized by "four general facts of political sociology and human psychology," facts about which we are presumably agreed, or at least accept as not fundamentally controversial. First, plurality - diversity and the resulting conflict of divergent ideas and pursuits of the good - is a permanent feature of modern democratic societies. Second, "only the oppressive use of state power can maintain a continuing common affirmation of one comprehensive religious, philosophical, or moral doctrine." Third, "an enduring and secure democratic regime...must be willingly and freely 
supported by at least a substantial majority of its politically active citizens." Fourth, "the political culture of a reasonably stable democratic society normally contains, at least implicitly, certain fundamental intuitive ideas from which it is possible to work up a political conception of justice suitable for a constitutional regime."95

A fifth general fact is added shortly thereafter: most of our important decisions will not reach anything like full consensus, even given the conceptual bases and limits of reasonable and rational discourse. ${ }^{96}$ These five facts become the empirical basis for political liberalism which, in turn, demonstrate the altered perception of the aims of political philosophy for Rawls. The "burdens of reason" upon rational discourse and agreement serve as bases for political liberalism and the public conception of justice; reason can serve as a basis for agreement, even though we may disagree as to substance; so we can agree to institutions and even to their "kind," but not necessarily to their substantive and normative content. ${ }^{97}$ Political philosophy is then to articulate this possibility, and promote the conditions for its acceptance and growth.

Anticipated Objections. In keeping with these distinctions of moral versus political philosophy on the one hand and comprehensive versus (particular) political conceptions of justice on the other, Rawls proceeds to address four possible objections to the "idea of social unity founded on an overlapping consensus of a political conception of justice."98 First, despite the observation that a liberal democratic society is composed of "conflicting and indeed incommensurable comprehensive conceptions of the meaning, value and purpose of human life (or conceptions of the good)," still the idea of an overlapping consensus is not a modus vivendi, or a mere treaty between competing interests; it is a moral conception that includes and relies upon citizens, society, and the sense of justice as derived (agreed upon) by that society. ${ }^{99}$ Second, such a conception does not imply indifference or skepticism; the idea of an overlapping consensus instead implies that individuals must indeed hold these conceptions as part of such an idea. "Rather, we 
appeal to a political conception of justice to distinguish between those questions that can be reasonably removed from the political agenda and those that cannot...."100

Third, agreeing upon the idea of an overlapping consensus does not mean that we must accept either politics as a modus vivendi or as a comprehensive doctrine; these are not the only available or viable choices. Describing an overlapping consensus entails the use of "free public reason" to "identify the fundamental roles of political values in expressing the terms of fair social cooperation consistent with mutual respect between citizens regarded as free and equal," and helps to uncover "a sufficiently inclusive concordant fit among political and other values as displayed in an overlapping consensus."101

The fourth objection is the purported utopian character of the idea of an overlapping consensus: "that there are not sufficient political, social, or psychological forces either to bring about an overlapping consensus (when one does not exist), or to render one stable (should one exist)."102 Rawls answers this by noting the three elements of a political conception of justice:

[F]irst, a specification of certain basic rights, liberties and opportunities (of the kind familiar from constitutional democratic regimes); second, an assignment of a special priority to those rights, liberties and opportunities, especially with respect to the claims of the general good and of perfectionist values; and third, measures assuring to all citizens adequate allpurpose means to make effective use of their basic liberties and opportunities. ${ }^{103}$

So the three positive aspects of the political conception of an overlapping consensus are that they first determine and fix the basic rights and liberties, and assign them a priority in order to avoid conflict about their content and place within a constitutional regime; second, given the conflict inherent in a pluralistic political culture, these positive aspects avoid conflict by justifying the placement and content of these basic rights and liberties and their priority through an appeal to free public reason, removing them from justification by appeal to any particular comprehensive moral doctrine, thereby placing them beyond political conflict; and finally, they encourage mutual cooperation and reasonable- 
ness, which reciprocally strengthens the ideas of free public reason and the policies and institutions resulting from these background considerations. ${ }^{104}$

\section{CONCLUSION}

Rawls's development of the idea of political liberalism reveals two primary shifts in his thought: first, while he is moving away from a liberally moral comprehensive doctrine that had guided his theory, he still maintains some of the core values of that Kantian doctrine. Second, Rawls seems to be more and more concerned with order and stability in his embellishments and revisions of a liberal theory of justice. But in moving from Theory to these later articles Rawls has, despite refinements that have significant consequences, left his two principles of justice as fairness intact. He has chosen instead to address the issue of how the principles operate in society, i.e., he has focused on context, not content. It is in the application and explication of these applications that Rawls's more controversial moves have surfaced.

Clearly Rawls has increasingly emphasized the procedural aspects of political philosophy in the development of his theory. This is indicated in the greater concern for the feasibility of his procedure, i.e., the "practicality" of the theory in, say, the construction of institutions, as opposed to the desirability of the theory, or how it withstands assessment, tempered by our considered judgments, in the theory's endeavor to distribute goods "fairly." Rawls implicitly denies to political philosophy a "search for truth," the subject that has dominated most philosophic subdisciplines and endeavors.

Another way to say this is that after Theory, Rawls had a choice of directions in which to move his theory. He could have moved towards a more individualistic theory, one that more fully accounted for people's moral psychology and would allow sufficient room for individual make-up, etc.; or he could have (as he chose to) moved towards a theory that is more historically- and community-based. But even this move has drawn 
fire from his critics. First, there were the emendations to his theory resulting from liberal critics. Then there were the critiques offered by philosophers and theorists postulating and formulating a theory of political association on radically alternative bases, the communitarian theorists. It is to two of those theories that I now turn. 


\section{NOTES}

${ }^{1}$ Ludwig Wittgenstein, On Certainty, trans. and ed. G. E. M. Anscombe and G. H. von Wright (New York: Harper Torchbooks, 1969): § 76, p. 12 e.

2 John Rawls, $A$ Theory of Justice (Cambridge, MA: Harvard University Press, 1971).

3 "Outline of a Decision Procedure for Ethics," Philosophical Review 60 (1951): 177-97; "Justice as Fairness," Journal of Philosophy 54 (1957): 653-62. This and the following three notes are in no way intended to be an exhaustive bibliography of Rawls's work.

4 These are, including Theory: "Concepts of Distributional Equity: Some Reasons for the Maximin Criterion," American Economic Review 64 (1974): 141-6; "Faimess to Goodness," Philosophical Review 84 (1975) 536-54; "The Basic Structure as Subject," American Philosophical Quarterly 14 (1978) 159-65; "A Well-Ordered Society," in Peter Laslett and James Fishkin, eds., Philosophy, Politics, and Society, 5th series (1979): 6-20.

5 The articles in this third period are: "Kantian Constructivism in Moral Theory: The Dewey Lectures 1980," The Journal of Philosophy 88, 515-572, 1980; "Social Unity and Primary Goods," in Utilitarianism and Beyond, ed. Amartya Sen and Bernard Williams (Cambridge: Cambridge University Press, 1982): 159-85; The Tanner Lectures on Human Values ii (Cambridge: Cambridge University Press, 1982): 1-89.

6 The fourth period articles are: "Justice as Fairness: Political Not Metaphysical," Philosophy and Public Affairs 14 (1985): 223-51; "The Idea of An Overlapping Consensus," Oxford Journal of Legal Studies 7 (1987): 1-25; "The Priority of Right and Ideas of the Good," Philosophy and Public Affairs 17 (1988): 251-76; "The Domain of the Political and Overlapping Consensus," New York University Law Review 64 (1989): 233-55.

7 Norman Daniels, "Introduction," in Reading Rawls: Critical Studies on Rawls' 'Theory of Justice,'” 2d ed. (Stanford, CA: Stanford University Press, 1975): xxxvii.

8 Perhaps the most accurate and concise summary of Rawls' Theory of Justice can be found in Chapter 6 of Allen Buchanan's book, Marx and Justice (Totowa, NJ: Rowman and Allanheld, 1982): 103-121. Other helpful and concise treatments and critical studies of Rawls as he has developed are: Chandran Kukathas and Philip Pettit, Rawls: A Theory of Justice and its Critics. (Stanford, CA: Stanford University Press, 1990); the various essays in Norman Daniels, ed., 1989 (2d ed.), Reading Rawls: Critical Studies on Rawls' Theory of Justice. (Stanford, CA: Stanford University Press, 1975); William Galston, "Moral Personality and Liberal Theory: John Rawls' Dewey Lectures," Political Theory 10 (1982): 492-519; Thomas Pogge, Realizing Rawls (Ithaca, NY: Cornell University Press, 1989); and Patrick Neal, "Justice as Fairness: Political or Metaphysical?," Political Theory 18 (1989): 24-50.

9 Buchanan, Marx and Justice, 105.

10 ibid., 106.

11 Theory, 302-3. 
12 Buchanan, Marx and Justice, 108. These basic liberties include: (a) the freedom to participate in the political process (the right to vote, the right to run for office, etc.); (b) freedom of speech (including freedom of the press; (c) freedom of conscience (including religious freedom); (d) freedom of the person (as defined by the concept of the rule of law); (e) freedom from arbitrary arrest and seizure [n.b.: this would seem to follow, or be subsumed under (d)]; and (f) the right to hold property; Theory, 61 .

13 Buchanan, Marx and Justice, 109; Theory, 98.

14 Theory, 98.

15 Buchanan, Marx and Justice, 110.

16 In later articles, Rawls grammatically rearranges the principles so that they accord with priority rules, which helps to avoid some confusion. See p. 34, infra, and n. 64 .

17 Theory, 303.

18 Buchanan, Marx and Justice, 111. See also Kukathas and Pettit, Rawls, 44-47.

19 ibid.

20 Buchanan, Marx and Justice, 113; emphases original, footnotes omitted.

${ }^{21}$ Rawls's full discussion of the maximin principle can be found in Theory, § 26, esp. pp. 152-57.

22 Theory, 17.

23 ibid., 115, 127-35. Feature (d) simply excludes alternative conceptions of justice, e.g., utilitarian, teleological, intuitionistic, and egoistic conceptions of justice. There is a useful table in Theory, 124, listing the excluded kinds of approaches/justifications towards a theory of justice.

24 ibid., 137.

25 Michael Sandel, Liberalism and the Limits of Justice (Cambridge: Cambridge University Press, 1982): 50 .

26 Theory, 136.

27 This is in distinction from perfect and imperfect procedural justice; see Theory, § 14, pp. 83-90.

${ }^{28}$ Kukathas and Pettit, Rawls, 115.

29 Theory, § 23, 130-36; Buchanan, Marx and Justice, 116-17.

${ }^{30}$ Kukathas and Pettit, Rawls, 45.

31 Rawls demonstrates in $\$ \S 28-29$ of Theory why justice as fairness would be preferred over utilitarianism of various kinds.

32 Theory, 177. 
33 Theory, 440.

34 Theory, 179.

35 Theory, 49.

${ }^{36}$ Kukathas and Pettit, 54.

37 This is additionally a characteristic Rawls uses to distinguish JAF from utilitarian and other teleological theories such as socialism, communism, communitarianism, and the like; see "The Original Position," pp. 6-9, above, especially the formal constraints of right.

38 Theory, 396.

39 Theory, 574.

40 Rawls, "Political Not Metaphysical," 224. It should be additionally noted that the most important elements that add to Rawls' theory are found in the first lecture of this series, that is the section entitled "Rational and Full Autonomy." The other two lectures, "Representation and Full Autonomy" and "Construction and Objectivity" are primarily expositions of the conceptual distinctions between Rawls's conception of justice and those historically proposed by Kant, Hume, and Sidgwick. As such, the first lecture is the most important for my purposes.

41 Theory, 516.

42 Rawls, "Kantian Constructivism," 518; emphasis added.

43 Kukathas and Pettit, Rawls, 125.

44 Rawls, "Kantian Constructivism," 523. This relies on what Rawls will later variously call free public reason, public rationality, or rational discourse.

45 ibid., 521.

46 Rawls, "Basic Liberties," 55.

${ }^{47}$ Rawls, "Kantian Constructivism," 523. Rawls' discussion of pure procedural as opposed to other conceptions of justice is found in $\$ 14$, Theory.

48 ibid., 521 .

49 ibid., 528.

50 ibid., 528.

51 id.

52 id.

53 ibid., 533-34; emphasis added. 
54 Galston, "Moral Personality and Liberal Theory," 496.

55 id.

56 id.

57 Such problems are beyond the scope of inquiry in this paper. But see, e.g., David Kaye, "Playing Games with Justice," Social Theory and Practice 6 (1980): 33-51.

58 Rawls, "Kantian Constructivism," 528.

59 ibid., 532-35.

${ }^{60}$ H. L. A. Hart, "Rawls on Liberty and Its Priority," in Norman Daniels, ed., Reading Rawls:

Critical Studies on Rawls' Theory of Justice, 2d ed., (Stanford: Stanford University Press, 1989): 230-52.

61 Hart, "Rawls on Liberty and Its Priority," 230.

62 Kukathas and Pettit, Rawls, 130.

63 Rawls, "Basic Liberties," 5.

64 id.

65 Rawls, "Basic Liberties," 6.

66 Kukathas and Pettit, Rawls, 130.

67 Richard J. Arneson, "Introduction (to a 'Symposium on Rawlsian Theory of Justice: Recent Developments')," Ethics, 99 (1989): 695-710.

68 Galston, "Moral Personality and Liberal Theory," 501.

69 ibid., 513; emphases original.

70 ibid., 514; emphases original.

71 Please refer to note 6.

72 Rawls, "Political Not Metaphysical," 225; emphasis added.

73 ibid., 230.

74 ibid., 233.

75 ibid., 239, 242-3.

76 Galston, "Moral Personality and Liberal Theory," 514-16. See, e.g., Larmore, Patterns, 125, and especially notes 67 and 68, pp. 174-75: "I cannot understand how Galston...could have come to the 
opposite conclusion, that the "Dewey Lectures" resolve the tension between Kantian and modus vivendi justifications in favor of the former."

77 Rawls, "Overlapping Consensus," 22. While Rawls does not use the term model-conceptions when presenting these ideas, they are embellishments of his prior use of the term in referring to a well-ordered society, a moral person, and the OP. The term "model-conception" thus remains congruent in its application; the number of model-conceptions themselves have simply been expanded.

78 ibid., 22-3.

79 id.

${ }^{80}$ Rawls, "The Priority of Right," 255-58.

81 Rawls relies on a conception of neutrality that is, in some respects, non-neutral: he relies on the phrase "the priority of the right over the good" to replace traditional conceptions of neutrality. However, it should be noted that this neutrality, what Kymlicka has called justificatory neutrality (or neutrality of aim or outcome), does not allow prohibition or promotion of visions of the good life by the state. That is a liberal principle that remains constant throughout Rawls's theory as it develops.

82 Rawls, “Overlapping Consensus," 1.

83 id. See also Kukathas and Pettit, Rawls, 137.

${ }^{84}$ Examples of this historical situated-ness approach to political theory are common from the "Cambridge school" by authors such as Quentin Skinner, James G. Pocock, John Dunn, and J. B.

Schneewind; see David Miller, "The Resurgence of Political Theory," Political Studies 38 (1990): 421-37. An example of analyzing a particular social period and major philosopher's background and formative influences in that period would be e.g. Richard Ashcraft's Revolutionary Politics and John Locke's Twe Treatises of Government (Princeton, NJ: Princeton University Press, 1986). An example of the development of a particular concept through time would be Harold J. Berman's study of the changing role of law from the founding of the Italian universities in the late to mid-Renaissance, Law and Revolution: The Formation of the Western Legal Tradition (Cambridge, MA: Harvard University Press, 1983).

85 Rawls, “Overlapping Consensus," 1.

${ }^{86}$ Rawls, “Outline of a Decision Procedure for Ethics," and "Justice as Faimess" (1957).

${ }^{87}$ Rawls, "Outline of a Decision Procedure for Ethics," 177.

88 Rawls, "Justice as Faimess," 653.

${ }^{89}$ Kukathas and Pettit, Rawls, 134; emphases added.

90 Rawls, "Political Not Metaphysical," 224.

91 Rawls, "The Priority of Right," 252.

92 Rawls, "Kantian Constructivism," 528-30.

93 Rawls, "The Priority of Right," 265-66. 
94 Rawls, "Domain of the Political," 234.

95 ibid., 235.

96 ibid., 238.

97 ibid., 241.

98 Rawls, "Overlapping Consensus," 9.

99 ibid., 9, 11.

100 ibid., 13.

101 ibid., 17.

102 ibid., 18.

103 ibid., 18, footnote omitted.

104 ibid., 19-21. 


\title{
CHAPTER III
}

\section{THE ONTOLOGICAL CRITIQUE OF}

\author{
MICHAEL SANDEL
}

\begin{abstract}
Nothing we do can be defended absolutely and finally. But only by reference to something else that is not questioned. I.e. no reason can be given why you should act (or should have acted) like this, except that by doing so you bring about such and such a situation, which again has to be an aim you accept.
\end{abstract}

\section{Ludwig Wittgenstein ${ }^{1}$}

Richard Arneson has recently commented that "[p]erhaps the most thorough extended critique of Rawls's theory is still Michael Sandel's Liberalism and the Limits of Justice"; ${ }^{2}$ think this statement continues to accurately describe the state of critique in the development of JAF. Focusing on the internal structure of Rawls's conception of the person in a liberal political society, Sandel analyzes the epistemological, ontological, and metaphysical aspects of Rawls's conception of the person within the structure of what is called "deontological liberalism," a name that emphasizes Rawls's debt to Kantian ethics. Rather than being a critique of rationality in modern moral, social and political thought, this critique focuses on the internal structure of Rawls's arguments, and the justifications for liberalism and JAF.

The various arguments historically relied upon to justify liberalism have been reevaluated since the inception of Rawls's Theory. Liberalism no longer has to rely upon the more "traditional" justifications for a neutral liberal state - experimentalism and skepticism - that have been advanced by some of the greatest historical political thinkers that we now consider to be liberals. ${ }^{3}$ In a very significant way, this point has been made 
all the more clear in Michael Sandel's critique: contemporary deontological liberalism is greatly in Sandel's debt if not for clarifying the terms of the debate, then for circumscribing and delimiting the conceptual limits of a liberal conception of the person.

However, while Sandel's argument is largely in opposition to Rawls's theory and the model-conceptions and the way they are used (the difference principle, the argument for a construction of the person that does not rely upon a conception of desert, and the novel use of the social contract), these are aspects of Sandel's argument I must put aside in order to address a narrower focus: the liberal construction and placement of the person in society, and the communitarian objection to that construction.

Sandel's critique generates three distinct but inter-related claims: "descriptive claims which stress that people are social beings; normative claims which celebrate the value of community and solidarity, and a meta-ethical claim emphasizing that political principles should mirror 'shared understandings.' "4 I am primarily concerned with the descriptive and normative claims. In particular I want to show how these claims are advanced in Sandel's theory in contradistinction to liberalism, and why and how such claims (a) fail as a result of the confusion of separate descriptive claims, but also (b) in confusing those claims with other normative claims. Additionally I will show that while the descriptive and normative claims do account for our way of understanding and doing politics and political theory, Rawls has adequately answered the pertinent aspects of this part of Sandel's critique, and has thus overcome a fundamental communitarian criticism.

I will proceed as follows. Before examining Sandel's critique, I will make the deontological liberal and communitarian positions more clear by characterizing them in a general, if truncated form. I will then examine Sandel's critique as it has been stated in his primary work, Liberalism and the Limits of Justice. Here I will explore the claims that Sandel makes against Rawls's theory, claims that are advanced through a critique of 
the conception of the person that Sandel says Rawls must rely upon in order support the major point of his theory - justice as fairness.

In the second section, I will examine the underlying claims that fuel Sandel's critique. These underlying claims - the justification for the communitarian position have been variously called the social thesis, the social embeddedness thesis, the social fixedness thesis, etc. I will examine only one form of this idea as it presented in Sandel's (and later Alasdair MacIntyre's) work, the social embeddedness thesis. Here I will note that Sandel must rely upon a rather weak form of this claim, a claim that at once disallows some of his criticisms of Rawls and also allows Rawls to respond adequately and convincingly to Sandel's critique.

I will then examine several of the most common liberal objections to Sandel's critique to see which of these liberal responses are apt, and which are not. Obviously, Sandel's critique has provoked a passionate response not only amongst deontological liberals, but also amongst liberals who are sympathetic but not always in agreement with Rawls and his project. I will conclude by noting that Sandel's critique has provided more food for liberal thought than have some liberal theories, and perhaps even more than some liberals would care to admit.

\section{COMMUNITARIANISM AND LIBERALISM:}

\section{A STUDY IN CONTRASTS?}

Deontological liberalism is a theory about justice and the fundamental place that justice occupies in contemporary Western moral and social ideals. The core thesis of this form of liberalism is stated as the idea that

...society, being composed of a plurality of persons, each with his own aims, interests, and conceptions of the good, is best arranged when it is governed by principles that do not themselves presuppose any particular conception of the good; what justifies these regulative principles above all is not that they maximize the social welfare or otherwise promote the 
good, but rather that they conform to the concept of right, a moral category given prior to the good and independent of it. ${ }^{5}$

JAF and political liberalism seek to define, discover, or create moral standards that can subsume a culture. However, such a project makes little sense if, as understood by communitarians, moral values do not precede a culture but are instead seen as being constituted by that culture. For the communitarians, practice precedes theory; liberal theory then not only asks the wrong questions, it gets the wrong answers. The job of political theory is not one of discovering principles through the use of an "ideal situation" (Rawls's OP) that may lead to some sort of fair or just association; it becomes rather the effort to describe our associations critically, and in so doing take the developments of social and political history seriously.

Liberals, on the other hand, have traditionally valued diversity, pluralism, tolerance, and freedoms and rights of various kinds; these have been prized as vehicles or means towards the pursuit of a self-developing and self-constructing political and metaphysical being. ${ }^{6}$ In so doing, liberalism defines rights as the vehicles or means for attaining that good prior to any conception. The "right thing to do" must, for Rawls, be given lexical and moral priority over any concept or conception of a substantive idea or ideal of the good.

\section{The Communitarian Challenge}

Opposed to this liberal political idea is the communitarian concern of trying to describe a culture that cannot adequately define or promote a conception of the person (however conceived), the society, and the relation of the two. Morality is in effect not something in the abstract, something known from without or prior to political society or political association. Morality, and especially any meaningful concept of political morality, must be created in the historical tradition of a culture and derived from analysis of the practice of that particular culture. Laws and social rules of conduct - the things we 
agree to do or even agree upon - are thus not derived from abstract principles of reason and imposed upon the culture in the manner that liberals, following Locke, Kant and Mill, wish to advocate. Laws and morés are instead an integral part of - they are constitutive of - living and associating within a particular culture, a particular tradition that over the course of history comes to define a people and a way of life. In a sense, Rawls epitomizes the communitarian criticism that our theory allows if not encourages disagreements in morality, ethics, and politics. To the communitarian, "the foundation of morals lie not in philosophy but in politics."7

A clarification is in order here. Communitarians do not deny that any ordered society - for Rawls, this would be a "well ordered society" - cannot have laws and rules as an heuristic or defining element. To be sure, the rules and laws of a society are some of the things that one can use to describe and identify essential aspects of any society. What is objected to is the idea of discovering or formulating principles and rules of association if those laws are seen as rules derived from the "pure application of reason."

\section{A Response: Clarifying the Project of Liberalism}

Political liberalism responds to this objection by incorporating some of these criticisms, primarily formulated in the social embeddedness thesis, into its theory. As a descendent of deontological liberalism, political liberalism then has several distinguishing characteristics. In a straightforward moral sense, deontological liberalism focuses on the idea that justice is $a$ if not the primary value in modern society: "[t]he demands of justice outweigh other moral and political interests, however pressing these others may be. Justice on this view is not merely one value among others,...but the highest of all social virtues, the one that must be met before others can make their claims."8 Secondly, the principles of justice - the ways in which we conceive of our rules of association amongst individuals and in our institutions - are to be justified in 
such a way that those principles do not rely upon any particular vision of the good; justice in a liberal society above all must be neutral and independent in such a way that it cannot promote or inhibit any particular vision of the good.

So far, this is not terribly controversial. A crucial portion of the liberalcommunitarian debate has focused on whether or not such a conception of neutrality and independence of the principles of justice is not in itself a vision of the good. (This is a crucial question, but one that I can only address peripherally at best in Chapter V.) In this chapter, I will be concerned with how a definition of neutrality has been understood by Michael Sandel, and how political liberalism has responded to this interpretation and critique. One response has been to revise but not substantially alter the conception of neutrality in JAF. This has benefited both sides of the debate, as all are at least referring to the same kind, form, or definition of neutrality. Another response has been to promote and advance the aspects of neutrality and toleration in liberal theory, which has more closely linked those arguments concerned with state control and coercion with those arguments that are centered more on the construction and placement of the person in society.

But there is an additional characteristic of the role of justice in a liberal society, and this is the place where controversy between the liberal and communitarian positions often begins. Justice presumes that one of our important values in society - freedom, or autonomy - will be supported by relying upon neutrality and toleration as a justification for the primacy of such a particular conception of justice. "Only when I am governed by principles that do not presuppose any particular ends am I free to pursue my own ends consistent with a similar freedom for all."9 So on this deontological formulation, justice is closely linked to our conceptions of people (selves) in political society, our conception of what is fair with respect to treating other peoples (our associations, institutionally and personally, with other selves), and our intuitive notions of what is fair. 
Now, we should note that this way of putting the question - the right prior to the good - leads to a common criticism of liberalism: that "[as] the right is prior to the good, so the subject is prior to its ends." 10 Because we view individuals as beings that must be accorded equal status with respect to each other, and because we value those aspects of human life that are associated with the political, we must then - in a very real ontological and metaphysical sense - value a conception of persons and individuals above our conception of how we must treat those individuals. On this way of putting the argument, JAF and political liberalism have already lost: we cannot say that we value the (procedural) right over the (substantive) good, because if we value persons prior to associations of them, then we are placing a conception of the good - the priority of the person - over and above our ideas of how those persons should associate - the right.

Obviously, this way of characterizing the liberal-communitarian debate does not get us very far. Rather than posing better questions about how we conceive of justice and the implications and consequences that such a conception has for persons and society, we have already answered them. With this in mind, I would now like to explore Sandel's claims against Rawls in greater depth and detail, and see what is so objectionable about JAF's conception of persons.

\section{ONTOLOGY AND PERSONS IN JAF}

\section{Sandel's Two-Pronged Critique}

Turning to Sandel's critique, we find two attacks against Rawls's construction of the person, and how that person is conceived within political society. The first unpacks and exposes Rawls's construction of the choosing subject in the OP, and why such a construction fails. The second examines the place of the self in society, and how Rawls, despite claims to the contrary, relies implicitly upon a "transcendental" conception of the self, and not one composed of "self-distanced yet chosen" attributes. I will begin with 
Sandel's understanding of Rawls's conception of the choosing subject, and particularly how that subject is "constructed" in the OP.

The Self and Its Ends. Sandel notes that Rawls's approach to the person as a subject of possession - a person with "veiled attributes" - assumes some features about the concept of the person:

For justice to be the first virtue, certain things must be true of us. We must be creatures of a certain kind, related to human circumstance in a certain way. We must stand at a certain distance from our circumstance, whether as transcendental subject in the case of Kant, or as essentially unencumbered subject of possession in the case of Rawls. Either way, we must regard ourselves as independent: independent from the interests and attachments we may have at any moment, never identified by our aims but always capable of standing back to survey and assess possibly to revise them. ${ }^{11}$

Of course, for justice to be so important to us, there must be conflicting claims over what is right and good in society, as well as conflicting claims to distributive justice: who gets what, when, and how. The distributive aspect aside, JAF recognizes that conflicting claims are one of the most important considerations of justice: plurality, or the social fact of numerous and disparate notions of what is right and good must be accounted for in our political relations. That is, we must allow if not promote statesanctioned pluralism. Reflective equilibrium plays an important role here: it judges between those "reasonable and plausible" convictions about justice on the one hand, and those of our "more considered" or philosophically examined notions on the other. 12

This is what Sandel calls deontology's liberating project: the ability to liberate the self from his or her assets and attributes through the construction of a metaphysical way of conceiving the individual, i.e. those things we commonly think of as "who we are and what we do." Rawls proposes this detached version of the self in order to identify certain principles of association that would be "fair" (i.e., without regard to social status, race, color or creed, etc.) to show that these principles are in accord with the ideals of justice. Rawls assumes that if all players - representatives in the $\mathrm{OP}$ - begin from a position 
where ignorance would preclude some kinds of knowledge of one's self that would most certainly skew the outcome of a particular procedure - social status, wealth, intelligence, etc.; the results of the "natural lottery" - then the outcome is "fair" in that all persons start from the same position.

But by distinguishing the self from its ends in the OP, and by insisting upon the right over the good, Sandel notes that this implies that the self is prior to its ends. Indeed, this claim is acknowledged by Rawls in Theory:

We should not attempt to give form to our life by first looking to the good independently defined. It is not our aims that primarily reveal our nature but rather the principles that we would acknowledge to govern the background conditions under which these aims are to formed and the manner in which they are to be pursued. For the self is prior to the ends which are affirmed by it; even a dominant end must be chosen from among numerous possibilities.... We should therefore reverse the relation between the right and the good proposed by teleological doctrines and view the right as prior. ${ }^{13}$

Rawls insists, along with most liberals, that relations between people should not be based upon the vagaries and uncontrollable developments that characterize history and politics: we should not allow institutions to treat people and classes thereof only as means to an end. We must instead construct a way to view institutions - or even reconstruct those institutions - in a way that will accord with a theory of justice, a theory that accounts for our considered notions of fairness and equality. This assumes that there must be selves of a sort that are prior to the ends that may be chosen.

The priority of the self over its ends means that I am not merely a passive receptacle of the accumulated aims, attributes, and purposes thrown up by experience, not simply a product of the vagaries of circumstance, but always, irreducibly, an active, willing agent, distinguishable from my surroundings, and capable of choice. To identify any set of characteristics as my aims, ambitions, desires, and so on, is always to imply some subject 'me' standing behind them, and the shape of this 'me' must be prior to any ends or attributes I bear. ${ }^{14}$

Radically Disembodied or Radically Situated? The "self-prior-to-its-ends" can then be understood in at least two different ways. The first is a moral or a "must" self which 
"reflects the imperative to respect above all the autonomy of the individual, to regard the human person as the bearer of a dignity beyond the roles that he inhabits and the ends he may pursue." 15 This is obviously the more commonly understood Kantian self, a person to be respected as an end in himself, and never only as a means.

But the second Rawlsian notion is one "in which the self 'must' be prior to the ends it affirms - prior in the sense of independently identifiable - and this is an epistemological requirement." 16 Such a self is thus more than simply a "concatenation of various contingent desires, wants, and needs" because then the self would be different with any change in the attributes; the "attributively defined self" is then not an option that Rawls endorses. "The possessive aspect of the self means that I can never be fully constituted by my attributes, that there must always be some attributes I have rather than am."17

But neither can we have a coherent conception of the self that is "radically disembodied," i.e., defined as completely separate from its attributes. Behind the veil of ignorance, the self could not logically or coherently be in any place, so to speak, that would make sense. Such a radically disembodied self would have no experience; it would have nothing to strive for - no motivation - and would not have any way of distinguishing and deliberating about what can and cannot be chosen as a principle of justice. There would be no person as such because this conception does not allow for "a person" to exist on Sandel's interpretation, only the possibility of the attributes of such a person. Without some background information to situate the self, the task of formulating, accounting for, or discovering principles of justice would appear to be meaningless.

So Rawls has a choice of direction between two divergent constructs of the person in which to move his theory: the person as a moral subject who can stand back or "remove himself" from his attributes and thus be able to choose principles of association and justice from a standpoint of relative ignorance; or a conception of the person so 
radically disembodied from their attributes that choices made by such an individual would appear without basis, that is, "completely" arbitrary.

\section{The OP and the Derivation of the Self: Objections}

Following this distinction, Sandel claims that both definitions fail. The first fails because it emphasizes too greatly the role of the OP in the construction and placement of the person. Sandel questions whether or not this conception "achieves genuine detachment from existing wants and desires" because it emphasizes "the account of primary goods or some other aspect of the thin theory of the good and argues that it is biased in favor of particular conceptions of the good and against others." 18 Clearly, this is a central claim against Rawlsian liberalism, one that Sandel (unfortunately) does not pursue beyond this: that through the careful set-up of the OP, Rawls is not able to define the right over the good after all. Instead of enabling the procedural aspects of the right to take precedence over normative aspects of the good, the OP becomes a good in and of itself thereby stripping it of any unusual or unique philosophical or metaphysical strength that could be derived from a claim of neutrality, arguably the aim of the OP all along. ${ }^{19}$ (As will show in Chapter V, this argument fails because Rawls, and Larmore with him, essentially subvert this claim by noting that political liberalism, as an outgrowth of JAF, is not a moral conception of the good per se, but rather a morally neutral manner in which to justify a procedural and a substantive conception of the right and the good. Additionally, this confuses or mistakenly attributes to JAF and political liberalism a definition of neutrality that is inapposite; this too will be addressed in Chapter V.)

But we should note carefully the consequences of some changes that have been made in Rawls's position since Sandel's publication with regard to "social context." The OP does not now describe an "ideal" situation, devoid of any social context or any sociohistorical attributes from which a person can derive some "place." Rather, Rawls notes 
that our political practice is, in a very real sense, "grounded"; we have limited options available to us as those options have come to us through the circumstances of history, and have tended to shape our social, political, and individual preferences. ${ }^{20}$ The OP is then an heuristic, not a constructive or definitive device. "So what is (and always has been) at issue for Rawls is 'background justice' in already existing societies."21

The original position, then, is a device which serves to draw out the principles of justice appropriate for a polity which (implicitly) holds to these models of the person and of the well-ordered society. It does this because it is constructed and peopled in way which reflects the values implicit in the two model conceptions of the person and the well-ordered society.....

[So the] question has a context. And that context is society; or at least society as it has been modeled in the OP. ${ }^{22}$

The second objection is that the notion of the OP is certainly too abstract, not as a purely metaphysical matter, although that too is true. More importantly, it is too abstract because if the $\mathrm{OP}$ is to allow persons to derive principles of justice from an analysis of future contingencies, it cannot do this because of its own procedural restraints and epistemological consequences.

Such an objection would most likely take issue with the veil of ignorance on the grounds that it excludes morally relevant information, information necessary to generate any meaningful results. It would argue that the notion of the person embedded in the original position is too formal and abstract, too detached from contingency to account for the requisite motivations. ${ }^{23}$

So, "[w]here the first objection complains that [Rawls's] thin theory of the good is too thick to be fair, the second contends that the veil of ignorance is too opaque to yield a determinate solution." 24

Dispossession and (In)difference. Mutual disinterest between the person and his or her ends and between persons is then a key factor. There must be some "metaphysical space" between subject and object. This idea "is not an assumption about what motivates people, but an assumption about the nature of subjects who possess motivations in 
general.... It concerns the subject of interests and ends, not the contents of those interests and ends, whatever they may happen to be."

In Rawls's view, any account of self and [its] ends must tell us not one thing but two things: how the self is distinguished from its ends, and also how the self is connected to its ends. Without the first we are left with a radically situated subject; without the second, a radically disembodied subject. ${ }^{25}$

Thus, the moral person is "a subject with ends he has chosen, and his fundamental preference is for conditions that enable him to frame a mode of life that expresses his nature as a free and equal rational being as fully as circumstances permit." 26 These two ways of viewing the self as apart or distinct from its ends creates an essential but unresolved tension that Sandel calls a form of "dispossession" or "disempowerment." Again, the first holds the self and its ends at some distance from each other, while the second seeks to collapse or minimize this distance. But the aspect of mutual disinterest, once properly understood, ${ }^{27}$ alleviates the tension here.

All interests, values, and conceptions of the good are open to the Rawlsian self, so long as they can be cast as the interests of a subject individuated in advance and given prior to its ends, so long, that is, as they describe the objects I seek rather than the subject I am..$^{28}$

Choices and Ends...? But this dilemma is avoided only to face another: given that interests, values, and conceptions of the good can only be "cast as the interests of a subject in advance," the Rawlsian self is first incapable of choice due to the lack of choice allowed in the OP, and second is no longer "independently identifiable and prior to its ends," because it relies instead upon an intersubjective conception. ${ }^{29}$

The distinction here between the construction of intersubjective and intrasubjective conceptions of the self is important. An intersubjective self allows for the conception of more than simply one "self" when referring to some kinds of moral situations, i.e., family, communal or national obligations of a moral nature. Intrasubjective conceptions are a conceptual tool that allow the existence of multiple aspects of a self or even "selves 
within a self" in some moral situations, primarily to promote and carry out moral discourse. An example of the former would be a person who has received contrary advice from two friends about some action that a person (the subject) is supposed to take; an example of the latter might be the metaphorical "angel and devil" sitting atop a subject's right and left shoulders, dispensing advice appropriate to their respective positions.

Sandel notes that

[w]hile Rawls does not reject such notions explicitly, he denies them by implication when he assumes that to every individual person there corresponds a single system of desires..., [that] the problem of conflating desires does not arise in the individual case, and the principle of rational prudence can properly govern one's conduct towards oneself. ${ }^{30}$

So individuals in the OP are incapable of choice for several reasons. First, the individual is conceived as distant from interests and conceptions of the good.

The motives attributed to the parties in the original position neither reflect the actual motivations current in society nor determine directly the motives of persons in a well-ordered society....

One consequence of this distance is to put the self beyond the reach of experience, to make it invulnerable, to fix its identity once and for all.... ${ }^{31}$

This removal of the self from its ends has consequences for any conception of a link between the good (or available goods) and a public life:

[1] A self so thoroughly independent as this rules out any conceptions of the good (or of the bad) bound up with possession in the constitutive sense.

[2] It rules out the possibility of any attachment (or obsession) able to reach beyond our values and sentiments to engage our identity itself.

[3] It rules out the possibility of a public life in which, for good or ill, the identity as well as the interests of the participants could be at stake.

[4] And it rules out the possibility that common purposes and ends could inspire more or less expansive self-understandings and so define a community in the constitutive sense, a community describing the subject and not just the objects of shared aspirations. ${ }^{32}$

I have already noted that on a revised understanding of the role of the OP in JAF, we must assume that society is a "given," that people do come from a particular society with particular rules and understandings of politics and people; i.e., there is a certain way that "things are done" in a society that makes sense - may only make sense - to the 
inhabitants of that society. Now, this does not dispel the four negative characteristics about liberalism and modern life that Sandel is wont to raise. But it does provide a basis from which to question his position, and analyze what Sandel is really saying. This I must postpone for a while until section 3, "The Social Embeddedness Thesis."

... Or Ends Without Choice? A second objection to Rawls's choosing subject is developed when Sandel notes that Rawls sets up the OP so that the individuals have little choice but to decide upon the principles of justice as formulated, i.e., that the subject is no longer identifiable and prior to its ends.

The aim is to characterize this situation so that the principles that would be chosen, whatever they turn out to be, are acceptable from a moral point of view. The original position is defined in such a way that it is a status quo in which any agreements reached are fair. ${ }^{33}$

The idea of the original position is to set up a fair procedure so that any principles agreed to will be just. The aim is to use the notion of pure procedural justice as a basis of theory. ${ }^{34}$

We could take the generous view, as Sandel initially suggests, and read these passages rather "liberally" and accept that such a procedure would indeed be fair. But "there is another, less expansive reading of [the situation of the participants in the OP] which gives considerably less scope to their enterprise."

On this view, "any agreements reached" in the original position are fair, not because the procedure sanctifies just any outcome, but because the situation guarantees a particular outcome. But if the principles agreed to are just because only (the) just principles can be agreed to, the voluntarist aspect of the enterprise is not as spacious as would first appear. The distinction between pure and procedural justice fades, and it becomes unclear whether the procedure "translates its fairness to the outcome" or whether the fairness leads to the right result. 35

Thus, not only is the self proposed by Rawls incapable of choice because it cannot deliberate and reflect upon the bases of choice, but the options available to the individual are constrained in such a way as to move the choosing self towards only one option. The self is not allowed to choose so much as the choices are determined for it. ${ }^{36}$ 


\section{The Claims Regarding Persons. Justice, and the Community}

Sandel's argument can be summarized by noting the several points of correspondence found between Rawls's moral theory and his theory of the person.

Where the morality of right corresponds to the bounds of the self and speaks to that which distinguishes us, the morality of good corresponds to the unity of persons and speaks to that which connects us. On a deontological ethic, where the right is prior to the good, this means that what separates us is in some important sense prior to what connects us epistemologically prior as well as morally prior. We are distinct individuals first, and then we form relationships and engage in cooperative arrangements with others; hence the priority of plurality over unity. We are barren subjects of possession first, and then we choose the ends we would possess; hence the priority of the self over its ends. ${ }^{37}$

We must keep in mind that Sandel wishes to argue against this position, that he wishes to argue for an intersubjective conception of the self, a definition that can sustain close scrutiny on the distinction between the object and the subject of possession. Again, this is an area of Sandel's argument that I cannot pursue. But we should note that to this end, Sandel argues against Rawls's and Dworkin's arguments advanced in favor of e.g. affirmative action on the grounds that either the conception of rights upon which affirmative action arguments are based ignores the community allegiances that we develop in our lifetimes; Rawls and Dworkin provide no good reasons to rely upon "more general social concerns" as opposed to relying upon specific community concerns when evaluating claims as to where individual attributes lie; and that by relying upon a false idea of community - placing some attributes in "society as a whole" instead of within the individual - they either contradict the Kantian injunction against using others only as a means to an end, or they evade the contradiction by failing to distinguish the ends and the self sufficiently. 38

Three Conceptions of Community These distinctions of the relation of self to community, and deontological liberalism's failure to adequately provide and maintain and adequate distinction, are shown more clearly in Sandel's three definitions of 
community. The first is called an "instrumental view"; it is one that Sandel and Rawls both correctly dismiss. It is a notion of a "private community," one "where individuals regard social arrangements as a necessary burden and cooperate only for the sake of pursuing their private ends." The second, a "sentimental view," regards the scheme of social cooperation as a good in itself, one in which participants have shared final ends; this is the strong sense of community that Sandel claims Rawls relies upon. In the instrumental view, community "is wholly external to the aims and interests of the individuals who comprise it," whereas in the sentimental view community is completely internal to the subjects "in that it reaches the feelings and sentiments of those engaged in a cooperative scheme." 39

But these can be distinguished from a third sense of community, one that is constitutive of the conceptions of identity "as defined to some extent by the community of which they are a part. For them, community describes not just what they have as fellow citizens but also what they are, not a relationship they choose...but an attachment they discover, not merely an attribute but a constituent of their identity." 40

Conceptions of the Relation of the Right and the Good. This corresponds roughly to Sandel's characterization of Rawls's use of the relation of the right to the good. We should recall that Rawls promotes the right over and above the good. Again, this relation like the others reviewed by Sandel, can be viewed in three different ways: the right as an antecedent prohibition upon conceptions of the good ("the principles of justice... are not [then] subject to our agency; they apply whether we like them or not..."); the good as an arbitrary or indeterminate decision from the result of contigencies, while the right is again determined previously; and the view that the priority of the right as "the need for some ultimately 'unchosen' background as a precondition of choice in conceptions of the good. This is the epistemological priority that deontological ethics carries over in a moral priority."41 
In each of these instances of correspondence in Rawls's moral and political theory, Sandel implies that there is a discrepancy between the assumptions about and use of the person in Rawls's moral theory that subsume his political theory, and what that person can coherently and epistemologically "look like" under that conception. To Sandel, there is at best a confusion and at worst a fatal flaw in Rawls's theory regarding how the person "fits" into the construction of the liberal society where "justice is the first virtue of social institutions." But before evaluating Sandel's claim as a whole, we must first examine more closely what Sandel means when he says that people must be viewed as radically situated and intersubjective selves.

\section{THE SOCIAL EMBEDDEDNESS THESIS}

I have noted that Sandel, along with other communitarians, relies on a set of descriptive and normative claims that have been variously labeled as the social embeddedness thesis, the social thesis, the cultural options thesis, the idea of shared relations, etc. Some theorists tend to rely upon a particular view of this set of claims and how they are to be understood in modern political theory. So, for example, Simon Caney taxonomically places Sandel and MacIntyre in the "social embeddedness thesis" camp, Charles Taylor in the "social thesis" camp, and Michael Walzer in the "cultural options thesis camp." 42 (The distinctions between these different claims are not important here, as I will be addressing only Sandel's and MacIntyre's arguments against Rawls's form of deontological liberalism.) For simplicity's sake, I shall discuss only the embeddedness thesis, or that narrower claim that "a persons' character is shaped by their social [and therefore moral] context." 43

The social embeddedness thesis is the idea that people are constituted by their social context, i.e., that people 
...conceive their identity - the subject and not just the object of their feelings and aspirations - as defined to some extent by the community of which they are a part. For them, community describes not just what they have as fellow citizens but also what they are, not a relationship they choose (as in voluntary association) but an attachment they discover, not merely an attribute but a constituent of their identity. ${ }^{44}$

It then has as much to do with the self-conception of the person as it does with the selfsociety relation. How then ought political theory to conceive of these relations, and how do Sandel and Rawls do so? In what ways are they different, how do they claim distinction from each other, and can these differences be sustained? But before we can discuss the way and Sandel and Rawls discuss this, we must note two important distinctions.

\section{Metaphysical or Political Beings?}

We can distinguish first between two conceptions of the self made under this embeddedness thesis: these are, for lack of better terms, a "metaphysical" claim and a "political" one. ${ }^{45}$ The metaphysical claim we must reject; it assumes that liberalism is a metaphysical theory, or makes claims that must either be subsumed or justified by some greater metaphysical assumptions about the self and its relation to society.

Liberalism cannot be construed in this way. Certainly, liberalism has under some philosophers assumed a fundamental conception of the kind of person that is necessary for the theory to make certain claims. While I cannot pursue this claim, we should be careful to note that liberalism as a political theory has historically tried to distance itself from such claims. So when most liberal theorists write about liberalism, they "do not mean a vague Zeitgeist or the outlook of modern man but a clearly identifiable cluster of political principles and positions defended by, among others, Milton, Spinoza, Locke, Montesquieu, Hume, Voltaire, Smith, Kant, Madison, and J. S. Mill....'Liberalism' is as good a term as any for this shared body of political purpose and moral principles."46 
This does not mean that liberals have not made metaphysical claims; indeed, some have done so as part of a moral or an epistemological theory, or within a different kind of argument altogether, and this perhaps erroneously. (Locke's theory of government, bolstered by his theory of human understanding, can be plausibly and most coherently viewed this way. Kant's moral theory too is an example of this kind of conflation.)

What I want to say is that we must distinguish claims that have been made and vindicated by liberal thinkers as matters of moral and political theory from claims that are more concerned with social and "constitutive" relations. We can see that Sandel has the latter concern in mind when he writes that a person's identity consists in "those qualities most plausibly regarded as essential to a person's identity - one's character, values, core convictions, and deepest loyalties." 47

\section{Wholly or Partially Determined Social Beings?}

Secondly, the embeddedness thesis is ambiguously understood under two different guises. One conception is that individuals are partly shaped by their community or social context, in which case they have the conceptual ability to distance themselves from the dominant conception of what a person should be; this is the "partially embedded" thesis. The other or "wholly embedded" thesis is that people are wholly determined by their community or social context, in which case they cannot have the conceptual ability to distance themselves from the dominant conception of what a person should be.

A similar point has been expressed by Patrick Neal and David Paris. ${ }^{48}$ They note that the concept of "shared relations" has different meanings for liberals and communitarians. But a misunderstanding of the conception of shared relations that is found in liberalism leads communitarians to attribute to liberalism a metaphysical sense of the good and the self, a conception which misses the point of a liberal conception of a political self. ${ }^{49}$ 
Liberalism can generally be understood as having a contingently-based conception of shared relations, which means each person is a "self" that "exists" beyond the reach of society's influence. This should not be construed to mean that the content (normative or other) of a self - a person's "beliefs and preferences" - is not unaffected by society; this would be patently false and would "ignore the most mundane facts of socialization." 50 Any ideas about liberalism that rely upon such a conception rely upon a false understanding of the dominant liberal conception of the self.

Communitarianism, on the other hand, generally relies upon an essentially based conception of shared relations in society. This means that "the identity of each self is partially or wholly constituted by the relation." 51 Now, we could dismiss this claim as a mere sociological aphorism that "a person's character is shaped (but not determined) by cultural context." 52 However true, that statement is relatively uninteresting; but we should note an important shared feature: neither conception bears any direct or obvious relation to any particular set of normative political commitments. ${ }^{53}$

Now, these conceptions of the self - contingent and essential - are rather abstract. And due to this one important similarity, we know two things about the conception of the self in liberal and communitarian constructions. First, these descriptions have to do not with the normative content of the concept of person, but instead with how the self-society relation is conceived logically and coherently. Secondly, that these different ways in which the self-society relation is conceived have different consequences for that normative content; that is, while the normative content of the person is in some ways limited to the description of the concept of person being used, still there is no one single or definitive kind of person that must be used according to that description. "Conceptions of essentially and contingently shared relations are conceptions of how relations are shared, and correspondingly of how the self is defined and understood." 54 


\section{Oscillation Between Conceptions}

Sandel seems to want to affirm both the partially- and wholly-embedded theses. This is particularly apparent in his discussions of the radically disembodied as opposed to the radically situated subject. On the wholly embedded construction, Sandel writes that a subject (the person) acquires ideals of association (self-command) "not by choosing what is already given but by reflecting on itself and inquiring into its constituent nature, discerning its laws and imperatives, and acknowledging its purposes as its own....It succeeds by restoring the shrunken space between self and ends." So the relevant question for a subject (person) to ask is "not what to choose,... but rather who I am, how I am to discern in this clutter of possible ends what is me from what is mine. Here, the bounds of the self are not fixtures but possibilities, their contours no longer self-evident but at least partly unformed. Rendering them clear and defining the bounds of my identity are one and the same." 55

But at times Sandel supports the partially-embedded construction of this thesis. This is apparent in his idea of a constitutive community.

For a subject to play a role in shaping the contours of its identity require a certain faculty of reflection.... What is required is a certain capacity for self-knowledge, a capacity for what we have called agency in the cognitive sense....56

Additionally, people have the capacity for self-reflection:

Unlike the capacity for choice, which enables the self to reach beyond itself, the capacity for [self] reflection enables the self to turn its lights inward upon itself, to inquire into its constituent nature, to survey its various attachments and acknowledge their respective claims... and so gradually, throughout a lifetime, [allows the self] to participate in the constitution of its identity. 57

As Caney notes, this ambiguity between different versions or constructions of the social embeddedness thesis is significant:

[W] hile it is plausible to say that a person's character and core commitments are partly shaped by their community, it is implausible to suggest that they are wholly determined by their community and that we 
cannot attain any critical distance. Sandel's own test of what is the best conception of the self - an appeal to that which accords best with our selfunderstanding - surely supports the partial thesis and not the wholly embedded thesis. We do think of ourselves as being able to distance ourselves from parts or our community. 58

Having clarified the social embeddedness thesis and Sandel's use of it, we can see that this concept has only limited application. But we can see further that on a reading of this thesis that Sandel implicitly supports, there is some agreement on the way in which the self-society relation must be viewed in political theory. Granted, we are left with a somewhat dissatisfying conclusion at this point: that "it is a sociological fact [if not a truism] that a person's character is shaped (but not determined) by cultural context."59 But in examining some of the liberal responses to Sandel's critique in the next section, I will show that this ambiguity in Sandel's conception of the social embeddedness thesis weakens, but does not render powerless - does not dismiss - his critique.

\section{LIBERAL RESPONSES}

Many contributors to the debate have commented on the nature and focus of Sandel's extended critique. The differences of opinion and assessment here are almost as numerous as the interpretations of Rawls's work itself: some agree with Sandel, others fault Sandel for certain of his errors but not others, some disagree with his critique but nevertheless recognize its value and importance, while others still disagree with him almost completely.

The objections to Sandel's critique that I will address fall roughly into four categories. The first addresses the objection that some liberal defenders have raised: that Sandel is unfair because he either misinterprets Rawls's theory, or else he fails to account for developments that have taken place in Rawls's thought post-Theory. A second objection follows from the above interpretation of the understanding and use of the social embeddedness thesis, both as used in Sandel's own theory and his critique. A third 
objection, really an observation of a point of similarity between Rawls and Sandel, notes that on this reading of the social embeddedness thesis, Rawls and Sandel can actually be seen as not so far apart in their respective epistemological stances. Finally, on an understanding of the person, we can see more clearly how Rawls and Sandel are truly different by examining the different interpretations and uses of the political conception of the person.

\section{Objection One: "Interesting Misreadings"}

An early criticism is that Sandel does not take into account crucial developments, revisions, or additions in Rawls's theory. ${ }^{60}$ This is a common accusation, and rests on a view of the discrepancy (chronological as much as anything else) between Sandel's account of the person in JAF and Rawls's developments following Theory, particularly in the Dewey Lectures and Tanner Lectures. Thus Wallach's statement: "Because so much of Sandel's critique depends on Rawls's theory relying on a metaphysical conception of 'the moral subject,' Rawls's remarks in "Justice as Fairness: Political Not Metaphysical," along with those in "Kantian Constructivism in Moral Theory," published two years before Sandel's book, tend to place Sandel's book qua Rawlsian critique in the category of interesting misreadings of $A$ Theory of Justice." 61

I believe that this response misses the point of both Rawls's project and Sandel's critique. Sandel does not say that Rawls has committed himself to a conception of the person and then devised a theory of justice from such a construction however perceived. Rather, Sandel claims that Rawls's project of providing a basis for institutional justice implicitly commits him to a conception of the person or kinds of people we must be in order to live in a liberal society where "justice is the first virtue of social institutions." 62 Again, "[f] or justice to be the first virtue, certain things must be true of use. We must be creatures of a certain kind, related to human circumstance in a certain way...."63 
Thus, "Rawls's liberalism presupposes a philosophical conception of persons as essentially autonomous choosers of all of their private ends and values, none of which define their identities, their sense of "who they are." 64 That is, Sandel's critique, aimed at both the Kantian theoretical and the practical justifications for social justice, demonstrates that in some very significant and conceptually fundamental ways Rawlsian liberalism contains a conception of the person that either leads us to misunderstand ourselves in practice, or does not allow us to coherently reflect upon the content and justification for moral and practical insight.

Additionally, as I noted above in passing, this criticism rests upon a view of the chronological discrepancy between Sandel's critique and Rawls's revision in light of that critique. It would be difficult to sustain an objection that does not take into consideration the development of a theory over time, and in timely response to legitimate critique. So while "the starting point of this philosophical inquiry is not the OP but the prevailing moral beliefs and intuitions of modern liberal democratic societies,"65 we can understand this objection as a successful defense by Rawls against claims of "rootlessness" or the formulation of principles justice through the application of pure reason.

There is, however, a closely related objection that I think is valid: that Sandel essentially ignored a part of Rawls's theory that was gaining prominence in the Dewey Lectures (1980) but was not emphasized until the Tanner Lectures (1982) and after. That part was Rawls's de-emphasis of Kantian expressivism in describing the role of persons, and emphasizing the modus vivendi view, which makes more sense of the attachment of social and primary goods to persons that Rawls wishes to make. It additionally paves the way for political liberalism. This objection I will continue to address in the next section, "Objection Two: Context and Constitution," and in Chapter V. ${ }^{66}$ 


\section{Objection Two: Context and Constitution}

Many if not most liberals object to Sandel's assertion that the community is constitutive of the self. Indeed, many liberal defenders have taken Sandel to task here for his lack of justification, i.e., the few places where he definitively proposes an alternative to the liberal construction of the individual as a choosing self. The second objection then goes something like this: (1) identifying my community can be distinguished from identifying my place within it; (2) Sandel has not provided us with any argument substantiating or justifying the claim of the individual as constituted by the community; (3) a persuasive answer to either of these would not lead to a justifiable claim that "my context defines who I am." 67

[I]t looks like an exaggeration to say that my social context constitutes my identity, however constitution is understood....Quite clearly I can identify with my community; furthermore, I can be identified by my place within it. But this does not mean that my context defines who I am. ${ }^{68}$

This argument against the placement of "shared conceptions" in our social and political understanding prior to the reasonably articulated principles and notions of right or good is a central issue in the debate. Where do we "place" our considered reflections of the self-political society relationship when we consider the basic questions of political association? Clearly it is correct to see Sandel placing society and its practices prior to the articulation and acceptance of principles.

The priority of the self over its ends means that I am not merely the passive receptacle of the accumulated aims, attributes, and purposes thrown up by experience, not simply a product of the vagaries of circumstance, but always, irreducibly, an active, willing agent, distinguishable from my surroundings, and capable of choice. ${ }^{69}$

Sandel goes on to distinguish two ways that the self-prior-to-its-ends can be conceived under Rawls's proposal: as a moral imperative in order to reflect and secure autonomy and respect, and as an epistemic need or requirement to distinguish the subject from its situation..$^{70}$ Without the epistemic distinction, which accords a difference in the 
constitution of the self between having and being (that is, "I have $x, y$, or $z$ " cf. "I am $x, y$, or $z$ "), it becomes impossible to distinguish what is me from what is mine, and we are left with what might be called a radically situated subject. ${ }^{71}$ Without the moral distinction, we would not be something that is desirable under the deontological conception: we would not be bearers of dignity beyond the roles that we inhabit and the ends we are allowed to pursue..$^{72}$

Now this recalls the social embeddedness thesis, and here (as before) we should note that a strong liberal response is to raise questions about the structure of social $v s$. political relations; that is, questions about the communitarian's use of the terms self, having, constitution, and the like. On this liberal objection, communitarians such as Sandel have difficulty clearly distinguishing what the object of critique is when debating the various constructions of the self: does the self "have its attributes," or is the self simply "its attributes"? Further, though, is such a question truly necessary to our understanding of political theory?

Liberalism, and political liberalism in particular, does not need a "deep" or "constitutive" moral conception of the self beyond some of these basic assumptions that Sandel and Rawls are agreed upon. So there are three good reasons to either (1) reject the claim that liberalism (and JAF in particular) ignores our social or communal embeddedness, or (2) note where Rawls has responded to this claim adequately by revising his theory into political liberalism. The first reason we encountered above: that on any account of justice, we can argue that Rawls is very aware of the derivation of justice from within a social or tradition-oriented understanding; that is the point of Rawls's example of The Wars of Religion and England's Glorious Revolution in his later works. Additionally, we can note, as have Simon Caney and Stephen Holmes, that historically many liberals - Locke and Kant among them - have explicitly endorsed some form of the partially-embedded social thesis. ${ }^{73}$ 
This communitarian criticism is often portrayed as the liberal's desire to cling to the autonomous individual at the expense of communal attachments. But Rawls does not indeed never has - endorsed any conception of the individual that is so strong that it would place autonomy above political concerns. That is, Rawls has never worked from the conception of an existential individual, one who "creates himself from whole cloth."

Rawls could have moved in this direction after Theory; he could have developed a "theory of the person," one that concentrated on the psychological and anthropological aspects of the person. But he did not. Instead, he chose to develop a line of thought that dealt with the question - still unresolved - of the person-political society relation. In so doing, Rawls has emphasized the political aspect of his theory. The theory is now less "Kantian" in that it is not a moral theory of persons in politics; it is a theory of politics that accounts for the place of persons. Charles Larmore has put the idea like this: Rawls has moved away from the Kantian expressivism that seemed to dominate his theory towards a theory of politics that is more concerned with the relations of persons in politics, hence the emphasis on modus vivendi form of argument. ${ }^{74}$ Stated this strongly, we can clearly see that Sandel's objection cannot be that Rawls is promoting the individual via autonomy at the expense of the community or society. But once clarified, it is difficult to see precisely what Sandel's objection is.

Second, even though this aspect of his theory has been de-emphasized in Rawls's more recent theoretical developments, the whole point of the original position is to remove from consideration those social considerations that are so important to people that they would skew any fair and "neutral" conception of justice.

[T] he reason why information as to which community one belongs to is excluded is precisely because cultural attachments are so important to people. Were [they] to be included, people could then tailor the principles to favour their own views at the cost of others. Thus, information is excluded so that persons may live in accordance with their cultural commitments... That such knowledge is hidden behind the veil of 
ignorance reflects Rawls's appreciation of how strongly people are attached to their ends. ${ }^{75}$

Third, "[t]here is copious textual support for the thesis that Rawls adheres to the embeddedness thesis." 76 While I cannot re-rehearse this claim here, my exposition of Rawls in Chapter 1 clearly shows that Rawls does pay close attention to this claim and incorporates it into his theory.

But there is textual support for the claim that even before Sandel's critique had raised the issue that Rawls had explicitly endorsed a form of the partially-embedded social thesis. Indeed, Rawls does this in two related ways: as early as 1975 he denies that JAF relies upon some form of abstract individualism, and acknowledges that JAF relies in a fundamental way upon the existing institutions and practices that are essential to any understanding of the social embeddedness thesis.

[Abstract individualism] is defined as the doctrine that the fundamental aims and interests of individuals are determined independently from particular social forms; society and the state are regarded as institutional arrangements that answer to these antecedent individual ends and purposes, as specified by a fixed and invariant human psychology. In contrast to this view, the theory of a well-ordered society stresses that the interests and ends of individuals depend upon existing institutions and the principles of justice they satisfy. Moreover, the parties in the original position are presumed to know whatever general truths characterize the dependence of individuals on their social background. The account of primary goods does not deny these facts, long recognized by social theory and common sense. ${ }^{77}$

Indeed, "apart from our place and history in a society, even our potential abilities cannot be know, and our interest and character are still to be found."78

However, the change that has had the greatest significance and impact for Rawls's liberal theory of justice, a change that took place as early as 1980 , is also the clearest indication of Rawls's endorsement of the partially-embedded social thesis: grounding his theory in the practices of a modern, liberal, democratic, capitalist society. ${ }^{79}$ 


\section{Objection Three: Of Distinctions and Difference}

This is closely related to a third objection: that Rawls and Sandel may actually be, despite first appearances, in agreement in some fundamental ways. Rawls and Sandel both agree that persons actively participate in the act of their own constitution; epistemologically, Sandel's claim of a self constituted by its desired ends and Rawls's view of the self prior to his or her ends acknowledges that idea that both accept the person as prior to his or her ends. ${ }^{80}$ Thus, there is a fundamental philosophical consensus on the nature but not necessarily the placement of the self.

Rawls wishes to place the right prior to the good in social and personal constitution in order that, under the conditions of the veil of ignorance in the OP, they may not know - that is, are not allowed to know - crucial information that would certainly bias the procedure. The metaphysical and epistemological aspect in Rawls's OP is crucial to his conclusions about the desirability and feasibility of justice as fairness in society. Sandel's critique, on the other hand, claims that given this composition or constitution of the choosing/self-constituting self in the OP, the self cannot arrive at an analysis of the available methods for distribution of goods, let alone choosing the procedural and epistemological methods that would render Rawls's theory coherent.

Gutmann, for example, correctly states Sandel's central argument as an exposition of Rawlsian liberalism's "mistaken metaphysical and meta-ethical views," and that "because its foundations are necessarily flawed...we should give up the 'politics of right' for a 'politics of the good.' "81 However, Sandel takes a wrong turn in attributing to Rawls a meta-ethical claim "that the foundations of justice must be independent of all social and historical contingencies without being transcended." 82 Referring to claims by Rawls and others that liberalism does not presuppose a metaphysics, Gutmann states

The major aim of liberal justice is to find principles appropriate for a society in which people disagree fundamentally over many questions, in- 
cluding such metaphysical questions as the nature of personal identity.

Liberal justice therefore does not provide us with a comprehensive moral-

ity; it regulates our social institutions, not our entire lives. 83

Gutmann's characterization of communitarianism as placing political philosophy in a position of being forced to choose between conceptual opposites - a "tyranny of dualisms" - may be appropriate here: "Because the [communitarian] critics misinterpret the metaphysics of liberalism, they also miss the appeal of liberal politics for reconciling rather than repressing most competing conceptions of the good."84

Now, some will object that Sandel's point is just that: liberalism, and particularly Rawlsian liberalism does "regulate our entire lives" because it predetermines the choices available for sociability, i.e., what is acceptable political behavior, and what is an appropriate place to start theorizing about politics. But this criticism can be easily turned around: liberals have often complained against communitarianism (especially in other guises) that it identifies a community in opposition to others as much as it identifies what consists and coheres a particular community. Some liberals have even gone so far as to note that there is a fundamental intolerance that underlies communitarianism, an intolerance reminiscent of totalitarianism and fascism. ${ }^{85}$ Clearly these kinds of criticisms are disingenuous, and should be more closely examined before they are articulated and incorporated into any serious response to legitimate criticism.

\section{Objection Four: Against a Political Conception}

A fourth objection is that Sandel "never indicates why he thinks the self must be politically created." 86 Now certainly we have seen from the discussion of the social embeddedness thesis and some of the above clarifications that our context helps to form and establish our identity on any moral, political, or sociological understanding, although only to a limited extent. That is, we cannot rely upon a theory that presumes or assumes 
that people do have pre-formed or fully-formed preferences and motives in some sort of pre-social environment or ideal situation. 87

Sandel's objection focuses on the idea that we must consider the political background of persons when referring to any scheme of justice; i.e., any scheme that can adequately account for people as subjects of justice, so that people in a political community (or other jurisdictional entity) come to the actual bargaining table deeply informed of their political motivations. The liberal response is that such deeply-formed commitments and attachments - those truly radical and fundamental parts of the composition of subjects that distinguish individual selves - must be left behind, and for a very good reason. Those constitutive attachments are to be removed from consideration because they are so important to people. To accord persons a place at the bargaining table in the OP on the condition of the positions they hold (desert based upon contingent attributes) is not accord people with equal respect as persons, but only to accord equal respect to the positions that those people happen to hold. That is, for political and theoretical purposes there is a difference between persons and the ideas, beliefs and opinions that they (will and must) hold.

I will develop this idea further in Chapter V, but for now we should note that there is a distinct and important difference between respecting persons and respecting the ideas they hold. In our political and theoretical concerns, we can respect the zealot or the true believer as person: they are human beings capable of a capacity for reason, and capable of exercising that capacity. That they choose not to exercise that capacity as a matter of faith, i.e., beyond rational understanding, is of no consequence except that such a basis for decisions about politics cannot be shared by all. Because we cannot agree with their reasons for doing $x$ in a political situation, we need not respect the ideas that such persons hold, only their ability as a person to hold an idea. Again, the prima facie reason is selfevident: persons who advance zealously-held beliefs do not respect others of differing 
opinions. They do not respect other people as people, nor do they respect the ideas that other people hold. Such persons do not have any account of tolerance and justice in their system of belief. They cannot give good reasons - either justifiable reasons or reasons that rationally persuade us - and thus the motives for their intolerance and lack of mutual respect are insufficient to warrant a claim of intolerance.

While this may to some liberal defenders and detractors alike sound like intolerance (which it is: intolerance of the intolerant), ${ }^{88}$ or paternalism (which it is not), I will here suggest that while this may not be an inaccurate defense of liberal toleration (an important and essential aspect of liberalism), it is a defensible and reasonable, if not feasible and desirable justification.

\section{CONCLUSION}

In examining and evaluating a small part of Sandel's extended critique, we should not forget its object or purpose. Sandel's critique, as I have noted in the chapter title, is ontological. It is not, as Charles Taylor has recently pointed out, a theory of advocacy; its primary purpose is not the promotion of a particular way of seeing, but instead showing the many different ways in which such issues can be seen. "Taking an ontological position does not amount to advocating something; but at the same time, the ontological does help to define the options which it is meaningful to support by advocacy." 89 That is, Sandel's book is most important as a contribution towards understanding the relation between different models or conceptions of how we live and some of the various ways we view individuals and society. Given the choices available to us - as a particular body of peoples with a unique heritage about the relations of society-self and government-self; as members of a liberal, democratic, capitalist society; as people within the conditions of Humean relative scarcity and with the aspects of 
plurality - how do we know what is available? That is Sandel's question, the point of inquiry upon which his argument is based.

However, that is not to say that Sandel does not, during the course of his argument, advocate a particular view; he does. But it is not terribly difficult to distinguish his ontological arguments from others designed to persuade. Seen in this way, "the point of [Sandel's] argument, whether right or wrong, is to define the alternatives in an important choice."

Sandel's point pushes us toward the issue of whether the kind of egalitarian redistribution Rawls recommends can be sustained in a society which is not bound together in solidarity through a strong sense of community; and whether, in turn, a strong community of this kind can be forged around a common understanding which makes justice the principal virtue of social life, or whether some other good does not have to figure as well in the definition of community life. 90

If anything, Sandel's point has been to give the liberal theorist some not altogether tasteful food for thought. He has questioned the manner in which a particular view of individuals or selves has been conceived, and the relation of individual to society given several common conceptions of each. In turn, I have questioned one aspect of Sandel's critique that is central to those claims he wishes to advance beyond his ontological argument. I have shown some places where Sandel's argument is certainly vindicated. But we can note other places where the ontological argument, when evaluating the liberal and opposed claims, falls short of being able to adequately distinguish between conceptions.

I will next examine the theory of another prominent communitarian critic of liberalism, Alasdair MacIntyre. Rather than questioning liberalism "from the inside," MacIntyre criticizes liberalism from without. In comparing liberalism with other, more tradition-oriented understandings of the self-society relationship, we can learn a great 
deal not only about the workings of theory, but also about how it makes sense to view an historically-contingent self. 


\section{NOTES}

${ }^{1}$ Ludwig Wittgenstein, Culture and Value, trans. Peter Winch (Chicago: University of Chicago Press, 1980), $16 \mathrm{e}$.

2 Richard J. Arneson, "Introduction (to 'Symposium on Rawlsian Theory of Justice: Recent Developments")," Ethics 99 (1989): 695-710.

${ }^{3}$ This line of thought, and the reason for eschewing some of the traditional justifications of liberalism and liberal doctrines advanced in support of those justifications I will address further in Chapter IV, "Political Liberalism." The idea comes from Rawls's new focus in political liberalism, but especially Charles Larmore's articulation in Patterns of Moral Complexity (Cambridge: Cambridge University Press, 1987).

4 Simon Caney, "Liberalism and Communitarianism: A Misconceived Debate," Political Studies 60 (1991): 273, emphases original.

${ }^{5}$ Michael Sandel, Liberalism and the Limits of Justice (Cambridge: Cambridge University Press, 1982): 1 .

${ }^{6}$ The contention of whether or not Rawls actually has a metaphysical claim has itself been a source of much academic debate; this is, in effect, Sandel's whole argument. Part of the confusion in understanding Rawls's position has resulted from Rawls's reluctance to "correct misunderstandings" of his position; that is, confusion as to what Rawls "really means" has been exacerbated by (1) his style and approach to these theoretical problems, and (2) his reluctance to defend his position, instead considering each critique as worth consideration in some aspects. See, e.g., Thomas Pogge Realizing Rawls (Ithaca, NY: Cornell University Press, 1989): 4.

${ }^{7}$ Chandran Kukathas and Philip Pettit, Rawls: ATheory of Justice and its Critics (Stanford: Stanford University Press, 1990), 95.

8 Sandel, Liberalism, 2.

9 ibid., 6.

10 ibid., 7.

11 ibid., 175; as found in John Rawls, "Kantian Constructivism in Moral Theory: The Dewey Lectures 1980," The Joumal of Philosophy 77 (1980): 544-5; emphasis added.

12 ibid., 47.

13 Theory, 560; emphasis added.

14 Sandel, Liberalism, 19.

15 ibid., 20. 
16 id.; emphases added.

17 id.

18 ibid., 27.

19 ibid., 27.

20 John Rawls, "Fairness to Goodness," Philosophical Review 84 (1975): 536-54.

21 Kukathas and Pettit, Rawls, 123.

22 ibid., 128.

23 Sandel, Liberalism, 28.

24 id.

25 ibid., 54.

26 Theory, 561.

27 Theory, 584.

28 Sandel, Liberalism, 61-62; emphasis added.

29 ibid., 61-63; Kukathas and Pettit, Rawls, 108.

30 ibid., 63. While explicating an additional example would be beyond the scope and space of this paper, I should note that Sandel shows in his discussion in chapter 2, "Possession, Desert, and Distributive Justice," pp. 66-103, why, given an analysis of Rawls' idea of the idea of desert having no basis in a society dedicated to justice as faimess, the self in the OP is not allowed any basis for choice.

The distinctions made here by Sandel are quite similar to those made by Emily R. Gill, "Goods, Virtues, and the Constitution of the Self," in Liberals on Liberalism, Alfonso J. Damico, ed., Totowa, NJ: Rowman \& Littlefield, 1986: 111-128. The distinction between Gill and Sandel is primarily in the conclusions derived about the nature of the person, not so much in the procedural inquiry. Gill's argument is then in favor of Rawls's position: that liberalism can support both an intersubjective and an intrasubjective conception of the self, given the derivation of moral agents in the OP. Again, as the veil of ignorance becomes thinner, the attributes of persons (and hence their visions of the good) become thicker.

31 Sandel, Liberalism, 61.

32 ibid., 61-62; emphasis original.

33 Theory, 120; emphasis added. A similar passage is noted in Rawls's "Kantian Constructivism in Moral Theory," The Journal of Philosophy 88 (1980): 120. This reference is the kind of "tinkering" with the conceptual position from which different theorists assume certain things in order to begin theorizing. In Rawls's case, this is (of course) the OP. Sandel's objection is obviously that the OP does not adequately represent "persons" in any way, shape, or form. 
34 Theory, 136; emphasis added.

35 Sandel, Liberalism, 79-80; emphasis added.

36 Kukathas and Pettit, Rawls, 100.

37 Sandel, Liberalism, 133.

38 Sandel, Liberalism, 146-47.

39 ibid., 148.

40 ibid., 150.

41 ibid., 156.

42 Caney, “A Misconceived Debate,” 273-74.

43 ibid., 275.

44 Sandel, Liberalism, 150.

45 Other liberals, e.g., Caney, wish to distinguish these terms as "metaphysical" and "psychological." However, I think that this too misunderstands Rawls's and Larmore's desire to propose a political conception of the person that makes sense of our intuitive and considered judgments about justice. That is, perhaps a psychological conception of the self is not necessary for Rawls's narrower political theory.

46 Stephen Holmes, "The Permanent Structure of Antiliberal Thought," in Liberalism and the Moral Life, ed. Nancy L. Rosenblum (Cambridge, MA: Harvard University Press, 1989): 237.

47 Sandel, Liberalism, 74.

48 Patrick Neal and David Paris, "Liberalism and Communitarianism: A Guide for the Perplexed," Canadian Journal of Political Science 23 (1990): 419-40.

49 I should note that while I agree with Neal and Paris's distinction here, I disagree with their argument and conclusion for a more contingently constituted self.

50 Neal and Paris, "A Guide for the Perplexed," 425.

51 ibid., 425.

52 Caney, “A Misconceived Debate," 276-77; emphasis added.

53 ibid., 427.

54 ibid., 428.

55 Sandel, Liberalism, 58-59. 
56 ibid., 152.

57 ibid., 153.

58 Caney, "Misconceived Debate," 276; emphasis added.

59 ibid., $276-77$.

60 Gerald Doppelt, “Is Rawls's Kantian Liberalism Coherent and Defensible?” Ethics 99 (1989): 81551, at 816-19, 829, 832-33; Amy Gutmann, "Communitarian Critics of Liberalism," Philosophy and Public Affairs 14 (1985): 308-22, at n. 118, p. 312; Kukathas and Pettit, Rawls, 107; Will Kymlicka, "Liberalism and Communitarianism," Canadian Journal of Philosophy 18 (1988): 181-203, passim; Charles Larmore, "Review of Sandel's Liberalism and the Limits of Justice," Journal of Philosophy, 81 (1984): 340; Jeffrey Paul and Fred D. Miller, Jr., "Communitarian and Liberal Theories of the Good," The Review of Metaphysics 43 (1990): 803-30, at 820, 823-24; Robert B. Thigpen and Lyle A. Downing, "Liberalism and the Communitarian Critique," The American Journal of Politics 31 (1985): 637-55, at 640, 643.

61 John R. Wallach, "Liberals, Communitarians, and the Tasks of Political Theory," Political Theory 15 (1987): 581-611, at n. 7, pp. 607-8.

62 Sandel, Liberalism, 5; Rawls Theory, 3-4, 586.

63 Sandel, Liberalism, 175. The omitted reference is to Rawls 1979,$7 ; 190,544-55$. It is interesting to note that these "interesting misreadings" of Sandel pace Rawls are nevertheless informed by the very same readings and sources of which Sandel is accused of ignoring.

${ }^{64}$ Doppelt, “Coherent and Defensible?", 817.

${ }^{65}$ Kukathas and Pettit, Rawls, 107.

66 This is the confusion that Larmore notes in Galston's analysis of Rawls's "Dewey Lectures"; see note 76 , chapter $I$.

67 Kukathas and Pettit, Rawls, 108. Allen E. Buchanan, “Assessing the Communitarian Critique of Liberalism," Ethics 99 (1989): 852-82, at 852; Doppelt, “Coherent and Defensible?" 829-32; etc.

68 Kukathas and Pettit, Rawls, 107-108; emphasis original.

${ }^{69}$ Sandel Liberalism, 19.

70 ibid., 20.

71 ibid., 21; emphasis original.

72 ibid., 20.

73 Caney, "Misconceived Debate," 277; Holmes, “Antiliberal Thought," 236-53.

74 Larmore, Patterns, 119-25. 
75 ibid., 278.

76 ibid., 279.

77 John Rawls, "Fairness to Goodness," Philosophical Review 84 (1975): 536-54, at 547.

78 John Rawls, “The Basic Structure as Subject," American Philosophical Quarterly 14 (1977): 162.

79 Rawls, "Kantian Constructivism," 515-72.

${ }^{80}$ Doppelt, "Coherent and Defensible?" 817; Kukathas and Pettit, Rawls, 108; Kymlicka, "Liberalism and Communitarianism," 192.

81 Gutmann, "Communitarian Critics," 310; footnote omitted.

82 ibid., 311; from Sandel 1982, pp. 16-17.

83 ibid., 313.

84 ibid., 318.

85 Buchanan, Gutmann, etc.

${ }^{86}$ Kukathas and Pettit, Rawls, 108-9; emphasis original.

87 id.

88 I am indebted to Professor Craig Carr for this phrase.

89 Charles Taylor, "Cross-Purposes: The Liberal-Communitarian Debate," in Liberalism and the Moral Life, ed. Nancy L. Rosenblum (Harvard University Press, 1989): 159-82, at 161.

90 ibid., 162. 


\title{
CHAPTER IV
}

\author{
ALASDAIR MACINTYRE \\ AND THE VIRTUE OF THEORY
}

Tradition is not something a man can learn; not a thread he can pick up when he feels like it; any more than a man can choose his own ancestors.

Someone lacking a tradition who would like to have one is like a man unhappily in love.

\section{Ludwig Wittgenstein 1}

A significant challenge to liberal theory is aimed not at the intrinsic arguments of the liberal conception of the person as is Sandel's critique of JAF, ${ }^{2}$ but at the fundamental structure of liberal thought. In particular, this communitarian challenge asserts that liberalism, as a product of modernity, misunderstands the deep levels of association that must inform our political theory in order to make sense of our political practice. By promoting false ideas of the aims of theory and the assumptions that guide our theory-creation, liberalism renders our conception of selves incoherent, incomplete, and insufficient. ${ }^{3}$ Liberalism, as the claim goes, portrays the self variously as an individual who is a wholly autonomous creature, or a being that is the result of purely contingent circumstances without relation to historical circumstance, or similar incoherent formulations. Somewhere along the way we have forgotten how to conceive of ourselves logically and conceptually as political creatures. We have forgotten what it is to be a people who live according to and are informed by a tradition of inquiry that not only constitutes us and allows us to determine who we are and what we do, but informs us of the correct choices we must make in politics, and how we must make them. 
One of the strongest proponents of this anti-liberal thesis is Alasdair MacIntyre. He provides a fresh insight into what informs - and what should inform - our moral and political theory. MacIntyre is deeply opposed to much of what he sees in liberal society and liberal philosophy. In this chapter, I will address the pertinent aspects of MacIntyre's theory that run through two of his recent works that have drawn much critical attention: After Virtue: A Study in Moral Theory, and Whose Justice? Which Rationality? ${ }^{4}$ Both of these works are notable (if not laudable) for their broad-ranging and in-depth arguments that cover a variety of disciplines and subdisciplines. ${ }^{5}$ MacIntyre addresses many topics in these two works. Amongst other areas of thought he draws upon analyses and conclusions from moral theory, the history of ideas, the philosophy of social sciences, and contemporary political philosophy. I will discuss only those pertinent aspects of his theory as they relate to his critique of modernity and liberalism, and how this critique is informed by his view(s) of rationality.

Like Sandel's critique, MacIntyre's theory cum critique generates three different kinds of philosophical claims: descriptive claims about what kind of people we are, normative claims about the value of community and solidarity in our personal and political lives, and a meta-ethical claim that emphasizes the view that political principles should mirror "shared understandings."6 As with my discussion of Sandel, I will be primarily concerned with the descriptive and normative claims. In particular I want to show first how these claims are used in his theory as assumptions about persons and goods; second, how these assumptions are advanced in MacIntyre's theory in contradistinction from and opposition to liberalism; and third why and how such a claim fails primarily as a result of confusions not only of these separate descriptive claims, but also in confusing those claims with other normative claims.

I have characterized MacIntyre's position as a "theory cum critique" for one obvious reason: MacIntyre relies upon the conclusions from his theory as a basis for compari- 
son with modern political liberalism. By looking at MacIntyre's theory, I will examine and discover what fuels his critique; by critiquing his theory, I will show how some of MacIntyre's assumptions do not accord with the theory he promotes, nor do they accord with the conclusions he draws from his critique. There are then some conclusions that MacIntyre draws that we must question: some we will accept, but some we must reject. I will proceed by first examining the primary aspects of MacIntyre's theory that pertain to and are advanced in support of his critique of liberalism and modernity. I will then review a fundamental supposition in communitarian theory, the social embeddedness thesis. Here I will note how MacIntyre uses this idea and how it informs his theory and critique.

With these important distinctions in mind, the third section will examine MacIntyre's critique of liberalism through his account of rationality: I will address how MacIntyre characterizes JAF and compares it with other traditional conceptions of rationality, and especially how well this comparison proceeds and succeeds. This analysis will be continued in the fourth section, where I will compare and contrast these accounts of rationality, and note the consequences of these accounts on the conception of the person, and on accounts of the good and goods.

\section{THE CALL: A RETURN TO VIRTUE}

\section{Three Theses}

There are three theses in MacIntyre's thought. The first is a thesis about the link of history and political thought. This is the thesis that the history of ideas has developed through ways of understanding that MacIntyre calls traditions of inquiry, or simply a tradition. Here MacIntyre discusses various traditions and their respective conceptions of justice and rationality, and notes that the way we think about justice and rationality has changed not only with these several traditions, but that these conceptions have been 
formed through and make sense only when considered from within the historical and social context of that tradition. Several commentators have noted that this discussion of the history of ideas is neither terribly controversial nor objectionable. ${ }^{7}$ This aspect of MacIntyre's theory is beyond the scope of my argument and personal competence.

The second plank of MacIntyre's theory is his epistemological thesis about the concept of rationality that informs and is informed by a tradition. This thesis too is not terribly controversial or objectionable, ${ }^{8}$ although there does appear to be less consensus here about MacIntyre's idea of a social science than with his interpretation of the history of political thought. I shall not quarrel with this aspect of his work, but shall address the conception of rationality proposed by MacIntyre in order to follow his argument and approach his critique of liberalism.

However, the third plank of MacIntyre's theory and his culminating argument, is a critique of contemporary ethical and political theory and practice. This argument seems to mischaracterize the state of liberal theory and modern culture (particularly the role that rationality plays in this culture), and leads him to some dubious conclusions. It is as if the first two planks of his theory do not quite fit with this third and final one.

\section{"A Disquieting Suggestion"}

MacIntyre begins by suggesting that what we today call the social sciences have suffered nothing short of an apocalypse, but one without any clear road to salvation. ${ }^{9} \mathrm{He}$ suggests that a destruction of what had previously been known and accepted as true and valid statements regarding our moral theories, convictions, judgments and actions has taken place. This apocalypse has left our moral and consequently our political theory in the state of chaos and disarray we experience today. ${ }^{10}$

Diagnosis... MacIntyre offers a diagnosis and cure for what he sees as the ills of modern liberal society resulting from this apocalypse. ${ }^{11}$ To be fair, his analysis is 
"primarily diagnostic rather than prescriptive. He has little to say about how we might reconstruct a viable notion of justice in modern circumstances." 12 Nonetheless, his diagnosis is that somewhere on the road to modernity we lost our way, having lost the conceptual map that might point us to a place we wish to go. In abandoning and rejecting the Aristotelian notions of right actions and the good, we have lost the ability to act rightly and seek an objective good in any rational manner. In Aristotelian terms, we have forgotten the necessary link between goods and goodness.

...And Cure. The cure is that we must return to such Aristotelian ideas and ideals: we must radically alter our theory of political association as well as the moral notions and justifications we have for them. The gist of MacIntyre's project is contained in the title of his earlier work After Virtue, which is a rather clever play on words. MacIntyre first wants to make the reader aware that as philosophers, we are discussing politics and morality in a post-Aristotelian state; that is, we are discussing the basic questions of political philosophy in an age that falls after the conception of virtue was a dominant and central consideration. Second, notwithstanding this post-apocalyptic state, we should try to recapture and actively seek a place for virtue and the virtues in contemporary political philosophy, so MacIntyre is seeking - or after - virtue.

Moral Disagreement. MacIntyre notes that moral disagreements can generally be characterized in three different ways. First, they can be due to conceptual incommensurability, in which case the fundamental assumptions of the rival justifications for moral actions are at odds. Secondly, they can be due to an appeal to rival criteria that are claimed to be impersonal. Examples here would be appeals to power and authority, or appeals to duty, honor, or even happiness. Finally, moral disagreement can be due to an appeal to rival historical doctrines or practices that have persuaded us as valid and true arguments about the nature of ethics and ontology. 13 
Modernity: Liberalism and Emotivism. Tied to this, MacIntyre claims that modernity has come to accept or internalize the basic tenets of emotivism, which, crudely put, is the idea that our actions and desires are merely the products of the expression of will or desire. In earlier writings, MacIntyre has noted that this is an idea that stems in part from an Hobbesian reformulation of the sophists' claim: a justification for actions consists in "being instructed as to what action will produce for us most of what we now want...."14 In emotivism, moral decisions are not founded upon any rational basis; the rational or logical justification of moral actions and decisions is thus an empty concept from the start. But MacIntyre notes that because emotivism views all decisions as the product of choice-preferences, it "is thus a theory which professes to give an account of all moral judgments whatsoever." 15 Emotivism is then a philosophical way of expressing a sophisticated and universalized moral relativism: "What I have suggested to be the case by and large about our own culture - that in moral argument the apparent assertion of principles functions as a mask for expression of personal preference - is what emotivism takes to be universally the case." 16

To this end, he offers a characterization of practical reasoning or rationality according to the members of a liberal political order - be they philosophers or (other) ordinary folk - in his liberal-emotivist practical syllogism:

I want it to be the case that such and such; Doing so and so will enable me to achieve its being the case that such and such; There is no other way of so enabling me which I prefer; Doing so and so will not frustrate any equal or stronger preference. ${ }^{17}$

MacIntyre then links this consequentialist view of rationality with his historical argument about the discontinuity of thought that sprang from the Enlightenment: "The incoherence of our attitudes and our experience arises from the incoherent conceptual scheme which we have inherited."18 So to MacIntyre, the ideas and conceptions of rationality as developed through a tradition have a direct and formative influence upon our current ideas: we 
either accept former traditions, or we reject them. MacIntyre is clearly saying that the modern view of ethics makes little sense because we have rejected a tradition of thought that renders ethical and practical reasoning coherent. What then comprises MacIntyre's moral theory?

\section{Practices, A Unified Life, and Traditions}

MacIntyre's moral theory proceeds in three stages.

A first [stage] which concerns virtues as qualities necessary to achieve the goods internal to practices; a second which considers them as qualities contributing the good of a whole life; and a third which relates them to the pursuit of a good for human beings the conception of which can only be elaborated and possessed within an ongoing social tradition. ${ }^{19}$

I will briefly discuss these three stages in order.

Practices. A practice for MacIntyre is "a cooperative human enterprise in which goods internal to the enterprise are achieved in the course of exercising the standards of excellence appropriate to the enterprise." 20 A practice then assumes that a group of people - a community - has grown together through ties beyond kinship in order to promote a ways and means of association that is a good all of its own, not a good that is merely the result of that association.

This is the important distinction between internal and external goods. ${ }^{21}$ Using the game of chess as an example, MacIntyre defines an internal good as a certain quality or excellence of playing the game of chess only for the sake of playing the game; i.e., to be as good a chess player as one could possibly be would be an internal good. This is contrasted with external goods, which in the game of chess might be psychological or even material gains realized from playing the game well, such as fame or fortune. External goods are thus a kind of by-product of the practice. Macintyre stresses that virtue and right action require that we seek to do things - that is, we ought to do those things - not by looking towards those external goods, but primarily to internal and more appropriate 
goods. This leads to a provisional definition of virtue: it is a quality or characteristic that is necessary for the achievement of internal goods under an account of those practices and internal goods. ${ }^{22}$

Why begin moral inquiry from an examination and account of practices? It is because "the exercise of the virtues is not only worthy for its own sake," but more importantly because our conception of and respect for the virtues grows as they are assimilated into our practice. The virtues are not mere skills, or a means to an end. Neither are they categorical imperatives - moral rules that are conceived a priori and binding at all times - as conceived by Kant. Internal goods are achieved by exercise of the virtues and not merely or only the end result of that practice. The study of practices reveals the excellences, goods, and virtues of that practice. ${ }^{23}$

The Unity of a Human Life. The second, more complex stage in MacIntyre's theory is the idea of the unity of a human life. This is explored and demonstrated by an extended analogy of the literary concept of dramatic narrative. MacIntyre notes that the idea of a human life - "the self" - conceived as a story is missing in almost all contemporary philosophies, analytic and political philosophy in particular. ${ }^{24}$

This idea of a "narrative self" or "narrative subject" requires that we presuppose two interdependent ideas: the self as a subject of a story (not an object), and that as a subject within a social, historical, and political context we are only co-authors of our own lives. ${ }^{25}$ Thus, "I am not only accountable, I am one who can always ask others for an account, who can put others to the question. I am part of their story, as they are part of mine. The narrative of any one life is part of an interlocking set of narratives." $26 \mathrm{We}$ should note here that this is not so different from the political liberal's account of rationality and "offering good reasons," which is closely linked to liberalism's ideas of autonomy and equal respect: "To have respect for a person is to view him as capable of elaborating beliefs that we would respect."27 
The unity of a life then bears some resemblance to two notions found in the medieval idea of a quest. First, people on a quest set out with a purpose or goal, a telos. A telos was inspirational: in a quest, the purpose was to find the object of desire, or the object that would fulfill some purpose in and of itself. But it was not merely the attainment of that thing that was the purpose of the quest: the purpose was the quest itself, which leads to the second notion. The telos was not a wholly determinate or pre-determined goal; it was a conception of the good that developed over time, experience, and reflection. A quest is then "always an education both as to the character of that which is sought and in self-knowledge." 28 So the quest, as an analogy for a human life, serves to clarify what we must do to shape and refine that goal, but also what we must do to seek and attain that telos.

Additionally, that telos is socially and not individually formed; we are what we become in large part because we are products of a particular culture, or a way of life. So in answering the question "What is the good life for me?", MacIntyre implies that we can make sense of this only if we simultaneously ask "What is the good life for man?" MacIntyre thus claims, in an oft-noted and -quoted phrase, his second provisional conclusion about the virtues: "The good life for man is the life spent in seeking for the good life for man, and the virtues necessary for the seeking are those which will enable us to understand what more and what else the good life for man is." 29 Some commentators have noted that "while at first sight this definition appears less than illuminating," we should here bear in mind MacIntyre's larger argument, so that "when placed in the context of the third part of MacIntyre's account-the role of tradition" the point is clarified, if still somewhat vacuous. ${ }^{30}$ It is from inherited and historically interpreted traditions that an individual begins and follows his quest for the good life. This raises the idea of the social embeddedness thesis, which will be discussed below. 
Traditions vs. Modernity. This third stage of MacIntyre's theory, which is explored in depth in his subsequent work Whose Justice? Which Rationality?, is where we come to understand what relevance practices and unified narrative lives have to the concept of the self, and the central place that MacIntyre argues virtues should occupy in political and social philosophy.

A tradition for MacIntyre is not simply a way of doing things: it is "more than a coherent movement of thought. It is such a movement in the course of which those engaging in that movement become aware of it and of its direction and in self-aware fashion attempt to engage in its debates and to carry its enquiries forward." 31 I shall have more to say below about MacIntyre's idea - which I think for the most part is correct - of the development of a tradition, and how a tradition (or the members thereof) cognizantly change and grow in response to problems encountered. But for now we should note that a tradition is "a way of seeing" peculiar to a culture which contains a specific language that can but does not necessarily preclude intelligibility in trans-traditional, transhistorical, and trans-cultural conversations.

Another feature of a tradition is that it can grow or mature, and as it does so it encounters problems that challenge the assumptions, reasoning, and conclusions that had previously been accepted by the members of that community sharing in that tradition. ${ }^{32}$ But while a tradition is self-cognizant, it cannot know the outcome of any particular debate it might be involved in, e.g., a debate that could be potentially destructive for that tradition. So traditions tend to "run into" problems as a matter of course, problems that can be attributed to the epistemological stance of that tradition. ${ }^{33}$ For MacIntyre, a tradition of inquiry is not unlike a unified human live, or a story unfolding through time. An analogy might help here: a biography written prior to the death of the subject (or the subject's retirement from that activity to which they contributed) might be interesting, but certainly incomplete and therefore possibly flawed or even incoherent. 
MacIntyre implies that a tradition either transcends the period of time in which it arose and became dominant, or it dies in the attempt. ${ }^{34}$ Now we cannot question this claim because we think that MacIntyre may have left out one "explanation" of the development of a tradition of inquiry. So because MacIntyre does not mention e.g. the possibility of a synthesis of traditions, or that traditions may live out their spans in ignorance of each other and therefore of their incommensurable claims (mutual understanding is, after all, necessary before disagreement can logically take place), ${ }^{35}$ we cannot say that he has missed the point. But we can respond, as has Emily R. Gill, that MacIntyre's account of the goods of excellence and effectiveness - internal and external goods, respectively that conflict is a necessary part of any and all traditions. "It is clear from [MacIntyre's] own account...that conflict characterizes all traditions.... We can see in his account that all traditions define goods of excellence as well as those of effectiveness, and that conflict within traditions is over how the goods of excellence are to be defined and achieved."36

\section{Some Preliminary Objections}

What I suggest here is that MacIntyre's idea about the development and history of tradition-oriented modes of inquiry does not provide an adequate basis from which to adequately and accurately critique liberalism in general and JAF in particular. That is, there is a tenuous link in MacIntyre's thought between his version of the history of political philosophy, his account of rationality and intelligibility, and his critique of liberal and modern thought that relies on some radical and questionable assumptions about a particular view of politics and association. What I will argue for is that MacIntyre, in the link of these three parts of his theory, has misunderstood and therefore misrepresented liberalism and Rawls by relying upon a faulty conception of these basic assumptions. However, I can only address the link between MacIntyre's argument for a particular conception of rationality and his argument against liberalism. 
These tenuous links raise a common criticism against MacIntyre: that his characterization of liberalism is at once too broad and too narrow. As Emily Gill has noted:

MacIntyre's conception of liberalism, I believe, is at once too broad and too narrow. It is too broad because he 'identifies 'liberalism' with 'modernity,' as if there were no important illiberal strands within modern culture." Or rather, he asserts that conflicts with liberalism have been reformulated as debates within liberalism.... His conception of liberalism is, on the other hand, too narrow. The goods valued by the liberal self, in his view, are only valued as expressions of preference, and the skill valued by the liberal social order is the ability to bargain.

I will, of necessity, concentrate on the latter claim against MacIntyre to see in what ways this makes sense; this involves an analysis of MacIntyre's use of the terms self, rationality, goods and the like. We will them more clearly see how these concepts are inter-related in MacIntyre's theory.

I have noted three primary aspects of MacIntyre's theory and also his assumptions regarding emotivism and its link with liberal rationality, two important parts of MacIntyre's theory that are brought up to emphasize his dissatisfaction with modernity. While I have noted that much of what his theory offers is indeed worthy of consideration and should be considered by liberal theorists, we should evaluate these claims very carefully to note where they are applicable and where they are not. I will now explore an implicit part of MacIntyre's communitarian argument that is used not only to justify his position, but constitutes the basis for his attack on liberalism. This is the social embeddedness thesis.

\section{THE SOCIAL EMBEDDEDNESS THESIS}

MacIntyre's tripartite theory, along with his caricature of liberal-emotivist practical rationality, assumes a bundle of descriptive claims about human nature that I referred to previously as the social embeddedness thesis ${ }^{37}$ On this reading, the social embeddedness 
thesis has as much to do with the self-conception of the person as it does with the selfsociety relation. But before we can discuss the way MacIntyre understands how this assumption operates both in his and in liberal theory, we should briefly recall the claims of the social embeddedness thesis.

\section{Two Distinctions}

First, there is the distinction between metaphysical and political conceptions of persons. A metaphysical conception of the person assumes a very close relation between the person and their conception of the good to the extent that such goods are determinant of the character of that person. The metaphysical sense is an effort to describe the person in a moral-anthropological-historical manner, one that assumes this close relation between a person and their conception of the good. A political conception, on the other hand, assumes this position too; people's psychological and moral compositions are important and vital to any conception of people. But it does not regard these personal, comprehensive-moral factors as important to the self-political society relation. That is, one's personal make-up - moral, spiritual, communal identity, etc. - are assumed in political liberalism, but they are not used as a basis from which to decide questions of vital importance in political society: distribution of goods, resources, and the like.

This turns upon a second distinction: how "fully" are people "composed" by their surroundings, their community? Liberals point to a partially embedded or contingentlybased conception of the self: a person is socialized into accepting their native tongue and society as a norm or standard, a standard which is often confused with the idea that that standard is "good" or superior in some way. But by allowing a person to be only partly determined by their society, liberalism allows some space for the person to question and choose for themselves those aspects and values in society that are "good" for him. Communitarianism, on the other hand, assumes a very close relationship here. This 
wholly determined or essentially-based conception of self has little choice: only those aspects of society that are present in the person's community and education are available as paths to be chosen in a life. Alternative pathways are present, but they cannot be chosen as they often at some fundamental level irreconcilable with the individual's more basic, more substantial commitments - communal ties, moral education, etc.

In sum, there are two points. First, "[c]onceptions of essentially and contingently shared relations are conceptions of how relations are shared, and correspondingly of how the self is defined and understood." 38 Second, neither conception bears any direct or obvious relation to any particular set of normative political commitments. ${ }^{39}$

\section{Between Conceptions}

MacIntyre oscillates uncomfortably between the two conceptions of an essentially and a partially constituted self. At the price of inconsistency, it is not clear that he commits himself to one or the other. Despite his disclaimer that he is "not arguing that the concepts of narrative or of intelligibility or of accountability are more fundamental than that of personal identity....The relationship is one of mutual presupposition...," it is at times apparent that he prefers the wholly embedded thesis. This is apparent when MacIntyre describes the source of our commitments; e.g., "[T]he relationship between me, my social identity, and my good will preclude...re-evaluation...."40 Or again,

I am never able to seek the good or exercise the virtues only qua individual....I am someone's son or daughter, someone else's cousin or uncle; I am a citizen of this or that city, a member of this or that guild or profession; I belong to this clan, that tribe, this nation. Hence what is good for me has to be good for one who inhabits these roles. 41

But at other times MacIntyre seems to adopt a contingently-based conception. Sometimes even the fact that a person is embedded in communal practices "does not entail that the self has to accept the moral limitations... of those forms of community." 42 Or, to put it another way: 
I do not want to suggest that there is anything peculiar to the present in [defining persons in opposition to bureaucratic modes of control]....It is often and perhaps always through conflict that the self receives its social definition. However, as some theorists have supposed, that the self is or becomes nothing but the social roles which it inherits. The self, as distinct from its roles, has a history and a social history and that of the contemporary emotivist self is only intelligible as the end product of a long and complex set of developments. ${ }^{43}$

Here we must remember that this "long and complex set of developments" refers not only to the history of the concept of self that MacIntyre traces throughout, but also to the process that individuals engage in when living a meaningful life, one rendered coherent by partial embeddedness within a tradition.

Again, to emphasize this ambiguity in MacIntyre's thought:

"[T]he story of my life is always embedded in the story of those communities from which I derive my identity. I am born with a past; and to try to cut myself off from that past, in the individualist mode, is to deform my present relationships. The possession of an historical identity and the possession of a social identity coincide. Notice that rebellion against my identity is always one mode of expressing it." 44

That is, MacIntyre is saying we can choose to reject our roots or adopt an "alternative lifestyle" that places one in the position of continually attempting to justify life choices one's very existence - without the epistemological and morally relevant tools to do so; we can choose to be different than we are, but only at the price of personal moral confusion and incoherence.

We can see then that MacIntyre adopts a form of both kinds of the social embeddedness thesis. At times he adopts one version, at times another. This, in itself, is not to be condemned. What is unusual, and what we should question about this use of the social embeddedness thesis are the conclusions that MacIntyre draws from this dual use, and why he thinks that this conception of the individual is in some way different to or superior to the liberal view of the self. I do not mean to suggest that at base Rawls's view of liberalism and MacIntyre's community and morally-guided theory are the same. I do mean to suggest that they are in some ways similar in that they do rely upon the same 
claims; the object is to discover those claims, and see what conceptual sense we can make of them.

Why does MacIntyre think that viewing the self the way he does is superior to the liberal view of the self? To answer this, we must look at MacIntyre's view of rationality, and how rationality is closely tied to goods and persons. I will return to the consequences that this view of the social embeddedness thesis has on MacIntyre's critique in the next section. I will then defend Rawls's view of rationality in opposition to MacIntyre's, and show why liberalism's account of persons and rationality is persuasive.

\section{ACCOUNTING FOR RATIONALITY}

Because virtue and the nature of the virtues has changed, politics and the art of political association and governing have changed too. "Politics, as Aristotle conceives it, is a practice with goods internal to itself. Politics, as James Mill conceives it, is not."45 MacIntyre traces one of the most significant points of this change back to the Enlightenment, with its emphasis on Cartesian rationality and empiricism as opposed to Aristotelian practical rationality.

\section{The Role of the Virtues In Modernity}

MacIntyre here qualifies an earlier position. In After Virtue he had stated that modernity has specifically rejected virtue-oriented theories or accounts of the virtues that were central to the formations of conceptions of the good and the right. He now notes that the concepts of virtue and the virtues $d o$ have a place in modernity, but that that place has changed significantly since the formulation given it by Aristotle. ${ }^{46}$

Under that earlier conception, a virtue is derived not only from those practices and individuals that are indicative of a people or culture, but also from the traditions peculiar to that culture. The way that virtue and the virtues have changed can be seen by looking 
at the Enlightenment's treatment of these concepts, particularly David Hume's "quite new conception of the relationship of virtues to rules." Hume's conception has had three consequences, only the second which need concern us. ${ }^{47}$

Virtues are indeed now conceived of not, as in the Aristotelian scheme, as possessing a role and function distinct from and to be contrasted with, that of rules or laws, but rather as being just those dispositions necessary to produce obedience to the rules of morality. The virtue of justice, as Hume characterizes it, is nothing but a disposition to obey the rules of justice. ${ }^{48}$

As previously noted, this idea seems a return to one of the primary ideas found in Stoicism. "The virtues are now not to be practiced for the sake of some good other [than], or more than, the practice of the virtues itself. Virtue is, indeed has to be, its own end, its own reward and its own motive." 49 In modern times, virtue and rationality have become linked in a different and distorted way: virtue is now "to be generally understood as a disposition or sentiment which will produce in us obedience to certain rules, [and rationality an] agreement on what the relevant rules are to be [which] is always a prerequisite for agreement upon the nature and content of a particular virtue."50 So the concept of virtue exists today; MacIntyre's objection is that our modern concept of virtue is contentless or meaningless as it stands.

\section{Aspects of Rationality in Liberalism}

MacIntyre seeks to clarify the liberal ideas of justice and rationality by expanding upon his earlier characterization of the liberal-emotivist syllogism. He offers an examination and critique of the structure of debate that is carried on in a liberal culture at a theoretical level and in practical politics by noting four separate levels upon which the emotivist assumption operates in liberal theory and politics, presented in order from most apparent to most deeply ingrained in modern society. 51

Four Levels of Debate. First, different individuals and groups express their views and attitudes in their own terms. That is, debate is not actually carried out; there is no ar- 
gument and counter-argument. Instead, rival claims and views are asserted and counterasserted. "Nonrational persuasion displaces rational argument."52

Second, a tallying and weighing process is envisioned and put into practice where the expressions of preference are taken into account, and not the coherence or rationality of the claims. But this requires a prior step, MacIntyre's third characteristic, that the procedures and rules that govern the second step are themselves the outcome of rational debate, a debate that is only slightly different. The second level then relies upon the idea of rationality derived from some sort of philosophical discovery that has already been agreed upon.

Fourth and finally, the rules and procedures in step two become codified and legally encoded. These laws are then given the sanction of the state through enforcement of order. To MacIntyre, this means that the lawyers are the clergy of the secular liberal society. .53

Plurality and Rationality These characteristics - a multiplicity of conceptions of the good and the subsuming rationality - form MacIntyre's primary complaint against modernity. Their combination leads to interminable conflict about how to best justify those disparate conceptions. We have no primary shared moral principles from which to discuss moral and political issues reasonably and rationally. Consequently, moral consensus, let alone informed discussion, is precluded from modern politics.

We should note that MacIntyre's use of the terms reasonable and rational differ somewhat from Rawls's. Rawls uses these terms to define a conception of what it is to be a rational creature. To be able to participate in a discussion about politics assumes that one can discuss things at a reasonable level of sophistication (the issues will at least be clear), and that one has a basic understanding of the way arguments proceed, as well as some basic tools at one's disposal in order to articulate and defend a position. ${ }^{54}$ MacIntyre uses these terms as a description of the manner in which a tradition proceeds. 
Rationality on MacIntyre's use is more concerned with $a$ or perhaps the way of seeing; on Rawls's use, it is a way to account for ways of seeing that can be envisioned, given plural conceptions of the good. (Here we must remember that MacIntyre does not deny pluralism or plurality; he only denies it as a basis from which to form principles of association.)

At this point we can understand MacIntyre's earlier unfinished argument against emotivism: it has reduced our moral thinking to the premise that actions, regardless of consequences, can be interpreted and understood simply and merely as Nietzschean expressions of will or volition. Bereft of a tradition of thought that entails a controlling concept of virtue, "there seems to be no rational way of securing moral agreement in our culture." 55 We argue interminably about what is a - or the - correct moral point of view without looking to (or creating) a rational basis upon which to build a consensus, let alone creating a yardstick of measurement to evaluate different moral positions.

The three above-mentioned aspects of liberalism and modernity - individualism, the lack of a concept of desert to inform theory, and the incommensurability of truth and validity claims to which we can appeal in the event of conflict - coupled with MacIntyre's characterization of the development of debate and rationality in liberalism create a recipe for social disaster. To MacIntyre, "[m]odern politics is civil war carried on by other means, and [the Supreme Court case involving reverse discrimination claims in Regents of the University of California v.] Bakke was an engagement whose antecedents were at Gettysburg and Shiloh."56

\section{Analogy and Dichotomy}

But what precisely is MacIntyre comparing here? If MacIntyre wishes to compare and contrast the various traditions he has presented for study, then certainly we can agree with him that "in each of them intellectual enquiry was or is a part of the elaboration of a 
mode of social and moral life of which the intellectual enquiry itself was an integral part, and in each of them the forms of that life were embodied with greater or lesser degrees of imperfection in social and political institutions which also draw their life from other sources." We can also agree with MacIntyre when he says that these different traditions "differ in their catalogs of the virtues, in their conceptions of selfhood, and in their metaphysical cosmologies," and we can agree that "these traditions have very different histories in respect of their relationships with each other" so that "there is no standing ground, no place for enquiry, no way to engage in the practices of advancing, evaluating, accepting, and rejecting reasoned argument apart from that which is provided by some particular tradition or other." That is, between a dialogue of two traditions, "logical incompatibility and incommensurability may both be present." 57

But what are we to make of his argument that "[i]t is indeed a feature of [the account of traditions and rationality] that in one way or another all of [those accounts] have survived so as to become not only possible, but actual, forms of practical life within the domain of modernity." 58 How is this to be reconciled with his earlier complaint against modernity and liberalism, that we have no traditions of inquiry from which to draw upon in order to make some sense of the practices of our lives? On the one hand MacIntyre is celebrating the ability of modernity and liberalism to accommodate various conceptions of the good and methods of inquiry, or liberalism's ability to accommodate plurality. On the other, he condemns the kind of rationality that enables liberalism to do just this because it engenders an individualism that appeals to the way people view their contingent attachments: the necessary ability from people draw a conception of rationality from which to judge and evaluate their development as a person within any particular tradition. 


\section{A Question of Justification}

One way to view this is to examine how MacIntyre sees the resolution of practical and rational conflict. He notes that the idea of a proof in philosophical discussions and disputes is relatively barren; but this does not mean that we cannot know with certainty the truth of some matters in moral and political theory. 59 That is, truth can be decided through the settling of certain philosophical issues, but that is something that happens only when "the contending parties...have stood back from their dispute and asked in a systematic way what the appropriate rational procedures are for settling this [or that] particular kind of dispute."60 But he tempers this by adding that many will disagree with this account, particularly a "motley party of defenders" of liberalism. ${ }^{61}$ But on the whole, debate on these issues of political philosophy have not borne out this last statement. For example, many theorists, accept (with some reservations, e.g., the portrayal of David Hume's role in the Enlightenment) MacIntyre's historical argument in the presentation of the several traditions of thought. ${ }^{62}$ Indeed, most liberal thinkers agree with the bulk of his account of rationality and intelligibility, found mainly in his latter book. ${ }^{63}$

Further, we should note that MacIntyre's distinction between proof and justification is quite similar in many respects to Charles Larmore's distinction of the same in his latest article, Political Liberalism. ${ }^{64}$ The admonition to "stand back from the dispute and ask in a systematic way what the appropriate rational procedures are for settling this [or that] particular kind of dispute" bears a striking resemblance to the second of Larmore's two norms of political liberalism, that of rational dialogue:

In discussing how to solve some problem (for example, what principles of political association they should adopt), people should respond to points of disagreement by retreating to neutral ground, to the beliefs they share, in order either to (a) resolve the disagreement and vindicate one of the disputed positions by means of arguments which proceed from this common ground or (b) bypass the disagreement and seek a solution of the problem on the basis simply of this common ground. 
Now Larmore is not entirely clearly how this neutral ground is to be recognized, or if it is even attainable. (This criticism I shall discuss when I address the problems of neutrality in political liberalism in Chapter V.) MacIntyre is even less so. He asserts that at some point in the development of modern civilization (he places this point in the Enlightenment era), humankind "forgot" the lessons of ancient Greece in how to proceed in a rational way when two sides appear to be opposed on a particular issue. Yet given his account of traditions of inquiry and the conception of rationality that must inform those traditions, he denies himself the ability to return to such a conception.

I must forestall one objection to my account of MacIntyre. I am not saying that MacIntyre has not provided us with a procedural or conceptual account that would guide us in "recapturing the past." That is not MacIntyre's purpose. Aside from the impossibility of such a project, such a complaint against MacIntyre's procedure in his critique would be disingenuous. True, communitarian criticism of liberalism has been mainly destructive, not constructive. What I am saying are two things: first, that his diagnosis of modernity and liberalism denies him the ability to advance his prescriptive claims. Second, his account of rationality, as it informs and fuels his critique of liberalism, catches him on the horns of an additional dilemma. It is at this place in his theory where MacIntyre links his argument for a view of rationality and intelligibility with his argument for a tradition-, virtue-, or rationally-oriented theory of his own devising - that MacIntyre has drawn so much critical attention.

\section{The Christian Dilemma}

Perhaps this is too quick; a comparison may help here. MacIntyre, as we have seen, abhors an instrumental or consequentialist view of rationality, a view of rationality that views life choices in terms of choices that will maximize an individual's or society's interest, whatever that may happen to be. He denies consequential rationalism because it 
affords no place for the good in the view of a human life. But he ultimately relies upon a view of rationality and human nature that is designed to try to dodge the same kind of "captive dilemma" that has plagued Christianity since Aquinas:65 "If I believe in God, I shall go to heaven and reap eternal rewards; if I do not believe, I shall go to hell and reap eternal damnation. On the whole it is best to believe because I will then certainly reap untold rewards, as opposed to not believing and only having a chance of reaping limited rewards in this mortal life. Because I have a choice between two things to do - one good, one evil - and because I am rewarded to do good, I shall do good. It is in my best interest."

MacIntyre wants to dodge this dilemma because he too wants a choosing agent, one that is grounded in society retains and exercises the characteristics of choice with regard to life plans, experiences, conflicting moral conceptions, and decisions as to how best to resolve those conflicts. It is in the account of these - one's "life narrative" - where we can make sense of that telos MacIntyre wants to consider.

But again, why rationality? It is ultimately because MacIntyre believes, like the liberal, that an account of rationality lies at the heart of understanding human nature, and one must understand human nature - a theory of human nature must be assumed - in order to understand man's actions and his ability to account for those actions. Turning to MacIntyre's critique, it makes all the more sense. He does not want to view man as continually upon the horns of a dilemma: free but not free; autonomous, but only to a limited extent. He does not want to see man as being forced to maintain an uncomfortable position in relation to society: what Mendus has called "distance yet proximity," or the need for the agent to be both detached from yet embedded in his world. ${ }^{66}$ He wishes for man to transcend politics by understanding what is good for man, not by considering that which we may consider right. This view of man more than anything is what has led sev- 
eral critics to note that MacIntyre too is a liberal; a reluctant liberal, but a liberal nonetheless. ${ }^{67}$

I have shown how MacIntyre's view of rationality displays a fundamental similarity with liberal accounts of the person, the very object that MacIntyre wishes to discredit. But MacIntyre's argument still retains a great deal of power; his arguments for a particular view of the social sciences have been favorably received, for the most part. Given this similarity in view and assumptions of liberals and communitarians with regard to the conception of the person, how does MacIntyre derive such an uncomplimentary picture of modern man and morality.

Perhaps a great deal of the power behind MacIntyre's argument is from the way he combines his critique with his theory. But such characteristics are common in anti-liberal criticisms, as Stephen Holmes has noted. Amongst other kinds of "historical errors," MacIntyre has engaged in what Holmes calls antonym substitution, another name for unfair or inaccurate terms of comparison. ${ }^{68}$ Referring to MacIntyre's characterization of liberal theory as "implicitly [defined] as the sum total of all the ideas going around in contemporary 'liberal societies,' " Brian Barry has commented that “...in contrasting liberalism with his other traditions [MacIntyre] does not play fair. He fails to compare like with like.... Given that these are the terms of comparison, it is hardly surprising that liberalism does not make a good showing." 69 Instead of comparing sociological theories of management with political theories of the construction of the state (and those first principles necessary for a state to exist in a society with a common tradition of liberal and republican thought), MacIntyre should look to the moral bases of the traditions he examines in the effort the see what if anything is comparable and commensurable with modern liberalism. He should do this not in the effort to merely say that one theory is more coherent and therefore superior, but to understand what in the past can and does make sense to us, 
and what we can and should reconsider in our political theory today. That is, not only is MacIntyre's argument and characterization of liberalism unfair here, it is disingenuous. Or, as Emily Gill has succinctly put the point:

I agree with MacIntyre's conviction that the virtues and practical rationality can only be understood within the context of particular historical settings which condition this understanding....I disagree, however, with his assertion that liberalism contains more interminable debate than other traditions and has fewer resources for resolving such conflicts. ${ }^{70}$

\section{THE CRITIQUE OF LIBERALISM AND RATIONALITY}

MacIntyre's characterizations of the modern conceptions of virtue and rationality introduces his critique of Rawls's and, by comparison, Robert Nozick's theories. ${ }^{71}$ There are three points here. First, by comparing the two liberal theories MacIntyre drives home his point about the incommensurable nature of contemporary moral and political philosophy and discussion in general. But this move is questionable. Nozick's book had at least two purposes: to criticize a view of persons and society that he thought was hopelessly vague or empty, and to build a theory that would allow for a strong individualism yet not engender conflict by promoting "mini utopias." In order to offer a critique of Rawls's position, it was first necessary that Nozick understand Rawls's theory. In order to offer a counter-theory, it was necessary that there be some basis for comparison between the two theories. They may have incompatible conclusions and suggestions for practical politics, but at bottom the two theories are not so dissimilar; contra Macintyre, they are not incommensurable.

Second, MacIntyre notes that Rawls makes no allowance for the concept of desert in his theory; there is no place for individual merit in our social relations. "Individuals [on Rawls's account] are thus...primary and society secondary, and the identification of individual interests is prior to, and independent of, the construction of any moral or social bonds between them."72 And this is akin to his third point: that this primacy of individ- 
ual interests promotes a rampant "sociological" individualism. It encourages us to view others not necessarily as others in the sense that they are like us, but as others in the sense that they are strangers, indeed as "predatory strangers" who prey upon and exploit the weaknesses of others for personal gain. ${ }^{73}$

\section{Of Heterogeneity and Plurality: Strength or Weakness?}

These three points engender a lack of any dominant conception of the good. Rather than having a single conception of virtue derived from a tradition, modernity suffers from this multitude of conceptions.

[W]e have all too many disparate and rival moral concepts, in this case rival and disparate concepts of justice, and that the moral resources of [our] culture allow us no way of settling the issue between them rationally. Moral philosophy, as it is dominantly understood [today], reflects the debates and disagreements of the culture so faithfully that its controversies turn out to be unsettlable in just the way that the political and moral debates themselves are. ${ }^{74}$

To MacIntyre, this is incommensurability; I have shown that distinct or disparate views need not be seen as incommensurable, but can instead be seen as incompatible or merely controversial. To MacIntyre, though, this "incommensurability" is characteristic not only of our contemporary moral, philosophical, and political debates, but it also shows our inability to understand and truly appreciate the moral claims of other cultures, either contemporaneous or historic. This idea is very important to MacIntyre's theory and his critique. It is a point he raises several times in various guises. On modernity's understanding of the concept of justice, he states:

So the understanding of the rules of justice [as the expression of the desires of those not yet educated into the justice of the polis] has to be rejected [along with] any account of justice or right which prescribes that the desires of every individual are equally to be taken into account in deciding what it is right to do. ${ }^{75}$

Likewise liberalism, with the emotivist syllogism at its base, conceives of justice itself as an instrumental tool to balance between differing conceptions of justice: 
The liberal norm is characteristically...one according to which different kinds of evaluation, each independent of the other, are exercised in these different types of social environment. The heterogeneity is such that no overall ordering of goods is possible. And to be educated into the culture of a liberal social order is, therefore, characteristically to become the kind of person to whom it appears normal that a variety of goods should be pursued, each appropriate to its own sphere, with no overall good supplying any overall unity to life. ${ }^{76}$

MacIntyre here cites Rawls and notes that he too is aware of the undesirable consequences of a total lack of a formative or dominant conception of the good. However, MacIntyre thinks that Rawls's idea of neutrality commits liberalism and JAF to a form of neutrality that is at once too weak to command allegiance, yet too strong to allow the desired individual freedoms so dear to liberals. The point can be put another way: that liberalism is understood as another competing vision of the good has been acknowledged by many current liberal theorists. (This claim I will discuss more thoroughly in Chapter V.) What is significant here is that while liberalism views this as a source of strength (it allows for strong versions of neutrality and autonomy), MacIntyre views it as a weakness (it allows for no dominant conception of the good, and it encourages social discord).

We should be careful to note that MacIntyre's view of liberal neutrality and rationality has at its base a false dichotomy: liberalism either relies upon or derives an instrumentalist notion of rationality due to pluralistic conceptions of the good, which forces it to acknowledge the equal foundation of all such claims. But this view of liberalism as a "tyranny of dualisms" - inaccurately presents a choice of opposites, neither of which should command our allegiance. ${ }^{77}$ By presenting liberalism in such a dualistic, dichotomous way, "[t]he critics thereby do a disservice to not only liberal but [also] to communitarian values, since the same method that reduces liberalism to an extreme metaphysical vision also renders communitarian theories unacceptable."78

Gutmann's point should be carefully noted. In arguing against the liberal conception of the good and the self - what Sandel and others have called the "unencumbered 
self" - MacIntyre implies that there is only one good or one kind of good that would be or fulfill the telos of a certain role. But "[o]ne reason it does not follow [that what is good for me has to be THE good for one who inhabits these roles] is that none of these roles carries with it only one socially given good." That is, "we cannot accurately say that our roles determine our good without adding that we often choose our roles because of the good that is attached to them." 79 So not only is MacIntyre's claim that liberalism is without rational foundations or any coherent account of the good inaccurate, but it does not follow from his own account of rationality and goods.

\section{Liberalism As A Tradition}

It would be easy but disingenuous at this point to say that MacIntyre has simply misunderstood Rawls's theory and political liberalism. Instead, we can better appreciate MacIntyre's position and Rawls's theory by noting that Rawls's third and fourth period in the development of his theory owe a great deal to the communitarian critique in general, and MacIntyre's critique in particular. This does raise a minor point, mentioned previously. That Rawls has been unwilling to disagree with his critics and point out clear cases of mistaken readings indicates his willingness and desire to reach an overlapping consensus. ${ }^{80}$ But to say that MacIntyre has misunderstood Rawls would be too easy; it would be to dismiss a legitimate critique that must be accorded proper respect. That is, MacIntyre does not deny that liberalism is a tradition; what he denies is its coherence and explanatory power. ${ }^{81}$

Justification and the Social Thesis. Because there is a link between the descriptive and normative claims in MacIntyre's theory, we can see that there is a problem of justification, one that is shared by liberals and communitarians. Patrick Neal and David Paris note that his problem centers around the placement of some concepts, e.g., rights and freedoms, within an historical context that must be interpreted to be understood. ${ }^{82}$ 
The confusion can result from liberals incorporating one or another aspect of the communitarian critique into a liberal theory (that we must ascribe to a modified sociological or social embeddedness thesis), or from communitarians insisting upon the idea that as a philosophical conception of the self liberalism negates our shared understandings by promoting an individualist conception. But few liberals deny that "we should look to the community for shared understandings about the self or principles of justice," and many communitarians wish to emphasize just this point. "As 'rival hermeneuticists,' the two sides may not agree about what the community's 'historical understandings' are, or ought to be, but they do agree that these understandings are the fundamental phenomena with which the theorist necessarily works." 83

And therein lies the confusion. On the one hand, if we accept Rawls's view that political theory ought to be a descriptive and practical, (i.e., primarily a political task of finding what is both feasible and desirable in our political culture and theory), then need we accept the way he feels that this should be justified on the theoretical or philosophical level?84 On the other, must we accept MacIntyre's view of political theory as the justification for a particular view of "the right informed by the good"? "Clearly the debate is not merely about how the liberal community happens to understand itself; it is also about how it ought to view its 'shared understandings.' Again, the former question is more political, the latter more philosophical."85

This point has been made differently by Charles Larmore. He notes that much of what we take to be understood and accepted moral practices and conventions (norms) are socially derived: "Becoming a moral agent depends upon social conditions of training and practice that we do not control ourselves."

In general, our humanity requires that we do not lead our lives as merely a sequence of desires satisfied or disappointed, but rather that we shape and interpret our activities and experiences in terms of overarching rules and purposes; only in this way do peculiarly human values and significances become intelligible and accessible. ${ }^{86}$ 
It is in this way that liberalism and a political conception of justice and the self, properly understood, undermine the communitarian claim against liberalism's lack of coherence: because it is not derived from an historical culture or tradition-oriented mode of inquiry, it is necessarily denied commensurability and therefore intelligibility.

Towards a Political Conception. So there are three good reasons to reject, either on an account of rationality, or an a view of social embeddedness, the communitarian criticism that liberalism (and JAF in particular) ignores our social or communal ties. The first we encountered above: that on an account of justice, we can argue that Rawls is very aware of the derivation of justice from within a social or tradition-oriented understanding. This point has pushed Rawls to reconsider the justification of his theory. So the examples of, say, The Wars of Religion and England's Glorious Revolution as used in his later works show how much Rawls has conceded to the communitarian position, particularly on the historical view of rationality.

Second, we must question the role of goodness and goods in communitarian theory and critique. Even though this aspect of his theory has been as heavily emphasized in Rawls's more recent theoretical developments, the whole point of the original position is to remove from consideration those social considerations - comprehensive, moral, or religious conceptions of justice and the good - that are so important to people that they would skew any fair or "neutral" conception of justice.

The reason why information as to which community one belongs to is excluded is precisely because cultural attachments are so important to people. Were [they] to be included, people could then tailor the principles to favour their own views at the cost of others. Thus, information is excluded so that persons may live in accordance with their cultural commitments... That such knowledge is hidden behind the veil of ignorance reflects Rawls's appreciation of how strongly people are attached to their ends. ${ }^{87}$

Third, "[t]here is copious textual support for the thesis that Rawls adheres to the embeddedness thesis." 88 While I cannot rehearse this claim here, my exposition of Rawls 
in chapter I clearly shows that Rawls does pay close attention to the way individuals conceive of and are informed by their social environment; it is also clear that Rawls incorporates this partially-embedded social thesis into his theory. The clearest indication of Rawls's endorsement of the partially-embedded social thesis is his move of grounding JAF in modern, liberal, democratic, capitalist society, a change that took place as early as 1980. This move has had the greatest impact on JAF and the account of rationality that supports it.

\section{DISPARATE VIEWS, DISPARATE RATIONALITIES?}

I have presented MacIntyre's theory in the effort not only to understand it, but more importantly to understand his critique of liberalism, modernity, and his account of rationality. I have noted where MacIntyre relies on some unsubstantiated claims about the source and nature of social commitments and our "embeddedness" within the practices and traditions of inquiry found in our modern, liberal culture.

Additionally, I have noted that MacIntyre's account of rationality, relying as it does on the virtues and a particular account of traditions of inquiry, raises the question of how a dualistic or dichotomous analysis scan work without being itself caught upon the horns of a dilemma. I have noted some places where MacIntyre errs in the conclusions he draws from his theory, primarily from relying upon too strong a form of the social embeddedness thesis. I have also noted some other of his claims that should be questioned because they rely upon similar theoretical errors or historically inaccurate interpretations of liberalism.

I do not mean to discount MacIntyre's remarkable achievements in his historical recounting of moral and rational inquiry found in various traditions. But, as many have noted, MacIntyre suffers just like the rest of us; he too is a product of modernity, and while he may wish to subscribe to a particular view (MacIntyre ascribes to 
Aristotelianism cum Thomism) that criticizes modernity for a lack of virtues, still his understanding of that tradition is itself a product of the modern liberal culture he inhabits. ${ }^{89}$

We are, in a sense, "stuck" with liberalism. That point MacIntyre has amply demonstrated. And in some sense his diagnosis is accurate: liberalism on many analyses tends to engender the kind of sociological individualism that appears to have overtaken our culture: it encourages the conceptualization and assertion of rights as shields or cloaks or "trump cards" that are intended to stop certain governmental actions that would encroach upon an individual's liberty; it encourages the "primacy of privacy,"90 or an extremist view of the "right to be let alone." But as I have demonstrated, this is not a productive way to view liberalism, nor is it a conducive way to understand the value of political philosophy - liberal or communitarian - in a liberal culture. 


\section{NOTES}

${ }^{1}$ Ludwig Wittgenstein, Culture and Value, trans. Peter Winch (Chicago: The University of Chicago Press, 1980): 76e.

2 Michael Sandel, Liberalism and the Limits of Justice (Cambridge: Cambridge University Press, 1982).

3 The terms incomplete, insufficient, and incoherent are from Alphonso Damico's characterization of liberal criticisms. "Introduction" to Liberals on Liberalism, ed. Alphonso J. Damico (Rowman and Littlefield, Totowa, NJ: 1986): 1-12.

4 Alasdair MacIntyre, After Virtue: A Study in Moral Theory, 2d ed. (Notre Dame, IN: Notre Dame University Press, 1984); Whose Justice? Which Rationality? (Notre Dame, IN: Notre Dame University Press, 1988.) N.b.: all references are to the second edition.

5 I must necessarily consider these books as two parts of a larger theory, so I will address them as a whole. In fact, MacIntyre explicitly acknowledges that the second book is an account of rationality that fits into but subsumes much of his earlier book; chapter 19, (Postscript) After Virtue; 264-78; preface, Whose Justice?, etc.

${ }^{6}$ Simon Caney, "Liberalism and Communitarianism: A Misconceived Debate," Political Studies 60 (1991): 273-89, at 273; emphases original.

7 See, e.g., Charles Larmore, "Review of Whose Justice? Which Rationality? by Alasdair MacIntyre," in The Journal of Philosophy 86 (1989): 437-42; Brian Barry, "The Light that Failed?" Ethics 100 (1989): 160-69; J. B. Schneewind, "Virtue, Narrative, and Community," from a Symposium on Alasdair MacIntyre's After Virtue, The Journal of Philosophy 79 (1982): 653-63. But cf. Julia Annas, "MacIntyre on Traditions," Philosophy and Public Affairs 18 (1989): 388-404; and Emily R. Gill, "MacIntyre, Rationality, and the Liberal Tradition," Polity 24 (1992): 433-57.

8 See note 6.

${ }^{9}$ MacIntyre I think is actually referring to two different catastrophes: the destruction of the Hellenistic and Classical Greek ages, and the Fall of the Roman Empire with the ensuing loss or scattering of knowledge.

${ }^{10}$ MacIntyre, After Virtue, 1-5. See also MacIntyre's A Short History of Ethics (New York: Macmillan Publishing Company, 1966), esp. chapters 8 and 11.

11 The phrase "diagnosis and cure" is from Christopher Gowans, "Review of Alasdair MacIntyre's After Virtue," The International Philosophical Quarterly 22 (1982): 215-19.

12 David Miller, “The Resurgence of Political Theory," Political Studies 38 (1990): 421-37.

13 ibid., 6-11.

14 MacIntyre, A Short History of Ethics, 148. 
15 MacIntyre, After Virtue, 12.

16 ibid., 19.

17 MacIntyre, Whose Justice?, 340.

18 MacIntyre, After Virtue, 68.

19 ibid., 273.

20 Gowans, "Review of After Virtue," 217.

21 These have also been referred to as the goods of effectiveness and the goods of achievement, respectively.

22 MacIntyre, After Virtue, 191; see MacIntyre's discussion of this, pp. 187-97.

23 ibid., 273.

24 ibid., 221, 226.

25 ibid., 216.

26 ibid., 218.

${ }^{27}$ Charles Larmore, Patterns of Moral Complexity (Cambridge: Cambridge University Press, 1987): 64.

28 MacIntyre, After Virtue, 219.

29 id.

${ }^{30}$ Gowans, "Review of After Virtue," 218; emphasis original.

31 MacIntyre, Whose Justice?, 326.

32 MacIntyre, Whose Justice?, 326, 349.

33 In this aspect of his theory, the description of traditions maturing through history and the ensuing "epistemological crises," MacIntyre closely resembles Thomas Kuhn's paradigms and shifts of paradigms that result from conceptual inability to solve problems in the natural and physical sciences. Thomas Kuhn, The Structure of Scientific Revolutions, 2d ed. (Chicago: The University of Chicago Press, 1970).

${ }^{34}$ MacIntyre, Whose Justice?, 359-69.

35 MacIntyre, Whose Justice?, 370.

36 Gill, "MacIntyre, Rationality, and the Liberal Tradition," 438. 
37 Caney, “A Misconceived Debate,” 275.

38 Patrick Neal and David Paris, "Liberalism and Communitarianism: A Guide for the Perplexed," Canadian Journal of Political Science 23 (1990), 419-40, at 428.

39 Caney, “A Misconceived Debate," 427.

40 Alasdair MacIntyre, “Intelligibility, Goods, and Rules," The Journal of Philosophy 79 (1982): 664.

41 MacIntyre, After Virtue, 218-20; emphasis added.

42 ibid., 221.

43 ibid., 31 .

44 ibid., 221.

45 ibid., 227. This is a line of historical argument that I cannot pursue here; but it is significant, as MacIntyre notes, that David Hume's political thought is central to understanding the ideas of virtue, justice and rationality in this period, as demonstrated by MacIntyre's characterization of Hume's ideas about the virtues.

46 ibid., 244.

47 I cannot address MacIntyre's extended exegesis and critique of Hume's philosophy and contribution to the history of political ideas, a discussion that he takes up again at some length in Whose Justice? Which Rationality?, especially chapters XIII through XVI. There, as in the present book, MacIntyre introduces the ills of modernity via the transformation and bastardization of a tradition at the hands of a major Enlightenment philosopher.

48 Macintyre, After Virtue, 232.

49 ibid., 233.

50 ibid., 244.

${ }^{51}$ MacIntyre, Whose Justice?, 343-45.

52 ibid., 343.

53 It is somewhat surprising that MacIntyre does not include judges and politicians as targets for approbation; after all, lawyers merely (try to) interpret the law in various ways according to his deplorable rationality. Judges and legislators, on the hand, actually construct the law according to such a picture of rationality.

54 See, e.g., John Rawls, "Kantian Constructivism in Moral Theory: The Dewey Lectures 1980," The Journal of Philosophy 88 (1980), esp. lecture 1, 515-35; "Justice as Faimess: Political Not Metaphysical," Philosophy and Public Affairs 14 (1985), esp. § III, pp. 230-34, § V, pp. 239-44, and § VII, pp. 245-46; "The Idea of An Overlapping Consensus," Oxford Journal of Legal Studies 7 (1987), §§ I and II, pp. 1-9; 
"The Priority of the Right and Ideas of the Good," Philosophy and Public Affairs 17 (1988), §§ VII and VIII, pp. 268-76; and "On the Idea of Free Public Reason," unpublished paper (1988), passim; and "The Domain of the Political and Overlapping Consensus," New York University Law Review 64 (1989), §§ VIII through X, pp. 248-55.

55 MacIntyre, After Virtue, 6.

56 ibid., 253.

57 MacIntyre, Whose Justice?, 349-50.

58 ibid., 391; emphasis added.

59 MacIntyre, After Virtue, 259-60.

60 ibid., 260.

61 id.

62 Annas, "MacIntyre on Traditions," and Gill, "MacIntyre, Rationality, and the Liberal Tradition," take exception with MacIntyre's portrayal of Hume's role in the Enlightenment. However, most critics view MacIntyre's account of intellectual history as accurate on the whole.

${ }^{63}$ See Whose Justice?, chaps. X, XVII-XX. To be clear here, I agree with the bulk of MacIntyre's account of rationality in the social sciences; my point is that the conclusions he draws from this discussion, and the way he applies this to liberalism, is both unfair and in error. Critics of MacIntyre's recent work in general do agree with his account of rationality, as noted: Larmore, "Review of Macintyre's Whose Justice?," Barry, "The Light That Failed?," Annas, "MacIntyre on Traditions," and Gill, "Macintyre, Rationality, and the Liberal Tradition." Where these critics and I disagree with MacIntyre is (a) his conflation of modernity with liberalism, and with emotivism, and (b) his denial of coherence through a conflation of the terms of debate within liberalism.

${ }^{64}$ Charles Larmore, "Political Liberalism," Political Theory 18 (1990): 347-48.

${ }^{65}$ Macintyre's account of the way this dilemma has evolved is found in his Short History of Ethics, chapters 9, 11, and 18, and in Whose Justice?, chapters IX through XV.

${ }^{66}$ Susan Mendus, Toleration and the Limits of Liberalism (Atlantic Highlands, NJ: Humanities Press International, 1989). Mendus's discussion of the liberal need for "distance yet proximity" is in chapter 4, 69-110, but esp. 95-7 ("The Development of Autonomy") and 102-110 ("Autonomy and Toleration").

${ }^{67}$ Schneewind, 661-63; Larmore, Review of MacIntyre's Whose Justice? Which Rationality?, 440-41; Barry, "The Light That Failed?," 168; Gill, "MacIntyre, Rationality, and the Liberal Tradition," 448, 45657.

68 Stephen Holmes, "The Permanent Structure of Antiliberal Thought," in Liberalism and the Moral Life, ed. Nancy L. Rosenblum (Cambridge, MA: Harvard University Press: 1989): 237, 250-52.

${ }^{69}$ Barry, "The Light That Failed?," 165.

70 Gill, "MacIntyre, Rationality, and the Liberal Tradition," 436. 
71 MacIntyre, After Virtue, 246-252.

72 ibid., 250.

${ }^{73}$ I am indebted to Professor Craig Carr for this phrase.

74 ibid., 252.

75 MacIntyre, Whose Justice?, 98 passim.

76 ibid., 337.

77 Amy Gutmann, "Communitarian Critics of Liberalism," Philosophy and Public Affairs 14 (1985): 308-22.

78 Gutmann, 317.

${ }^{79}$ Gutmann, 316.

80 Thomas Pogge, Realizing Rawls (Ithaca, NY: Cornell University Press, 1989): 4.

81 MacIntyre, Whose Justice?, 326-48.

82 Patrick Neal and David Paris, "Liberalism and the Communitarian Critique: A Guide for the Perplexed," Canadian Journal of Political Science 23 (1990): 422.

83 ibid., 432.

84 id.

85 id.

${ }^{86}$ Larmore, Patterns, 31.

87 ibid., 278.

88 ibid., 279.

89 Annas, "MacIntyre on Traditions," 404; Larmore, review of Whose Justice? 441, and especially Patterns, chapter 2, "The Limits of neo-Aristotelianism," 22-39; Schneewind, "Virtue, Narrative, and Community," 662-63; Barry, "The Light that Failed," 168; etc.

90 I am indebted to Professor Craig Carr for this phrase. 


\section{CHAPTER V}

\section{POLITICAL LIBERALISM}

Who knows the laws according to which society develops? I am quite sure they are a closed book even to the cleverest of men. If you fight, you fight. If you hope, you hope.

You can fight, hope and believe without believing scientifically.

Let us be human.

\section{Ludwig Wittgenstein 1}

\section{INTRODUCTION}

Up to this point I have been concerned with two things: the development of JAF's conception of the person in response to communitarian criticisms, and clarifying what those criticisms are in order to see which are apt. I have expressed these concerns by examining and analyzing the concepts of the social embeddedness thesis, rationality and morality, as well as the various model-conceptions found in JAF. Specifically, I have shown how liberalism cannot be construed, or how it does not make sense to view and critique liberalism, and how JAF has responded to those criticisms that are accurate by adapting the theory to account for a stronger yet sustainable version of the social embeddedness thesis, a concern that has increased as the theory has developed.

This naturally leads to an important question: since I have shown what a political conception of the person does not look like, what does it look like? In what does the conception of the person in political liberalism consist? An oft-noted criticism of liberalism in general is that it relies upon a "conception of the person," or that it must have a "full" view of human nature or the human condition in order to operate: that men must be angels or devils, or beings "constructed" in a particular way in order for liberalism to oper- 
ate. I will here argue implicitly that this view is largely mistaken: liberalism need assume very little about human nature in order to operate and successfully command allegiance. Of course, there are social and historical conditions under which liberalism appeared, and under which it can operate and flourish. There are also ways to view individuals if we wish to accord them with certain characteristics, e.g., equality, autonomy, and rationality. In my analysis of JAF and communitarianism, I have implied where these concepts are found in the respective theories, and that both theories - indeed most political theories have some conception of these characteristics of persons implicit within, either positive or negative - rely upon them in different formulations. But this should not lead us to assume that liberalism needs a full view of the person in order to make sense in theory and practice. It needs $a$ view, and that view is one that is both acceptable to others, and superior to the communitarian formulation.

\section{Ethics or Epistemology?}

One way to view this situation is to ask whether liberalism relies upon ethical or epistemological considerations: does liberalism ultimately rely upon our conceptions of morality, or upon our view of persons as creatures of a particular kind, related to the world in only a specific or certain kinds of ways that "make sense"? A concern with ethical problems would indicate that liberalism is more pragmatic, or more concerned with the here-and-now problems of living in a pluralistic society; viewing liberalism on an epistemological basis would indicate that political liberalism is more concerned with figuring out what people are, rather than how they can and should act towards each other.

Liberalism is of course a political theory: it does not and need not account for all aspects of the person, but it must at least account for those aspects that have to do with politics. What aspects of persons then have to do with politics? I will show that liberalism need not justify itself by making claims about "the nature of persons." What is im- 
portant is how we view people, so that the way we associate - the way we do politics and think about it - can account for and create a logical and coherent place for persons.

A simpler way to say this is that there are distinctions between the concept of the person in religion, in psychology, and in politics. In a way, to say that political liberalism has a "conception of the person" is slightly misleading. But at base, liberalism - and political theory - must assume some things about persons in order to account for them coherently and completely. In this chapter, I will show how political liberalism views the person, and in doing so has (in some very limited ways) transcended the current debate by adopting some communitarian concerns, and continued with the job of politics: managing conflict by appealing to moral considerations.

Political liberalism is in part a response to the criticism that the neutral conception of the good envisioned by Rawls is not just $a$ neutral conception of the good: it is simply another conception of the good that promotes principles of association - the right - over any substantive conception of the good in order to achieve neutrality and fairness amongst competing conceptions. Instead of relying upon a neutral conception of the good, political liberalism offers a neutral justification of that conception of the right as a means of promoting a conception of the good which can include toleration, neutrality, etc. It is a moral conception, but it is a minimal moral conception that can command allegiance and provide for a degree of social stability and predictability unavailable to communitarianism, without subjecting or denying some visions and pursuits of the good.

The crucial question then is whether in constructing this moral view of political society they have not simply posited (or simply "injected" or "snuck into" the theory) a "full" idea of the person that happens to accord with their theory, or whether they have assumed some characteristics of persons that are necessary but (at base) uncontroversial in order to begin political theory. Obviously, I will argue that they make the latter move: 
political liberalism assumes some things about people, and then gets on with the job of politics. Only then can we ask if such a conception is intelligible.

I can here only suggest some of the ways to resolve some of the tensions regarding the inter-relations of these various concepts within liberalism. To do more is beyond the scope of my inquiry here, which is to show why and how a liberal conception of the self (as opposed to a communitarian one) should command our allegiance. That is, while I put forth the concepts that subsume and constrain liberalism, I address these with the idea that they are superior to communitarian versions of them, not that they are the best available within political theory in general.

\section{Structure of the Chapter}

Because of the length and complexity of the issues and concepts involved here, I would like to begin by briefly reviewing the substantive issues in the argument up to this point. I will again suggest what I have implied before, that liberalism and communitarianism are compatible in some ways, and in others not. But this by itself shows that the two positions are not incommensurable.

In the second section, I will examine some of the basic concepts of liberalism, and show how a liberalism based upon the concept of autonomy is central to political liberalism as a foundation. This analysis will be continued in section three, where I show that while neutrality and a conception of rationality are both necessary parts of liberalism, they are best and most coherently understood as aims or guiding purposes of liberalism, not as bases or foundations.

I will follow this in section four by noting how political liberalism incorporates this view of the person into a neutral justification of the kind of good that liberalism promotes. I will conclude by noting how, by recognizing its own limitations, liberalism has pushed the argument past the current debate, and onto the question of politics. 


\section{A REVIEW OF THE ARGUMENT, AND SOME CONCLUSIONS}

\section{Rawls Reconsidered}

In Chapter II, I reviewed Rawls's theory as it has developed in response to critiques both from within and without. I noted the development of the model-conceptions in JAF, and how those amended model-conceptions have allowed JAF to withstand some criticisms. (We have only been concerned with the criticisms of those theorists loosely labeled as communitarians, and even then only with two theorists and their theories cum critiques.) Given the account of the person that Rawls proposed in Theory, he had a choice of two directions in which to move his theory. One alternative was towards a "tougher-minded application of the individualist method,"2 which would have continued a line of thought that emphasized the rational choice and maximin elements in Theory. This alternative would have committed him to developing a highly-laden normative theory based upon rational choice in order to justify any fuller conception of the individual - a "more thickly constituted self" - than rational choice has been account for to date. Further, it would have necessitated the development of the model-conception of the OP and its accompanying model-conceptions, and the account of rationality that parties would choose principles of justice under the veil of ignorance, i.e., the rational pursuit of individual interests.

I say "would have committed him" because it is obvious that Rawls did not move in that direction. Instead, he developed a different aspect of his theory that allowed him to place persons within a socio-historical context, a context from which to choose those principles and those goals and life-plans that would be important to them, i.e., those formations of comprehensive ideals that would make life satisfying to a person for highly 
individual reasons. This allowed Rawls to account for a "fuller" conception of the individual person that could be considered apart from politics. Individual and group or community conceptions of the good are then still available, but what subsumes a society are those political principles (democracy, the rule of law, the acknowledgment of institutions that guide political and social change and development but respond to constituent pressures, etc.) grounded in rationality, a tradition or heritage of political thought, and common belief, not individual or comprehensive moral ideals. In a sense, the second of two intuitive arguments that Rawls suggested early in Theory have become more important in understanding and accepting political principles of justice: if a principle accounts for our considered moral judgments about what is just or unjust, then this is a good reason for accepting that principle. That is, political liberalism, as it has developed from JAF, is promoted by individuals because they can rely upon others to accept the principles as reasonable; such support would generate support and thus create stability; and it would become a basis for equal (or mutual) respect in a political system. ${ }^{3}$

Some have claimed that in this move towards a more "communitarian" approach Rawls has made some significant concessions to the communitarians. This is not to say that his theory has become communitarian, or is any more appealing to communitarians. It would be more accurate to say that the developments in JAF have allowed it to accommodate those communitarian claims that render the idea of the person more coherent and consistent.

\section{Sandel Reconsidered}

In Chapter III, I surveyed and analyzed Sandel's critique of Rawls, and showed where Sandel's critique was justified, and where it was not. Additionally, I pointed out some of the model-conceptions that have developed in JAF to push it towards a more "communitarian" justification. Many of these changes in JAF were due either to 
criticisms from the left (other liberals who either endorsed Rawls's view but wished to somehow make it stronger), or from the right (the communitarian criticisms that I now address). But it is important to note that on a fundamental level (the social embeddedness thesis), Rawls and Sandel are in agreement: persons can derive choices from their social context, and their social context sets the limits of available pursuits of the good that are feasible and intelligible to the individual. Again, liberals hardly deny the applicability or "truthfulness" of the social embeddedness thesis.

Rawls's response to Sandel's critique has been a kind of implicit acknowledgment of that "shared spirit." But I also made the argument that Sandel has a two-pronged argument against the liberal conception of the person which, like other communitarian criticisms, relies upon a conflation of descriptive, normative, and ethical claims. The first prong of Sandel's argument claimed that Rawls's conception of the person was, like Kant's, "contentless" because it had only an "empirically unconditioned sense of duty" to the social world; that is, the only thing that kept people from being less than human was Kant's distinction between the "noumenal" and the "phenomenal" worlds, and the duty that people have to be rational, or human. The Kantian view insisted upon that concept of rightness as prior to and controlling of any conception of the good; hence the Kantian categorical imperative and Rawls's formulation of it in the phrase "the right prior to the good." This view has obviously been altered by Rawls. As Larmore notes,

It is not necessary that we see this separation of the person from his conception of the good as itself representing an ideal of the person, a self prior to the ends that it chooses. That is the Kantian interpretation of the original position. But the modus vivendi view of justice offers a different and more economical rationale. ${ }^{4}$

Rawls's response noted that we need not rely only upon the idea of rationally autonomous persons in the (unjustifiable) sense that Kant understood persons. That is, in 1980 (only slightly before Sandel's critique came out in 1982) and certainly immediately after in Rawls's “Dewey Lectures," we see a shift in thought from an expressivist view - 
one that relies upon or is justified by this Kantian interpretation of persons - towards an emphasis of the modus vivendi view, one that is premised upon pluralism and the need to incorporate a strong but base-level neutrality. While this strain of Kantianism still retains a hold on Rawls's thought - "the desire to express our nature as a free and equal rational being can be fulfilled only by acting on the principles of right and justice as having first priority"5 - still the project of grounding JAF in socio-historical circumstance and relying upon neutral political principles are indications of Rawls's desire and need to account for the social embeddedness thesis. Why political liberalism needs a conception of neutrality I shall discuss below. For now, we need to note that this shift has taken place, one that responds to and answers the communitarian criticism of "contentless" persons.

The second prong of Sandel's argument was that viewing the self as prior to its ends "ignores the phenomena of character and of the intersubjective constitution of the self." That is, liberalism ignores the kinds of attachments to a vision of the good life that we make in our lives that we simultaneously share with others. But again, this criticism has been answered by Rawls. It is essentially a distinction between people as members of a group and members of the state. Citizens "do not view themselves as inevitably tied to the pursuit of the particular conception of the good and its final ends which they espouse at any given time." 7 To Larmore (and I think in his interpretation of Rawls here he is correct), this does not mean that

...our highest personal ideal must be to conceive of ourselves as prior to our ends, without any constitutive attachment to a conception of the good. It means, instead, that the political system treats persons as not necessarily tied to any particular conception of the good, that is, apart from status and ascription.... Outside the political realm, however, things may be different. ${ }^{8}$

Sandel then ignored a significant change in JAF, a change that has placed his critique in doubt: Rawls's recognition of embeddedness, and the adoption of a less expressivist justification of JAF, one that relied more upon a modus vivendi view of moral and 
political conflict, answers many of Sandel's (and MacIntyre's) objection regarding liberalism's lack of embeddedness, e.g., incoherence and incompleteness. Again, we should remember that this view was implicit in Theory and the writings immediately following; it was not until the Dewey Lectures, that is after Sandel's critique was published, that Rawls emphasized this aspect of JAF. But we must take care to note that this is the view that has commanded Rawls's, and arguably liberalism's, attention since then. It is for these reasons that Kymlicka notes "both [Sandel and Rawls] accept that the person is prior to her ends. They disagree over where, within the person, to draw the boundaries of the 'self'..."

\section{MacIntyre Reconsidered}

My critique of MacIntyre in Chapter IV, as compared to that of Sandel, was primarily negative: I noted places where MacIntyre's theory cum critique either misrepresented liberalism, or where he could be viewed as a liberal himself. I approached MacIntyre's critique by noting first how he understands Aristotelian practical rationality to take place in an ideal setting, and then examined how he understands modern liberal practical rationality. I noted some conceptual discrepancies in MacIntyre's analysis cum critique, and gave liberals good reasons to question, if not reject, MacIntyre's prescription.

I then moved to an examination of how MacIntyre understands the person-society through that set of common assumptions, the social embeddedness thesis. There I reached the conclusion that MacIntyre, like Sandel, understands this relation ambiguously: persons in his theory are at times partially embedded, at other times fully so. This embeddedness is important to MacIntyre because he wants to make a very close tie between rationality and morality. But this tie, he claims, can only be understood through an examination of socio-historical practices, like the re-telling of a tale that has become 
mythic in a culture: it is understood by all that share that culture, but might be unintelligible to others from without. I argued there for the point that we should not accept MacIntyre's criticisms because he misunderstands the complexity of liberal thought and rationality, and what this has to do with morality in the modern world; that is, despite MacIntyre's critique of liberalism, he too is a liberal.

This is clear in one of MacIntyre's crucial phrases, "the good life for man is the life spent in seeking for the good life for man, and the virtues necessary for the seeking are those which will enable us to understand what more and what else the good life for man is." 10 It displays MacIntyre's deep-seated yet disguised commitment to plurality and autonomy: that people must be allowed to pursue the good life as they know it to be, and that political society must provide (but not necessarily promote) the conditions for that kind of autonomy. That is, the commitment to goods, goodness, and rationality commits MacIntyre to embrace liberal and individualistic principles, a move he does not wish to make: MacIntyre's dilemma is that he wishes to accord persons freedom, yet does not wish to accord persons that freedom under conditions derived through consequentialist moral reasoning, the only alternative he is capable of seeing. The desire for a sociallyoriented view of intelligibility is over-riding in MacIntyre's view, and that obscures his recognition of the value of change and development - self-determination and liberty - in social and individual lives. That is, "MacIntyre's argument is epistemological foundationalism carried over to the realm of morality."11

What I mean to say is that the communitarian critique is not "all wrong," as some liberal defenders have suggested. There are some points of consensus, and there are certainly some places where the two sides are agreed about some things. (They have been referred to as "rival hermeneuticists" in some aspects.) ${ }^{12}$ How then are we to distinguish 
between these claims, especially when we consider the question of the construction of persons in political society?

I do not intend to evaluate the debate in terms of which side has "won," or "scored the most punches," so to speak. ${ }^{13}$ I have already noted where two representative communitarian theories have not succeeded in their critiques of liberalism: either through Rawls's concessions that had been implied in the theory and emphasized later, or by analyzing the way the rival theories view the social context for the individual. Rather, I wish to go beyond that question, a question that I think is now largely decided. The question before us now is how does political liberalism understand itself, given that there are some things we are agreed upon about persons?

\section{FOUNDATIONS AND LIMITATIONS OF POLITICAL LIBERALISM}

In this section and the next, I will examine the commitment to several ideas that are used to justify liberalism: equality, neutrality and freedom, and freedom's constitutive ideas of autonomy, liberty, and self-determination. ${ }^{14}$ But we must first ask what kind of individual must be presupposed in political theory, and specifically political liberalism. By this I do not mean the specific characteristics of the person (those will be discussed shortly), but rather what can be assumed in order to begin.

\section{Conceptions and Persons}

Political liberalism does not rely upon what Steven Lukes has termed an "abstract" individual: simply a way of conceiving the individual that is not morally neutral. It is more than simply "the relevant features of individuals determining the ends which social arrangements are held...to fulfill...independently of social context." It is more than the idea of persons "having certain sorts of wants and purposes, as acting on certain sorts of 
motives, as having certain interests." Political liberalism must demand more of persons than that. 15

However, liberalism cannot demand too much. Certainly, individuals in modern liberal democracies view the state as resting upon the inter-dependent ideas of consent, representation, and the protection of interests, amongst others; the state responds in a (somewhat) reciprocal fashion. Yet certainly there is some place "in between" these extremes, some conceptual space that persons can be placed in political society, and be more than interest maximizers relying upon institutional limitations to power and the "goodness" of other men?

Steven Lukes and Susan Mendus, each in their own way, have suggested just such a space. ${ }^{16}$ To Lukes, such a person would be

...the source of (yet to be discovered) intentions and purposes, decisions and choices, as capable of engaging in and valuing certain (yet to be discovered) activities and involvements, and as capable of (yet to be discovered) forms of self-development.

It is essentially a view of the person as

...a human being having certain capacities [as opposed to psychological features which determine his behaviour], the degree and form of whose realization is left open for investigation. ${ }^{17}$

So seeing persons as persons in political society requires more than simply attributing to them certain fixed psychological states or universal attributes, e.g., as self-interest maximizers (which is not clearly of itself), as bearers of particular roles, or as only means to an end. We recognize people as individuals when we recognize that we must not view them abstractly - merely as concepts within a theory - but when we recognize that we must abstract from a socially given context that defines persons. ${ }^{18}$ That is, we must acknowledge that there is a social background against which to view people, but that people must be seen at the same time as close to yet removed from that social background. (Mendus describes the condition as that of "distance yet proximity" to society.) ${ }^{19}$ What 
then are the attributes or characteristics of "the person" in political liberalism? What must such a person "look like" in order to be more than merely a political conception?

\section{Dignity and Equality}

A vital plank of liberalism is equality. Many writers, including Rawls, Larmore and Lukes, note that equality essentially rests upon the idea of human dignity, or equal respect. Human dignity has attained "the logical status of a moral...axiom which is basic, ultimate and overriding, offering a general justifying principle in moral argument." 20 Larmore incorporates the idea of human dignity and equality in his norm of equal respect; Rawls notes that at bottom equal respect in turn relies upon self respect which is one of the, if not the, greatest good. ${ }^{21}$

All persons then are deserving of respect in virtue of the fact that they are persons; they meet minimal standards of the person as described by others, they share attributes physical, mental, psychological, political and ethical - with other human beings. This is the distinction that Lukes wishes to draw, a distinction that I think holds.

We praise someone for his particular achievements and we admire someone for his particular qualities or excellences; whereas we respect him as a human being, in virtue of characteristics which he shares with all other human beings. [Further,]...it is the existence of the characteristics, not the degree to which they are possessed or actualized, which elicits the respect. $^{22}$

\section{Liberty}

Liberty is a complex and complicated concept. On most liberal accounts, it consists of at least the following ideas: autonomy, positive and negative freedom, and self-determination. We must keep in mind that we are speaking of political freedom here, not merely psychological, social, or physical (bodily) liberty. 
Positive Freedom. or Autonomy Positive freedom (or autonomy) "derives from the wish on the part of the individual to be his own master." Berlin's characterization is classic:

I wish my life and decisions to depend on myself, not on external forces of whatever kind. I wish to be the instrument of my own, not of other men's, acts of will. I wish to be a subject, not an object; to be moved by reasons, by conscious purposes, which are my own, not by causes which affect me, as it were, from outside. I wish to be somebody, not nobody; a doer - deciding, not being decided for, self-directed and not acted upon by external nature or by other means as if I were a thing, or an animal, or a slave incapable of playing a human role, that is, of conceiving goals and policies of my own and realizing them.... I feel free to the degree that I believe this to be true, and enslaved to the degree that I am made to realize that it is not. ${ }^{23}$

But autonomy has its dangers. To claim to be a free agent and to try to make others aware of their own positive liberty at the expense of their negative liberty is nothing short of tyranny. That use of positive freedom is really an abuse: to be avoided if possible, and to be guarded against at all times. ${ }^{24}$

There are additional restrictions to this concept. Autonomy implies that people are conscious when they make decisions about themselves and their society (e.g., when they vote), and that they reflect upon their choices. Obviously, they must have real or actual choices. Alternatives for self-development cannot be of the lesser-of-two-evils kind, or even a "Hobson's choice," i.e., no choice at all.

Negative Freedom, or Freedom from Coercion. The distinction between positive and negative freedom is the familiar one from Isaiah Berlin. Negative freedom is that idea that answers the question: "What is the [political or social] area within which the subject - a person or group of persons - is or should be left to do or be what he is able to do or be, without interference by other persons?" Positive liberty, a notoriously difficult concept, answers the question: "What, or who, is the source of control or interference that can determine someone to do, or be, this rather than that?"25 
Negative freedom is basically a freedom from, specifically freedom from coercion. "Coercion implies a deliberate interference of other human beings within the area in which I could otherwise act. You lack political liberty or freedom only if you are prevented from attaining a goal by human beings." 26 Negative freedom then is not absolute in the sense that inability to perform a particular task implies a lack of freedom. And it is not absolute in a second sense: absolute license is not a permissible definition of freedom because absolute license - to do anything one might wish - would certainly deprive others of their equal right to negative liberty. "[L]iberty in this sense means freedom from; absence of interference beyond the shifting, but always recognizable, frontier."27 Again, we must remember that it is political liberty we are speaking of.

Generally, theories of liberalism - and political liberalism is no exception here rely upon a conception of negative liberty. But of course it is not as simple as this: "The question has to be whether liberty - in any sense in which liberty is thought to be important - is attacked or undermined whenever a rule of social conduct is enforced." 28 So our conception of liberty must be informed by our social background for at least three reasons: it accords with our historically-derived idea that liberty is not an absolute concept (it has its limitations, e.g., liberty is not license); it allows people sufficient room politically to be self-determinant (discussed next); and it accords with our ideas of minimal political neutrality.

Self-Determination. Self-determination is that idea that if men are to be free, then they must be the authors of their own laws. A person "must himself create or prescribe the law to which he is obedient. (The agent must be independent both of the coercive action and of the will of others.)"29 This does create some tension, as Norman Jacobson points out, in what we call "the human condition": as creature and creator, we experience friction between what we are and what we make..$^{30}$ 
But we must be careful not to confuse or conflate autonomy with common misconceptions of self-determination; we cannot make the concepts identical. Mendus lists three common errors. First, autonomy cannot be merely self-determination because such selfdetermination can, like the conception of positive liberty, quickly turn into repression under the guise of "guiding one's fellows towards freedom." Secondly, autonomy cannot be the mere satisfaction of desires or the presence of self-mastery over one's desires; mere satisfaction is not full enough to account for political liberty. Self-mastery could even be inconsistent, as in conflicting psychological states: I may not always know what I want since sometimes I may want to be a victim which is, of course, not rational as I am not then the master of my desires. Finally, self-determination cannot be considered without any reference to rationality; without it there is no standard or rationale according to which we may judge rational behavior. ${ }^{31}$ Self-determination is most simply the idea that "...I should as far as possible determine and control the course of my life,... and that I should have the opportunity to bring to fruition certain characteristic human excellences." 32

Political liberalism then has a concept of the person that is not merely an abstraction. It is a conception of the person that is based upon the "dignity of persons," or the basis of equality. This equality is not of the kind that demands that goods be distributed equally in order to treat people equally. Rather, it is the idea that because human beings are capable of attaining those characteristics, and because they are characteristics that are at base mutually agreeable and desirable, and because those characteristics help people to attain those goals in their lives (whatever they may be, although not all visions of the good are allowable), we accord these characteristics to persons, and equally so. We accord them respect on the grounds that they can choose and act autonomously, that they require a certain amount of space (privacy) in which to pursue goods, and that they are 
capable of self-development. Respect then entails treating persons as though they are capable of attaining and acting upon this conception of liberty. The denial of any of these kinds of freedom diminishes the freedom of the person (and the conception thereof) in politics. $^{33}$

\section{AIMS AND JUSTIFICATIONS OF POLITICAL LIBERALISM}

Political liberalism is committed to the idea that "we must apply the principle of toleration to the idea of philosophy itself,"34 or that "political principles are to be 'neutral' with respect to controversial ideas of the good." This means that "neutral principles are ones that we can justify without appealing to the controversial views of the good life to which we happen to be committed." 35 What then is the role of neutrality in political liberalism? And what of skepticism, a "traditional" liberal defense? Further, we must ask how political liberalism views rationality.

\section{Skepticism}

There is a "traditional" justification of liberalism that says that we cannot know what is true, or right or good in moral terms, and therefore we should expect the state to enforce or disadvantage any particular conception of the good; skepticism relies upon the idea that "just because ideals and answers to issues may clash does not mean that we should conclude that there is no reason to prefer any of them, and so no government should seek to institutionalize them."36 But this indifference towards particular conceptions of the good does not get us very far.

We need only note two points that distinguish liberalism and skepticism to see why. First, skepticism suggests that there is no epistemological or moral way to judge or evaluate the relative worth of a particular pursuit of the good; indeed, the Benthamite aphorism that "pushpins is as good as poetry" applies. There is no way to distinguish between 
the truth of various positions, says the skeptic, so the state should not rationally attach itself to any particular position: the state should be indifferent between visions of the good life. "Skepticism entails pluralism, whereas objectivism entails intolerance."37

Clearly, the liberal does not seek the truth as an end in political philosophy, but this does not mean that the liberal is committed to being a skeptic. The liberal wants to avoid intolerance, but that does not mean that to the liberal that there is no truth nor objectivity. It is only to stress that truth - and its counterpart objectivity - are less important to the liberal than is the value of allowing people to discover that truth for themselves, or allowing people to choose paths to a good by themselves. The second point then is that "liberalism asserts what skepticism denies - that some values are superior to others."38 As I have shown, that value is liberty. At the heart of things, skepticism is antithetical to other more important liberal tenets; liberalism cannot rely upon a concept that would create an irresoluble conflict at its foundations.

\section{Neutrality}

For similar reasons, we should not think that neutrality depends upon or "collapses into" skepticism. After all, questions of truth - the basis of skepticism - are separate and distinct from questions of importance and belief. ${ }^{39}$ How then does liberal neutrality operate?

What Kind of Neutrality? First, we must note the different kinds of neutrality that are referred to in liberalism. The first is neutrality of purpose or intent, sometimes called procedural, reason-based, or justificatory neutrality. It is a requirement that governments not aim at disbenefiting certain groups of people simply because they have a particular conception of the good, or that the state cannot favor one conception of the good over another. ${ }^{40} \mathrm{It}$ is ultimately a doctrine of restraint, one that historically derives from John Locke's Letter on Toleration: the government should not persecute other religions sim- 
ply for religious reasons because true conversion can only be obtained when arrived at through true inner conviction, and not through force, threats or coercion. The government should refrain from religious persecution as it is ultimately an unreasonable act. ${ }^{41}$ Neutrality of aim, outcome (or consequentialist neutrality), on the other hand, is more pro-active, a more "modern" notion, if you will. Consequentialist neutrality holds that the state cannot promote one vision of the good life over another, or over any others. The state cannot, as a consequence of its actions, work towards disbenefiting or disadvantaging a particular group of peoples simply because they have been identified as a particular group: "The consequences of the laws should not be such as to discriminate against a particular group." 42 More than a doctrine of state restraint, it is a doctrine that licenses limited state promotion of equality to a certain degree, or interference onto the political scene in order to equalize some inequalities.

Two things to note about neutrality of aim or outcome. First, it limits its application only to those conceptions of the good that meet some requirements: they cannot be harmful to the state or to other people within the state, and they must meet some minimal standards, e.g., standards of rationality and normative content. Second, neutrality of aim does not require that all pursuits of the good be equally promoted, or that all succeed. Neutrality of aim at its simplest says that "all should be able to enter the race; but this does not guarantee that all will win or even finish." At base, consequentialist neutrality is a claim quite similar to equality of opportunity.

Political liberalism relies primarily upon a neutrality of aim or procedure (justificatory neutrality). ${ }^{43}$ One reason is Rawls's strong commitments to liberties and primary goods. If Rawls were to affirm a neutrality of aim or outcome, it would not allow sufficient "room" in his theory to accommodate pluralism and primary goods that are so important to his conception of persons. By allowing only certain kinds of goods necessary to various visions of the good life, consequentialist neutrality would necessarily 
exclude a number of pursuits of the good that political liberalism could otherwise include. ${ }^{44}$

Differences in Political Liberalism on the Role of Neutrality. We should note that there are differences in the way justificatory neutrality is formulated by Rawls and Larmore. Referring to what neutrality does rather than how it operates, Larmore says that "political neutrality consists in a constraint on what factors can be involved to justify a political decision. Such decisions can count as neutral only [that decision] can be justified without appealing to the presumed intrinsic superiority of any particular conception of the good life." 45 Further, political liberalism must rely upon a particular form of neutrality that splits the difference between those justifications that rely on comprehensive moral or individualist ideals, and those that consign themselves to a mere Hobbesian modus vivendi. ${ }^{46}$

The differences are these: whereas Larmore emphasizes the procedural aspects of neutrality in political liberalism in order to maintain a neutral attitude towards various conceptions of morality, Rawls emphasizes the importance of normative-laden ideas of the good that can fulfill a person's conception of justice, yet leaves the comprehensive identity (the normative laden ideals) of that person "alone," so to speak. Political liberalism refers only to what is required of people in a political sense, and it justifies this by relying upon a way of neutrally approaching moral conflict. (This is Rawls's method of avoidance, or Larmore's neutral dialogue.) To recall, Rawls distinguishes between procedural neutrality and neutrality of aim, but reminds us that we should not confuse this with consequentialist neutrality. ${ }^{47}$ So we should not confuse neutrality with equal opportunity, nor with the idea that all forms of life be represented in political life.

Instead, Rawls carefully weaves together something like a combination of the two kinds of neutrality: "The state is not to do anything intended to favor or promote any particular comprehensive doctrine rather than another, or to give greater assistance to 
those who pursue it...."48 To make the point clearly: justificatory neutrality is not a justification of liberalism; it is a liberal good - a normative statement of right - that is a reasonable and persuasive one. But it is an aim that allows Rawls (and Larmore, to an extent) to incorporate the idea of dignity of persons and its assumptions regarding equality to operate as a basis of liberalism.

Some Problems with Neutrality. This disagreement over the scope of neutrality does not mean that neutrality should be abandoned as a basic liberal tenet. Indeed, it only highlights the liberal dilemma: "the need for neutrality is created by the fact of diversity [plurality], yet the application of neutrality is possible only on the assumption that diversity is underpinned by unity - at least about the propriety of the neutrality principle itself." 49 As Charles Larmore has noted, "these classical liberal arguments for neutrality will convince, therefore, only those who believe some things about the nature of human flourishing that others will not accept, and for reasons that are not without any merit."50 How then do we reconcile the need to justify liberalism, and yet retain the values of autonomy and neutrality?

Neutrality as an Aim. One answer is that liberalism is ultimately justified not by neutrality, but by autonomy. That is to say, neutrality might perhaps best be thought of not as a justification of liberalism, but as a guiding purpose, an "end result." Neutrality could then be viewed

...as a practical aim of the liberal society - as answering questions about what liberals are for, rather than asking why they are for it....

Instead of dismissing neutrality as an ambiguous and inadequately supported philosophical foundation, we should instead construe it as a guiding principle. ${ }^{51}$

This idea of neutrality as a guiding principle has been explored by Will Kymlicka. To Kymlicka, considering neutrality as the basis for liberalism misconstrues the claims of neutrality and liberalism. Neutrality and the state are not dependent upon a "viable and flourishing culture," nor is it dependent upon the idea of total lack of state assistance; af- 
ter all, if the state is to survive it must promote that particular idea of good - preservation of the state - above all others. The claims of neutrality here are not about differences in the claims of communitarians that present perfectionist visions of the state in opposition to liberally neutral state theories; the disagreement here is about the role of the state as opposed to the role of society. The claims are thus about social as opposed to state perfectionism. Liberals, it must be remembered, are wary of the state and wish to establish limits to state action, not promote state action and assessment of visions of the good. "What the liberal denies is that I should have to give... an account of myself to the state." 52 This is what is meant by using neutrality as an aim of liberalism, as opposed to using neutrality as a justification. This preserves a primary aim of liberal neutrality: that it "does not deny these shared social requirements of individual autonomy but, rather, provides an interpretation of them."53

So neutrality cannot mean that liberalism is neutral with respect to morality. Again, "the point is rather that it claims to be neutral with respect to controversial views of the good life.... A more promising account [of neutrality] is that neutral principles are ones that we can justify without appealing to controversial views of the good life to which we happen to be committed." 54 Being committed to pluralism, liberalism accepts the conditions of plurality, which of necessity is not equally kind to all forms of life. But it does not accept that we base that acceptance of pluralism on individual or comprehensive conceptions of the good life and political morality.

We must find some other basis for political association if we are committed to pluralism; hence Rawls's idea of an overlapping consensus and Larmore's idea of neutral or rational dialogue based upon common ground. Liberalism on this face ultimately relies upon the concept of liberty: that it is better for people to pursue their own way of life than for them to have a way of life thrust upon them. Liberalism ultimately relies upon a normative-laden concept of liberty (in Rawls's, Larmore's, and Mendus's nomenclature 
this is autonomy) in order to justify the entailment of a "full" concept of the person, a coherent account of ethics, and the relation of persons to political institutions.

\section{Rationality}

We can now return to a topic that figured centrally in my critique of MacIntyre: rationality. How does liberalism view rationality? If neutrality is an aim of liberalism, and if freedom (autonomy) best justifies liberalism, then what part does rationality play? What epistemological assumptions are made by liberalism in order to account for persons, but not posit them with a fully-formed idea of "what it is to be a human being"?

Assumptions About Rationality, Liberalism assumes first that rationality means "being self-determined, where self-determination is a function of reasons, not of desires... Autonomy does not consist simply in doing what one wants: it consists in acting rationally, and we need a background against which to decide what counts as rational behaviour."55 We can dismiss the idea that liberalism and liberal people rely upon consequentialist practical reasoning, or simple self-interest maximizers. Lukes would refer to this as economic individualism. ${ }^{56}$ My critique of MacIntyre demonstrated that there is more to modernity that simply accounting for one's interests.

However, another assumption is that society must be comprehensible or transparent: "Intelligible justifications in social and political life must be available in principle for everyone, for society is to be understood by the human mind, not by the tradition or sense of a community."57 So there is a liberal need for social intelligibility; but liberalism "need not insist that everything shall be totally explicable."58 This accords with Rawls's ideas of the constraints upon the concept of right (in particular, the idea of a public conception of rules), and the way those constraints operate in JAF under the historical and social conditions of modern democratic societies, and the five facts of political sociology. 59 It more importantly recalls Rawls's distinction between the reasonable and the rational. 
One way to view this is suggested by Thomas Nagel. First, we must remember the distinction between justification and persuasion. Justification is a normative concept, i.e., one that implies a standard or rationale against which to evaluate things; persuasion is the art of rhetoric, or "winning the debate" regardless of reasons. So "arguments that justify may fail to persuade, if addressed to an unreasonable audience; and arguments that persuade may fail to justify." 60 (The distinction is obviously between persons and the beliefs they hold as well as the reasons they hold those beliefs.)

Secondly, the principles of justice are right because they are accepted; they are not accepted because they are independently morally right. Principles of justice meet a condition of minimal rationality: given a certain common moral motivation in addition to their more personal, private, and communal ends, the standard of rationality in politics is not what principles or institutions people will actually accept, but what would be reasonable for them to accept. This is a lower threshold for the presumption of rationality; it is lower than theories that rely upon commonality (e.g., communitarianism) and convergence (e.g., absolute sovereignty) as a basis for justification and intelligibility, and certainly lower than comprehensive theories of morality (e.g., religion). "What is reasonable to accept" is to be able to accept less than "the most reasonable option."61 It is a basis that all are capable of accepting, not a basis that will necessarily persuade all that it is acceptable.

Nagel calls this public justification. Rawls, after Kant, calls this (or something very close to it) free public reason. ${ }^{62}$ It requires at least two things:

[A] disagreement which falls on objective common ground must [first] be open-ended in the possibility of its investigation and pursuit, and [second] not come down finally to a bare confrontation between incompatible points of view. I suggest that conflicts of religious faith fail this test, and most empirical and many moral disagreements do not. ${ }^{63}$

A minimum moral conception of rationality is needed in order to attain moral consensus as well as a minimum political conception of justice. Rationality then plays a key 
part in allowing some things such as civil rights, civil liberties, reasonable expectations of predictability in government actions, etc., to be considered essential to people in the political arena, while other things such as personal faith and belief systems are not. They are not essential because there is no way that such faith- or morally-based reasons could attain anything like consensus or command authority: lack of compatibility and intelligibility preclude this. Such arguments would fail to persuade, but more importantly they would fail to be arguments based upon reason.

What I want to say is that rationality occupies a similar place in the rationality-human nature question regarding the political conception of the person as does neutrality in the neutrality-autonomy relation. As neutrality is an aim in the state-to-person relation, rationality is an aim of persons in political liberalism; it is a constraint upon the actions they can take and justify. This conception of rationality does not rely upon the substance of those beliefs; i.e., it need not be normatively-laden, although some conceptions of rationality will inevitably be tied to goods and goodness. It does not make a conception of rationality dependent or determinant upon a conception of the good; it makes it contingent. Liberalism is of course only one conception of the good amongst many. But it is the manner in which that good is justified that liberalism draws its strength, and allows people their comprehensive conceptions of the good to flourish, without resorting to exclusionary definitions of persons and groups that communitarianism does rely upon.

The assumptions of autonomy as a basis for liberalism and the way that liberalism views individuals are first, that human beings are capable of forming a concept of rationality or a way of viewing life plans in order to make decisions about things that directly influence either them or their primary social goods. Secondly, individuals are capable of acting upon and revising a conception of rationality based in large part on the idea of (the concept of) rationality itself. Finally, this concept of rationality is agreeable because it is 
mutually acceptable. This is a more full conception of the person-rationality link than is commonly thought to hold in liberalism, but it is one that Rawls explicitly embraces. 64

\section{AIMS AND NORMS OF POLITICAL LIBERALISM}

\section{The Norms of Political Liberalism}

Political liberalism incorporates these minimal moral conceptions of persons and neutrality by referring to two basic, constitutive ideas, or norms. Charles Larmore has clearly expressed these norms as equal respect and rational dialogue.

Equal Respect. 65 This is the idea that people should be accorded equal respect and treatment not simply because they are "endowed with inalienable rights"; it is also more than the Kantian maxim to treat people "never as a means only but also as ends in themselves." The idea is rather that we treat people with equal respect because we recognize that people are capable of acting "on the basis of reasons" (they provide us with explanations as to the motivation and purpose for action), and because nobody who can offer a good reason for action can offer a good reason for the application of force to coerce another person into doing something they do not want to do. So we can distinguish between "political principles with which we believe people can be legitimately forced to comply," and those that are simply the exercise of force for coercion's sake. ${ }^{66}$ Conversely, equal respect holds that we must treat people with respect because they are beings capable of reason: "To respect another person as an end is to insist that coercive or political principles be as justifiable to that person as they are to us. Equal respect involves treating all persons, to which such principles apply, in this way."67

Rational Dialogue. The second norm is called "rational dialogue." It assumes that conflict is part of - one of the prices of, if you will - the fact of plurality and that governmental policies allow the existence of multiple yet disparate conceptions of the good to co-exist (pluralism). When issues arise that involve clashes between such disparate 
conceptions of the good, rational dialogue recommends that people should retreat to some sort of neutral ground, i.e., the beliefs that they do share or might find in common, "in order either to (a) resolve the disagreement and vindicate one of the disputed positions by means of arguments which proceed from this common ground, or (b) bypass the disagreement and seek a solution of the problem on the basis simply of this common ground."68

Equal Respect and Rational Dialogue: "Continuing the Conversation"" Now a quick objection to this - a common communitarian objection - can be readily foreseen and forestalled: what if retreating to that neutral ground means temporarily denying one's beliefs that must be held in order to be a member of a particular group or community? Questions of intelligibility aside, we must then refer to rationality and those things we do share: a commitment to pluralism, and freedom and all that it entails. We therefore need not respect the ideas and beliefs that people hold in the same way that we respect the people as people who hold those beliefs.

So we need not accord the ideas that people hold the same kind and degree of respect that we accord to people. Rational dialogue is a way to agree upon those ideas that are worthy of respect and contribute to rational dialogue in order to continue talking and associating with one another without resorting to force. There is then an important difference between respecting one's opponent and respecting the ideas they hold and use. "Tolerance of others who hold what one takes to be false ideas is one thing; tolerance of the ideas themselves is quite another." 69 As Jean Hampton notes, even as confirmed a rationalist as Socrates would only have adopted the former definition. ${ }^{70}$

One way to "continue the conversation" on matters vital to politics is then to avoid those areas about which we can have no reasoned agreement (or unreasonable disagreement). This should not be taken to mean that people will simply "agree to disagree": it is more than Pascal's dictum that "I may disagree with what you say but 
will defend to the death your right to say it." Obviously in such a situation, the conversants have arrived at a point in the conversation where conclusions and premises are either incompatible or incommensurable, and nothing productive can result from the conversation, i.e., there would be no useful conclusions. That is not the meaning of "stepping away from the conversation," or applying the idea of neutrality to philosophy itself. Rather, what is meant is that there are some areas of life - some concepts, some discussions of goods, resources, and power and access vital to all forms of life - that will be controversial. Given that these are necessary to all forms of life, and given that there will be competition of resources over them, what political liberalism offers is a way to continue the conversation, by removing from the agenda those moral dictas and precepts that govern people's lives.

This is necessary for several reasons, as both Rawls and Larmore have noted. Amongst others, it is because people's conceptions of the good can at times be so full that they are not able to envision other forms of life as legitimately holding purchase here on this earth; or sometimes people's conceptions of the good are full to the point that they do not accept other reasons as good reasons; or even that conceptions of the good are at base fundamentally incompatible. Political liberalism removes these ideas from the agenda in order to accord the people who hold those ideas equal respect, but not judge the ideas they hold with any lack of respect by acceding or not acceding to their demands.

The obligation of equal respect then is to treat others equally without regard to the opinions or beliefs they hold. Larmore notes that this understanding of equal respect in political liberalism is much like the notion of mutual respect as found in Hegel's work. "To have respect for a person is to view him as capable of elaborating beliefs that we would respect." 71 The conversation can continue about those things that are necessary and vital to speak about and make decisions regarding political association, and it accords equal respect to all forms of life by not disallowing people to enter the conversation. It 
accords equal respect by limiting the subject of conversation, so to speak, about those things that are important to us and by laying some ground rules for debate. It accords neutrality by allowing all to enter the conversation.

An Objection To Political Liberalism: Separating Persons and Ends. An objection to this strategy is that it divides the person from their attributes, that it denigrates the link between what we believe and what we do, and how those are essential to understanding who we are. To proceed in the way political liberalism recommends is to assume that we can separate people from their beliefs, something that cannot be done. The reply is that this fundamentally misunderstands the norm of equal respect and its basis in human dignity.

Political liberalism can be understood as the view that under the reasonably favorable conditions that make constitutional democracy possible, political institutions satisfying the principles of a liberal conception of justice realize political values and ideals that normally outweigh whatever other values oppose them....

Of course, there can be no guarantee of stability. Political good, no matter how important, can never in general outweigh the transcendent values-certain religious, philosophical, and moral values-that may possibly come into conflict with it....

[Political liberalism] elaborates a political conception working from the fundamental intuitive idea of society as a fair system of cooperation....The thought is not that primary goods are fair to comprehensive conceptions of the good associated with such doctrines by striking a fair balance among them, but rather that they are fair to free and equal citizens as persons affirming such conceptions. ${ }^{72}$

This accords with (and perhaps even instigated) Rawls's changed view of the scope or breadth of justice as fairness, and the roles that comprehensive and political conceptions play within an individual's view of life:

We now assume citizens hold two distinct views; or perhaps better, we assume their overall view has two parts. One part can be seen to be, or to coincide with, a political conception of justice; the other part is a (fully or partially) comprehensive doctrine to which the political conception is in some manner related. ${ }^{73}$

(I find it somewhat puzzling that this "new" interpretation of persons would either: (1)

have to be formally acknowledge or announced by Rawls at this point in the development 
of the theory (it would seem to have been implied as early as 1985); or (2) that it would not have been explicitly noted before, either by Rawls or other theorists. Be that as it may, the distinction now holds.)

\section{Moral and Personal Ideals: Kantian Ideals?}

What consequences has this conception of the role of neutrality as an aim of liberalism for liberalism's foundation in autonomy? First, we must recall the source of Rawls's idea of autonomy. It is, of course, Kantian but not necessarily from Kant; there are points of disagreement between Kant and Rawls, places where Rawls must necessarily disagree with Kant's view of persons and the world (Kant's metaphysical view). ${ }^{74}$ (These differences are basically that Rawls does not endorse Kant's use of a phenomenal self that is known through reason; rather, persons have a conception of reason that informs their place as persons in political society.) Significantly, one area of agreement between Rawls and Kant - a part of Kant's theory that Rawls adopts - is the categorical imperative: roughly, that one should never treat people as a means only, but always as ends in themselves. Kant believed (and we can see that Rawis and Larmore agree with Kant) that the personal idea of autonomy should form an indispensable part of political liberalism. Kant's idea of personal autonomy was supported by two beliefs, only the first of which is necessary for the contemporary theory of political liberalism that Rawls and Larmore endorse.

1. The scope of moral obligations is categorical, binding upon us whatever our empirically conditioned interests or desires.

2. The empirically unconditioned scope or morality implies that we must have an empirically unconditioned motivational basis for heeding its demands. ${ }^{75}$

Larmore gives us good reasons to accept only the first (in qualified form) and not the second belief supporting the idea of autonomy. But he also notes that Kant ignored, for the most part, the idea of a person's embeddedness within a culture: that "we cannot 
come to know or believe what we morally ought to do, apart from a history of training and socialization."76 It is because Rawls and Larmore wish to account for social embeddedness that they can properly eschew the second belief, yet hold onto the first as formative in the conception of persons.

Complex and Conflicting Moral Claims. ${ }^{77}$ What kind of training does Larmore mean? It is the kind of moral training that most everyone grows up with and learns to recognize, but do not necessarily learn to clearly distinguish. Larmore notes three distinct and separate principles that are often found when we consider moral conflicts. These are the conflicting claims of the principles of partiality, consequentialism, and deontology.

Deontology we have already seen. It requires that we treat people in certain ways regardless of circumstances, that we never do things to people even if acting in that way will do "more good" or "less evil." Partiality refers to those relations we hold empirically with other people, or with regard to (in virtue of) some special relation: family, friends and legal relations are examples here. Consequentialism (in its simplest form) requires that our actions do the most good or the least evil in any situation; similar to the idea in some theories that view people as utility-driven beings or rational self-interest maximizers, consequentialism holds that our morals should as a sum total produce the greatest "amount" of good, or conversely the least "amount" of evil.

Now these general principles or ways of viewing moral judgments and decisions are often in conflict. But there are some priority rules. Deontological principles are the base level: we must never go below this level of ethics, for to do so would be to deny liberty and equality to others. So in situations where deontological and partiality-oriented moral judgments would conflict, we must side with deontology: there are simply some ways that we treat people regardless of circumstances. It is the dilemma that Antigone faced and resolved: there are simply some ways that we treat humans regardless of commands and state allegiances. 
Conflicts between consequential and partiality-oriented judgments are a little more difficult, though. Here we can note that consequentialism requires more of us than any relation that simply happens to hold; it is a more flexible doctrine, but one that still demands a great deal. The preference for consequentialism over partiality is not meant to disparage those relations. It is rather intended to point out the burdens of partial relationships when considering questions of justice. It is a dilemma of the sort that Sartre's fictional younger son could not resolve: to join the resistance, or stay with and protect his mother.

But conflicts between deontology and consequentialism are of a different sort: they are not fundamentally ambiguous, but their outcomes can be uncertain. Certainly, some situations will be clear; but others will not. Even distinctions such as duty or conviction on the one hand, and responsibility on the other might not help; neither might distinctions between agent-relative and agent-neutral responsibilities. (Larmore's example is that if you do not kill one person, an extortioner will kill ten. $)^{78}$ In these kinds of cases, we must suspend judgment until a decision can be reached by following the constraints of these moral principles.

Like Steven Lukes, Larmore does not claim that following these principles will make moral decisions and judgments any more palatable, nor can these principles themselves be backed up by a lower-level, more fundamental appeal to an objective rationale: "These fundamental moral commitments do not admit...of any justification at all. Nor are they 'absolute presuppositions,' except in the sense that we cannot understand what it would be to be moral agents and not to hold them fast. They set the limits of moral intelligibility." 79 What is important here is that political liberalism is able to account for these moral principles, and is able to render these principles coherent and applicable to our understanding of persons in a moral and political world. But even though persons (and the state) in political liberalism are "bound" by the limits of 
neutrality and rationality, this does not render these moral principles powerless. Political liberalism is a way to conceptualize the individual in order to preserve those moral and ideas and notions about people that are essential for our political understanding of ourselves and our account of justice.

\section{CONCLUSION}

In this chapter, I have shown how the liberal and communitarian positions are similar in some ways and different in others with regard to a political conception of the person. Further though, by examining the tenets of liberalism and discovering the aims of liberalism, I have demonstrated that political liberalism has a fuller conception of the person than Rawls had originally proposed in Theory, a conception makes sense of our political and moral conception of persons. This conception renders the way we view people in politics and the way we must view them coherent and sufficient, even if not always and at all times consistent. Political liberalism views persons as autonomous beings capable of decisions, yet constrained by conditions of the physical, political, and ethical world. ${ }^{80}$

I have shown how the person as conceived in political liberalism is able to refute communitarian claims of incoherency by showing how liberals do understand the person: how the constitutive concepts of liberty and equal respect make up the person in political liberalism. I have also shown how persons so conceived refute the other claim of insufficiency by showing how and why such implicit concepts make sense when we do consider persons in politics: we refer to moral disputes, not epistemological ones, and that political liberalism accounts for those ways we view moral conflict by incorporating those conflicting moral principles into the very idea of neutrality.

In the conclusion, I will point to some differences between the two primary champions of political liberalism that I have discussed here, Rawls and Larmore, and 
show which reading of the theory, given its aims and desires, is more acceptable and tenable. I will conclude by again noting why a political conception of persons is important in politics. 


\section{NOTES}

${ }^{1}$ Ludwig Wittgenstein, Culture and Value, trans. Peter Winch (Chicago: The University of Chicago Press, 1980): 60e, 30e.

2 David Miller, “The Resurgence of Political Theory,” Political Studies 38 (1990): 429.

3 Theory, 176-79; Allen Buchanan, Marx and Justice, Marx and Justice (Totowa, NJ: Rowman and Allanheld, 1982): 111; Chandran Kukathas and Philip Pettit, Rawls: A Theory of Justice and its Critics (Stanford, CA: Stanford University Press, 1990). 44-47. 124.

${ }^{4}$ Charles Larmore, Patterns of Moral Complexity (Cambridge: Cambridge University Press, 1987):

5 Theory, 574.

${ }^{6}$ Larmore, Patterns, 122.

7 John Rawls, "Kantian Constructivism in Moral Theory: The Dewey Lectures 1980," The Journal of Philosophy 88 (1980): 544.

${ }^{8}$ Larmore, Patterns, 125; emphasis added.

9 Will Kymlicka, "Liberalism and Communitarianism," Canadian Joumal of Philosophy 18 (1988): 192. Liberalism, Community, And Culture (Oxford: Oxford University Press, 1989): 55-6. 219.

${ }^{10}$ Alasdair MacIntyre, After Virtue, 2d ed. (Notre Dame, IN: Notre Dame University Press, 1984):

11 Larmore, Patterns, 29.

12 Patrick Neal and David Paris, "Liberalism and the Communitarian Critique: A Guide for the Perplexed," Canadian Journal of Political Science 23 (1990): 422.

13 The literature assessing the debate between the two camps is voluminous. This "second-order" debate, or the debate about the debate, has taken on something of a life of its own. The following list of articles in this secondary debate, listed in no particular order, has been helpful: Allen E. Buchanan, "Assessing the Communitarian Critique of Liberalism," Ethics 99 (1989): 852-882; Amy Gutmann, "Communitarian Critics of Liberalism," Philosophy and Public Affairs 14 (1985): 308-323; Nancy N. Rosenblum, Another Liberalism (Cambridge, MA: Harvard University Press, 1987); Robert B. Thigpen and Lyle A. Downing, "Liberalism and the Communitarian Critique," The American Journal of Politics 31 (1987): 637-655; Robert B. Thigpen and Lyle A. Downing, "Liberal and Communitarian Approaches to Justification," The Review of Politics 51 (1989): 533-550; James S. Fishkin, "Liberal Theory: Strategies of Reconstruction," in Liberals on Liberalism, ed. Alphonso J. Damico (Totowa, NJ: Rowman and Littlefield, 1986): 54-64; William A. Galston, "Liberalism and Public Morality," in Liberals on Liberalism, ed. Alphonso J. Damico (Rowman and Littlefield, Totowa, NJ: 1986): 129-147; Bruce Ackerman, "Neutralities," in Liberals on Liberalism, ed. Alphonso J. Damico (Totowa, NJ: Rowman and Littlefield, 1986): 29-43; Stephen Salkever, “'Lopp'd and Bound”: How Liberal Theory Obscures the Goods of 
Liberal Practices," in Liberalism and the Good, ed. R. Bruce Douglass, Gerald M. Mara, and Henry S. Richardson (New York: Routledge, Chapman, and Hall, Inc., 1990): 167-202; Jeffrey Paul and Fred D. Miller, Jr., "Communitarian and Liberal Theories of the Good," The Review of Metaphysics 43 (1990): 803-30.

Other theorists wish to go further and "bridge the gap" (as it were) between the two theories: Ralph Ellis, "Toward a Reconciliation of Liberalism and Communitarianism," The Journal of Value Inquiry 25 (1990): 55-64; and Patrick Neal and David Paris, "Liberalism and the Communitarian Critique: A Guide for the Perplexed," Canadian Journal of Political Science 23 (1990): 419-440.

There is, additionally, a great deal of literature dealing with the "larger" problem of how to conceive of the idea of political theory itself, a question that is being revised as the assessment of the debate and the effect of Rawls's theory and other liberal theories are evaluated. In this vein, Kurt Baier asks what the general aims of political philosophy are with relation to justice: Kurt Baier, "Justice and the Aims of Political Philosophy," Ethics 99 (1989): 771-790; Jean Hampton asks, in an Hobbesian vein, whether political philosophy should be done without metaphysics, and the possibility of such a project: Jean Hampton, "Should Political Philosophy Be Done without Metaphysics?" Ethics 99 (1989): 791-814; Gerald Doppelt inquires into the coherency of Rawls's position by examining his faithfulness to Kant: Gerald Doppelt, “Is Rawls's Kantian Liberalism Coherent and Defensible?" Ethics 99 (1989): 815-851; Kenneth Schmitz, in a series of articles, inquires into the historical and metaphysical foundations of justice and political philosophy: Kenneth Schmitz, "Community: The Elusive Unity," The Review of Metaphysics 37 (1983): 245-64; "Metaphysics: Radical, Comprehensive, Determinate Discourse," The Review of Metaphysics 39, (1986): 675-94; "Neither With Nor Without Foundations," The Review of Metaphysics 42, (1988): 3-25); and John Wallach asks (in an historical context) about the tasks of political theory as seen by the two sides in the debate: John R. Wallach, "Liberals, Communitarians, and the Tasks of Political Theory," Political Theory 15 (1987): 581-611.

The "boxing metaphor" is from Ellis, "Toward a Reconciliation," 56-7.

14 I rely to some extent upon the analyses of liberalism and individualism undertaken by Charles Larmore in Patterns of Moral Complexity, Steven Lukes in Individualism (London: Basil Blackwell, 1983), and Susan Mendus in Toleration and the Limits of Liberalism (Atlantic Highlands, NJ: Humanities Press International, Inc., 1989). However, I must make some linguistic clarifications here. The terms liberty, freedom, and autonomy are rather loose ones, particularly in political theory. I will therefore, for the purposes of discussion in this section, adhere to Lukes's use. There are some obvious clashes here, particularly between Lukes's use and Mendus's application of the terms (thankfully, each are consistent in their applications!): where Mendus uses the term "autonomy," Lukes uses "liberty." Both uses are intended to be broad, inclusive, or composite terms. For Mendus, autonomy is composed of positive and negative liberty, rationality, and self-determination; for Lukes, liberty is composed of autonomy (which is itself composed of positive and negative freedom; even "freedom" and "liberty" are interchangeable on some analyses) and self-determination. Rationality plays a different, distinct role in his analysis.

15 Lukes, Individualism, 73, 146.

16 While their analyses each point towards a socialist view of persons that would surpass liberalism, still their thorough examinations of the subjects are useful in describing some of the conceptual and practical limits and limitations of modern liberalism.

${ }^{17}$ Lukes, Individualism, 146.

18 ibid., 147.

19 Mendus, Toleration. Mendus's discussion of the liberal need for "distance yet proximity" is in chapter 4, 69-110, but esp. 95-7 ("The Development of Autonomy"), and 102-110 (“Autonomy and Toleration"). 
${ }^{20}$ Lukes, Individualism, 51.

21 Rawls's conception of dignity and self-respect as bases of persons can be found in Theory, 440, 544-46; it is expanded in The Tanner Lectures on Human Values iii (Cambridge: Cambridge University Press, 1982), lecture 2, "The Basic Liberties and Their Priority," 32-39, and again referred to in the political conception of persons in "Justice as Faimess: Political Not Metaphysical," Philosophy and Public Affairs 14 (1985): , esp. 231-45.

22 Lukes, Individualism, 126; emphases original.

23 ibid., 23.

24 ibid., 24-26.

25 Sir Isaiah Berlin, "Two Concepts of Liberty," in Liberalism and Its Critics, ed. Michael Sandel (New York: New York University Press, 1984): 15.

26 ibid., 16; notes omitted.

27 ibid., 19; emphasis original.

28 Jeremy Waldron, “Theoretical Foundations of Liberalism," The Philosophical Quarterly 37 (1987): 133. We should recall that Rawls's revised principles note that liberty (of choice and the capacity for rationality) must be preserved for the sake of liberties (guarantees of freedom to act in certain sociallysanctioned ways) or their potential, as opposed to the preservation of liberty merely for the sake of liberty (full autonomy unbound by rationality); Rawls, "The Basic Liberties and Their Priority," 5.

29 Mendus, Toleration, 89.

30 Norman Jacobson, Pride and Solace: The Functions and Limits of Political Theory (Berkeley, CA: University of California Press, 1978), 1-2.

31 Mendus, Toleration, 94-5.

${ }^{32}$ Lukes, Individualism, 130.

33 Lukes, Individualism, 125-37.

34 John Rawls, "Justice as Fairness: Political Not Metaphysical," Philosophy and Public Affairs 14 (1985): 223-51, at 231.

35 Larmore, "Political Liberalism," 341.

36 Larmore, Patterns, 51.

37 Mendus, Toleration, 76. See also John Rawls, "The Idea of An Overlapping Consensus," Oxford Journal of Legal Studies 7 (1987): 22-23.

38 ibid., emphasis added. 
${ }^{39}$ Mendus Toleration, 82.

40 Statements of liberal neutrality are almost as numerous as there are theorists. However, this formulation is from Mendus, Toleration, 130, 143.

41 See Mendus's discussion, chapter 2, chapter 4 (esp. pp. 79-88), and chapter 5 (esp. pp. 129-39), where the point is made much more clearly.

42 This is Mendus's quotation of Lord Scarman; ibid., 130.

43 Larmore Patterns, 44, "Political Liberalism," 346; Kymlicka, “Liberal Individualism and Liberal Neutrality," esp. 883-84.

${ }^{44}$ On this, Kymlicka's discussion is quite clear. See especially Kymlicka, "Liberal Individualism and Liberal Neutrality," passim, and "Liberalism and Communitarianism," passim.

45 Larmore, Patterns, 44.

46 Larmore, "Political Liberalism," 346. This point is made several times throughout Rawls's third period of articles, but especially in "Justice as Fairness: Political Not Metaphysical," and "The Domain of the Political and Overlapping Consensus," New York University Law Review 64 (1989).

47 John Rawls, "The Priority of the Right and Ideas of the Good," Philosophy and Public Affairs 17 (1988): 263.

48 ibid., 262.

${ }^{49}$ Mendus, Toleration, 88.

50 Larmore, Patterns, 52.

51 Larmore, "Political Liberalism," 113.

52 ibid., 893-95, 898.

53 ibid., 899.

54 Larmore, “Political Liberalism,” 341.

55 ibid., $90,91$.

${ }^{56}$ Lukes, Individualism, 88-93.

57 Jeremy Waldron, “Theoretical Foundations," 135.

58 Mendus, Toleration, 151.

59 See, e.g., Rawls, Theory, § 23, pp. 130-36; "Overlapping Consensus," 22ff; and "The Domain of the Political and Overlapping Consensus," New York University Law Review 64 (1989): 234. 
60 Thomas Nagel, "Moral Conflict and Political Legitimacy," Philosophy and Public Affairs 16 (1987): 218.

61 ibid., 218-22.

62 John Rawls, “On the Idea of Free Public Reason," unpublished paper, 1988, at 1.

63 Nagel, "Moral Conflict and Political Legitimacy," 232.

${ }^{64}$ Rawls, “Political, Not Metaphysical," pp. 239-44.

65 Larmore, Patterns, 9. In both Patterns and in "Political Liberalism," Larmore introduces these ideas in the reverse order, i.e., rational dialogue is the first norm and equal respect is the second. I have reversed their presentation because while these two norms are inter-dependent, I feel that the norm of equal respect is the more fundamental of the two.

66 Larmore, Political Liberalism, 348.

67 ibid., 349.

68 ibid., 347. 811.

69 Jean Hampton, "Should Political Philosophy Be Done Without Metaphysics?," Ethics 99 (1989):

70 id.

71 Larmore, Patterns, 64.

72 Rawls, "The Priority of Right and Ideas of the Good," 275-76; emphases added.

73 Rawls, "The Domain of the Political and Overlapping Consensus," 249; footnote omitted.

74 Many of the differences are pointed out in Rawls's "Kantian Constructivism in Moral Theory," 51619; also "Justice as Fairness: Political Not Metaphysical," 224, n. 2.

75 Larmore Patterns, 84.

76 ibid., 89.

77 This section is basically a summary of Larmore's argument in Patterns of Moral Complexity, chapter 6.

78 ibid., 146.

79 ibid., 150. Lukes, ibid. 
80 The terms incomplete, insufficient, and incoherent are from Alphonso Damico's characterization of liberal criticisms. "Introduction" to Liberals on Liberalism, ed. Alphonso J. Damico (Rowman and Littlefield, Totowa, NJ: 1986): 1-2. 


\section{CONCLUSION}

To be sure there is justification; but justification must come to an end.

Ludwig Wittgenstein ${ }^{1}$

We have seen that the theory of political liberalism has been a response by theorists concerned with the manner in which our moral theories and precepts are accounted for in our political and social structure. Additionally, political liberalism has responded to these concerns expressed as criticisms both from theorists within the liberal tradition, and from theorists outside that tradition, the communitarians. In these responses, though, we can see that political liberalism has itself responded in two different ways: by relying upon the idea of neutrality, or by relying upon the idea of liberty.

How then does political liberalism resolve this fundamental dispute? While I cannot give a full answer, I can point to a few reasons why I think (in addition to my argument in Chapter V) political liberalism must ultimately rely upon liberty and not neutrality for a coherent and defensible justification.

\section{RAWLS OR LARMORE? LIBERTY OR NEUTRALITY?}

Rawls views social institutions as a means of protecting individuals by helping to ensure that they are treated fairly in society, that they are treated equally in questions of distributive justice. He does this by relying upon an heuristic idea (the OP) from which people are set on equal footing (the veil of ignorance), from which they base their decisions about themselves, and from which they choose principles of justice and association.

In so doing, Rawls relies upon the idea of liberty. It is primarily an idea of negative liberty, or "freedom from." But to help ensure that people as persons (as distinct from a 
political conception of persons) can have and pursue a conception of the good life, they must have positive liberty, or "freedom to." Political liberalism must then remain neutral in certain ways with regard to people's visions of the good. That is to say, negative liberty plays a part in the political conception of persons. While it assumes that persons are capable of positive liberty, it says little about how that liberty can be exercised except that it cannot be exercised in such a way as to deny others the same kind of equal liberty: "Each person has an equal right to a fully adequate scheme of equal basic rights and liberties, which scheme is compatible with a similar scheme for all."2

This raises the rather thorny issue of a distinction that communitarians are wont to make: that liberalism relies upon a false distinction between public and private, between citoyen and homme. That is an issue that I have addressed only peripherally in my discussion, at best. But for our purposes, we must note that in moving from JAF to political liberalism, Rawls has de-emphasized the Kantian nature of persons, choosing instead to emphasize the structure of JAF within democratic society, a view that relies upon the idea summed up in the phrase "a modus vivendi view." One way to view this is suggested by Larmore: by reviewing the question of persons prior to their ends.

Citizens..."do not view themselves as inevitably tied to the pursuit of the particular conception of the good and its final ends which they espouse at any given time." This does not mean that our highest personal ideal must be to conceive of ourselves as prior to our ends without any constitutive attachment to a conception of the good. It means, instead, that the political system treats persons as not necessarily tied to any particular conception of the good, that is, apart from status and ascription.... Outside the political realm, however, things may be different. There, as Rawls notes, people "may have attachments and loves that they believe they would not, or could not, stand apart from." This is the difference between citoyen and homme that liberalism promotes as a sort of institutionalized myopia, and only the modus vivendi conception of justice makes it intelligible. ${ }^{3}$

How then, if political liberalism is more concerned with the basic structure as opposed to the person, can we say that it successfully accounts for the way we treat people?

I have responded to this objection by noting the manner in which people are viewed in 
political society: as a society that is committed in a deep sense to the idea of justice, we must structure and conceive of our institutions in such a way that those institutions account for the basic social unit, the person. That is, political liberalism must be based upon the assumption that Rawls makes: persons as beings capable of respect and therefore deserving of it. (I do not mean to imply that political liberalism relies upon an idea of methodological idealism as described by Steven Lukes.) ${ }^{4}$ Neutrality then does not play a part in the justification of liberalism; it is an aim, and an important one at that. But it is not a justification of liberalism, nor can a justification of liberalism rely solely upon neutrality.

How then do we understand Larmore's insistence that political liberalism is, to a degree, based upon the idea of neutrality, specifically a "neutral justification of political neutrality"? I would respond in the same way that Charles Larmore has responded to James Fishkin's review of Larmore. A justification of political liberalism "is neutral in that the moral norm of equal respect, on which it rests, is compatible with the wide range of views about the good life on which reasonable people disagree." But I would not say, as does Larmore, that "the two norms of rational conversation and equal respect lie at the same level, neither being derived from the other." 5

I have indicated reasons why we should consider the norm of equal respect as more fundamental than rational dialogue: because rational dialogue must assume that persons have an concept and a conception of rationality, and that we respect those persons with whom we engage in dialogue because we (1) respect them as persons in a basic sense, and (2) we consider that their being able to provide good reasons (if not necessarily persuasive ones) accords them equal respect as persons. Again, that is to say nothing of the ideas they hold: if we can trust Plato, then we can be sure that Socrates tolerated a great deal of stupidity and hard-headed opinion in his conversations with others. But that did not preclude Socrates from speaking with others, it did not prevent him from 
continuing the conversation. His purpose was, to a great extent, predicated upon being able to continue the conversation if not only to teach, but to associate and learn as well.

I do not mean to imply here that politics, despite prior claims to the contrary, is based upon the idea of a search for truth or knowledge. Certainly some will eschew knowledge, if not run from truth; others will (try to) embrace both. But I do mean that politics cannot be based upon that search for two reasons, as we can see is the case in Rawls's theory.

Political liberalism is not "true" in that it is some doctrine that we should rationally accept, whether or not we agree with it; nor is it "true" in the sense that it is simply one that people in Western society would agree upon because it is a socio-historically derived theory. To rely upon such slight reasons would be to denigrate the place and importance of theory in our social structure. Rather, the rational acceptability of political liberalism is based upon the idea that it is not based upon those ideas of truth and knowledge privy only to those who have accepted some basic tenet of faith, or who have devoted their lives to some search for "the truth."

To secure this agreement we try, so far as we can, to avoid disputed philosophical, as well as disputed moral and religious, questions.... We do this not because these questions are unimportant or regarded with indifference, but because we think them too important and recognize that there is no way to resolve them politically.... Philosophy as the search for truth about an independent metaphysical and moral order cannot, I believe, provide a workable and shared basis for a political conception of justice in a democratic society. ${ }^{6}$

\section{BEYOND THE DEBATE OVER PERSONS}

I have presented in this thesis a defense of political liberalism through an ontological analysis of the terms of debate by considering the conception of persons that are articulated by the theories of political liberalism and communitarianism. I have essentially argued against the communitarian position not only by arguing for liberalism, but also by 
showing how communitarianism, despite a similar basis, misunderstands the foundation and claims of liberalism.

But we must remember that these theories are simply the current way of arguing; it is an ongoing discussion that recalls the Hegelian response to Kant's moral philosophy. And like that debate, there are presently no clear winners and no clear losers. But that way of comparing these different periods does not accurately represent the issue: to say "that was then and this is now" is to miss the point of the debate. We should recall that even during Kant's time (and especially after) liberals were themselves not agreed as to the meaning of the terms of debate, and were even less certain of the way that persons should be treated in a democratic constitutional order, let alone the question of how individuals are to operate in such a regime. One need only read the records of the U.S. constitutional convention and the ensuing ratification debates to note this truism.

Perhaps, on a larger, more "sociological" view, the communitarians have a claim that can be substantiated: liberalism without an epistemology is incoherent or undesirable, and leaves us thoroughly confused as to who we are and what we want. I say "perhaps" because I have demonstrated that political liberalism cannot be understood as an epistemological theory: to try to describe liberalism like this is to misunderstand it. It is fundamentally a political doctrine, one that addresses the question of how do we get along, given that there are some things that we must accept: plurality, moral principles, the notion of equal respect and the like.

To be sure there are some things about persons and human nature that liberalism must assume in order to begin theorizing. We must accept these things for various reasons: they may be uncontroversial assumptions (we agree that they "exist" in the political world); we might think that these things are important in informing our political discourse (which does indirectly inform us as to who we are; but again, this is not a basis for decision making or liberal justification); or we may simply be committed to the idea 
of living in a world where these conditions hold, given a particular history of sociopolitical chaos and order. But what I have shown are two things: first that liberalism, in responding to the communitarian critique, offers an uncontroversial and neutral way of assuming these necessary minimal things about persons, and second that this conception is to be preferred to the communitarian conception because it does allow those assumptions to be borne out in our theory, and our practice.

This is not to say that political liberalism is "water tight"; no theory can hope for that. Complete consistency in any theory would certainly not be wide enough to account for anything controversial, and would be uncontroversial if not boring of itself. Rather, political liberalism is a way of dealing with those controversial aspects of social and political life that are a result of our historical efforts to deal with just such problems. It offers a way of structuring the political system around those things we know about moral complexity without rendering the situation too simplistic, yet accounting for those things we must accept about social conflict.

I have shown that the liberal and communitarian positions are not so dissimilar with regard to a political conception of the person, once we have examined the respective claims involved. Whether the two sides in the debate could "accept" the other theories, or make concessions enough to provide a consensus or synthesis is another question altogether; a significant point is that they are certainly not incommensurable, and are both well-represented in our reasoned and philosophical debate as well as our intuitive social understandings of the way persons and society can be understood.

Further though, by examining the tenets of liberalism and discovering the aims of liberalism, I have demonstrated that political liberalism has a fuller conception of the person than Rawls had originally proposed in Theory, but one that additionally makes sense of our political and moral conception of persons. That is, this conception renders coher- 
ent and sufficient, if not always and altogether complete and consistent, the way we view people in politics, and the way we wish to view them: as autonomous beings capable of decisions, yet constrained by conditions of the physical, political, and ethical world. ${ }^{7}$ However, this conception is not without costs; incompleteness and inconsistency are two difficult tests to pass, two heavy burdens for liberalism to bear. But as noted above, I think that this challenge is embodied within some of the essential tensions necessary to liberalism: within autonomy the tension represented by the distance yet proximity to the world, and in liberalism in general in the tension between autonomy and neutrality and between autonomy and equality. Additionally, I have shown how the political liberal can conceive of the self, and how it makes sense to conceive of the liberal self.

I have thus shown several things in the course of this thesis. First, the concept of the person in contemporary liberal political philosophy has developed in response to criticisms of communitarian theorists who have questioned the basis for that concept. As it has developed (a) in response to these criticisms, but also (b) from the concept of justice as fairness articulated by Rawls, and (c) as a return to an earlier liberal doctrine grounded in less substantial formulations of the concepts of autonomy, neutrality, and equal respect, political liberalism has been able to account for the social embeddedness thesis to a much greater extent than communitarians acknowledge or appreciate.

Second, I have questioned some aspects of the communitarian theories and criticisms by analyzing the way communitarianism tends to view the individual. I have further suggested that such communitarian views are either empty at base, or are inconsistent in that they do not allow strong claims to be made about the nature of persons in political society.

Third, I have shown that the concept of the person in a liberal society is capable of accounting for many of the characteristics that liberals generally want to attribute to people, but that these concepts have only a limited scope or application. That is, the liberal 
sense of the self is strong enough to refute claims of incoherence or emptiness, but it is not sufficient - nor should aspire to be so - to advance and support terribly strong or full conceptions of individuals. Political liberalism accounts for such a "lower-level defense" by resting upon the foundations of liberty; yet it retains neutrality as an aim or guiding purpose, not a foundation.

Finally, I have suggested that liberalism is a theory whose limits we must continue to explore. A valuable part of that exploration has been undertaken by communitarians. Like some liberals, they have undertaken a rigorous analysis of the limits of liberalism: how can liberalism make sense of autonomy? of neutrality? of persons? morality? toleration? The questions are valuable not only in themselves, but also - and especially - because they have been asked by both sides in the debate; the questions have shown a fundamental interest in continuing the debate.

Perhaps in the end Michael Walzer is correct: the communitarian critique "is like the pleating of trousers: transient but certain to return."8 If we agree that that is so, as I think we must (for good or ill), then liberals should welcome such opportunities-if not for the challenge, then for the strength that liberalism can derive from the continued conversation. 


\section{NOTES}

${ }^{1}$ Ludwig Wittgenstein, On Certainty, ed., trans. G. E. M. Anscombe and G. H. von Wright, (New York: Harper and Row, 1969): $§ 192$, p. 27e..

2 John Rawls, "The Domain of the Political and Overlapping Consensus," New York University Law Review 64 (1989): 251, n. 43.

${ }^{3}$ Charles Larmore, Patterns of Moral Complexity (Cambridge: Cambridge University Press, 1989): 125; emphases original, footnotes omitted.

${ }^{4}$ Steven Lukes, Individualism (Oxford: Basil Blackwell Ltd., 1973); see esp. chaps. 16 and 17, pp. $107-24$.

${ }^{5}$ Charles Larmore, "Liberal Neutrality: A Reply to James Fishkin," Political Theory 17 (1989): 58081; emphasis added.

6 John Rawls, "Justice as Fairness: Political Not Metaphysical," Philosophy and Public Affairs 14 (1985): 230; emphasis added, footnotes omitted. See also Charles Larmore, "Political Liberalism," Political Theory 18 (1990): 354-56.

7 The terms incomplete, insufficient, and incoherent are from Alphonso Damico's characterization of liberal criticisms. "Introduction" to Liberals on Liberalism, ed. Alphonso J. Damico (Totowa, NJ: Rowman and Littlefield, 1986): 1-12.

8 Michael Walzer, "The Communitarian Critique of Liberalism," Political Theory 18 (1990): 6. 


\section{SELECTED BIBLIOGRAPHY}

Ackerman, Bruce. "Neutralities." Liberals on Liberalism, ed. Alphonso J. Damico, 2943. Totowa, NJ: Rowman and Littlefield, 1986.

Annas, Julia. "MacIntyre on Traditions." Philosophy and Public Affairs 18, 388-404, 1989.

Arneson, Richard J. "Introduction to a Symposium on Rawlsian Theory of Justice: Recent Developments." Ethics 99, 695-710, 1989.

Ashcraft, Richard. Revolutionary Politics and John Locke's Two Treatises of Government. Princeton, NJ: Princeton University Press, 1986.

Baier, Kurt. "Justice and the Aims of Political Philosophy." Ethics 99, 771-790, 1989.

Barry, Brian. "The Light That Failed?" Ethics 100, 160-69, 1989.

Berlin, Sir Isaiah. "Two Concepts of Liberty." Liberalism and Its Critics, ed. Michael Sandel, 15-36. New York: New York University Press, 1984.

Berman, Harold J. Law and Revolution: The Formation of the Western Legal Tradition. Cambridge, MA: Harvard University Press, 1983.

Buchanan, Allen E. "Assessing the Communitarian Critique of Liberalism." Ethics 99, 852-882, 1989.

. Preface, Marx and Justice. Totowa, MJ: Rowman and Allanheld, xi-xiv, 1982.

. Chap. 6, "Marx and Rawls." In Marx and Justice. Totowa, NJ: Rowman and Allanheld, 103-121, 1982.

Caney, Simon. "Liberalism and Communitarianism: A Misconceived Debate." Political Studies 40, 273-289, 1992.

Damico, Alphonso. "Introduction." Liberals on Liberalism, ed. Alphonso J. Damico, 112. Totowa, NJ: Rowman and Littlefield, 1986.

Daniels, Norman, "Preface to the Second Edition." In Reading Rawls: Critical Studies on Rawls' Theory of Justice, xiii-xxvii, ed. Norman Daniels, 2d ed. (1989).

Stanford: Stanford University Press, 1975.

. "Introduction." In Reading Rawls: Critical Studies on Rawls' Theory of Justice, xxxi-liv, ed. Norman Daniels, 2d ed. (1989). Stanford: Stanford University Press, 1975. 
Doppelt, Gerald. “Is Rawls's Kantian Liberalism Coherent and Defensible?" Ethics 99, 815-851, 1989.

Dworkin, Ronald. Taking Rights Seriously. Cambridge, MA: Harvard University Press, 1978.

A Matter of Principle. Cambridge, MA: Harvard University Press, 1985.

Ellis, Ralph D. "Toward a Reconciliation of Liberalism and Communitarianism." The Journal of Value Inquiry 25, 55-64, 1990.

Fishkin, James S. Review of Patterns of Moral Complexity by Charles Larmore. Political Theory 17, 153-156, 1989.

. "Liberal Theory: Strategies of Reconstruction." Liberals on Liberalism, ed. Alphonso J. Damico, 54-64. Totowa, NJ: Rowman and Littlefield, 1986.

Galston, William. "Moral Personality and Liberal Theory: John Rawls' Dewey Lectures." Political Theory 10, 492-519, 1982.

- "Liberalism and Public Morality." Liberals on Liberalism, ed. Alphonso J. Damico, 129-47. Totowa, NJ: Rowman and Littlefield, 1986.

Gill, Emily R. "MacIntyre, Rationality, \& the Liberal Tradition." Polity 24, 433-57, 1992.

. "Goods, Virtues, and the Constitution of the Self." Liberals on Liberalism, ed. Alphonso J. Damico, 111-28. Totowa, NJ: Rowman and Littlefield, 1986.

Gowans, Christopher W. Review of After Virtue by Alasdair MacIntyre. International Philosophical Quarterly 87, 215-19, 1982.

Gutmann, Amy. "Communitarian Critics of Liberalism." Philosophy and Public Affairs 14, 308-322, 1985.

Hampton, Jean. "Should Political Philosophy Be Done without Metaphysics?" Ethics 99, 791-814, 1989.

Hart, H. L. A. "Rawls on Liberty and Its Priority." In Reading Rawls: Critical Studies on Rawls' Theory of Justice, 230-52, ed. Norman Daniels, 2d ed. (1989). Stanford: Stanford University Press, 1975.

Holmes, Stephen. "The Permanent Structure of Antiliberal Thought." In Liberalism and the Moral Life, 227-53, ed. Nancy L. Rosenblum. Cambridge, MA: Harvard University Press, 1989.

Jacobson, Norman. Pride and Solace: The Functions and Limits of Political Theory. Berkeley, CA: University of California Press, 1978. 
Kant, Immanuel. "Perpetual Peace: A Philosophical Sketch." Kant: Political Writings, trans. H. B, Nisbett; ed. Hans Reiss, 2d ed. Cambridge: Cambridge University Press, 1991.

Kaye, David. "Playing Games with Justice." Social Theory and Practice 6, 33-51, 1980.

Kukathas, Chandran, and Philip Pettit. Rawls: A Theory of Justice and its Critics. Stanford: Stanford University Press, 1990.

Kuhn, Thomas S. The Structure of Scientific Revolutions, second ed., enlarged. Chicago: The University of Chicago Press, 1970.

Kymlicka, Will. "Liberalism and Communitarianism." Canadian Journal of Philosophy $18,181-204,1988$.

. "Liberal Individualism and Liberal Neutrality." Ethics 99, 88-905, 1989.

. Liberalism, Community, and Culture. Oxford: Oxford University Press, 1989.

. Contemporary Political Philosophy: An Introduction. Oxford: Oxford University Press, 1990.

Larmore, Charles. Review of Liberalism and the Limits of Justice by Michael Sandel. In The Journal of Philosophy 81, 336-343, 1984.

. Patterns of Moral Complexity. Cambridge: Cambridge University Press, 1987.

. "Liberal Neutrality: A Reply to James Fishkin." Political Theory 17, 580-81, 1989.

. Review of Whose Justice? Which Rationality? by Alasdair MacIntyre. The Journal of Philosophy 86, 437-42, 1989.

. "Political Liberalism." Political Theory 18, 339-360, 1990.

Lukes, Stephen. Individualism. London: Basil Blackwell, 1973.

- "Making Sense of Moral Conflict." Liberalism and the Moral Life, ed. Nancy L. Rosenblum, 1127-42. Cambridge, MA: Harvard University Press, 1989.

MacIntyre, Alasdair. A Short History of Ethics. New York: MacMillan Publishing, Inc., 1966.

—_ "Intelligibility, Goods, and Rules," from "A Symposium on After Virtue." The Journal of Philosophy 78, 663-65, 1982.

. After Virtue: A Study in Moral Theory. 2d ed. Notre Dame, IN: Notre Dame University Press, 1984.

.Whose Justice? Which Rationality? Notre Dame, IN: Notre Dame University Press, 1988. 
Mendus, Susan. Toleration and the Limits of Liberalism. Atlantic Highlands, NJ: Humanities Press International, Inc., 1989.

Miller, David. "The Resurgence of Political Theory." Political Studies 38, 421-37, 1990.

Nagel, Thomas. "Rawls on Justice." In Reading Rawls: Critical Studies on Rawls" Theory of Justice, 1-15, ed. Norman Daniels, 2d ed. (1989). Stanford: Stanford University Press, 1975.

. "Moral Conflict and Political Legitimacy." Philosophy and Public Affairs 16, 215-240, 1987.

Neal, Patrick. "Justice as Fairness: Political or Metaphysical?" Political Theory 18, 24$50,1990$.

Neal, Patrick and David Paris. "Liberalism and the Commuitarian Critique: A Guide for the Perplexed." Canadian Journal of Political Science 23, 419-440, 1990.

Nozick, Robert. Anarchy, State, and Utopia. New York: Basic Books, 1974.

Paul, Jeffrey and Fred D. Miller, Jr. "Communitarian and Liberal Theories of the Good." The Review of Metaphysics 43, 803-830, 1990.

Paul, Jeffrey. Review of Liberalism, Community, and Culture by Will Kymlicka. The Review of Metaphysics 44, 643-645, 1990.

Pogge, Thomas. Realizing Rawls. Ithaca, NY: Cornell University Press, 1989.

Rawls, John. "Outline of a Decision Procedure for Ethics." Philosophical Review 60, 177-97, 1951.

. "Justice as Fairness." Journal of Philosophy 54, 653-62, 1957.

A Theory of Justice. Cambridge MA: Harvard University Press, 1971.

. "The Basic Structure as Subject." American Philosophical Quarterly 14, 159-65, 1977.

. "Kantian Constructivism in Moral Theory: The Dewey Lectures 1980." The Journal of Philosophy 88, 515-72, 1980.

"The Basic Liberties and Their Priority." The Tanner Lectures on Human Values, iii. Cambridge: Cambridge University Press, 1-89, 1982.

. "Social Unity and Primary Goods." Utilitarianism and Beyond, Amartya Sen and Bernard Williams, eds., 159-85. Cambridge: Cambridge University Press, 1982.

- "Justice as Fairness: Political Not Metaphysical." Philosophy and Public Affairs 14, 223-51, 1985. 
."The Idea of An Overlapping Consensus." Oxford Journal of Legal Studies 7, 1$25,1987$.

- "The Priority of Right and Ideas of the Good." Philosophy and Public Affairs 17, 251-76, 1988.

. "On the Idea of Free Public Reason." Unpublished manuscript, 1988.

. "The Domain of the Political and Overlapping Consensus." New York University Law Review 64, 233-55, 1989.

Rosenblum, Nancy N. Another Liberalism. Cambridge, MA: Harvard University Press, 1987.

Salkever, Stephen. “'Lopp'd and Bound": How Liberal Theory Obscures the Goods of Liberal Practices." Liberalism and the Good, ed. R. Bruce Douglass, Gerald M. Mara and Henry S. Richardson, 167-202. New York, NY: Routledge, Chapman, and Hall, Inc., 1990.

Sandel, Michael J. Liberalism and the Limits of Justice. Cambridge: Cambridge University Press, 1982.

, ed. "Introduction [to Liberalism and Its Critics ]." New York: New York University Press, Inc., 1984.

. "The Procedural Republic and the Unencumbered Self." Political Theory 12, 8196, 1984.

. "Morality and the Liberal Ideal." The New Republic 194, 15-17, 1984.

. "Democrats and Community: A public philosophy for American liberalism." The New Republic 198, 20-23, 1988.

Schmitz, Kenneth. "Community: The Elusive Unity," The Review of Metaphysics 37, 245-64, 1983.

. "Metaphysics: Radical, Comprehensive, Determinate Discourse," The Review of Metaphysics 39, 675-94, 1986.

_ . "Neither With Nor Without Foundations," The Review of Metaphysics 42, 3-25, 1988.

Schneewind, G. B. "Virtue, Narrative, and Community," from a Symposium on Alasdair MacIntyre's After Virtue. The Journal of Philosophy 79, 653-63, 1982.

Taylor, Charles. Hegel. Cambridge: Cambridge University Press, 1975. Sources of the Self. Cambridge, MA: Harvard University Press, 1989. 
. "Cross-Purposes: The Liberal-Communitarian Debate." Liberalism and the Moral Life, Nancy L. Rosenblum, ed., 159-82. Cambridge, MA: Harvard University Press, 1989.

Thigpen, Robert B., and Lyle A. Downing. "Liberalism and the Communitarian Critique." The American Journal of Politics 31, 637-655, 1987.

- "Liberal and Communitarian Approaches to Justification." The Review of Politics $51,533-550,1989$.

Unger, Roberto Mangabeira. Knowledge and Politics. New York: The Free Press (a division of MacMillan, Inc.), 1975.

Waldron, Jeremy. "Theoretical Foundations of Liberalism." The Philosophical Quarterly 37, 127-150, 1987.

Wallach, John R. "Liberals, Communitarians, and the Tasks of Political Theory." Political Theory 15, 581-611, 1987.

Walton, Douglas N. "What Is Reasoning? What Is an Argument?" The Journal of Philosophy 87, 399-419, 1990.

Walzer, Michael. "The Communitarian Critique of Liberalism." Political Theory 18, 623, 1990.

Wittgenstein, Ludwig. On Certainty, trans. and ed. G. E. M. Anscombe and G. H. von Wright. New York: Harper and Row, 1969.

Culture and Value, trans. Peter Winch. Chicago: The University of Chicago Press, 1980. 